PACIFIC LINGUISTICS

Series B - No. 27

\title{
THE CASE SYSTEM OF TAGALOG VERBS
}

\author{
by \\ Teresita V. Ramos
}

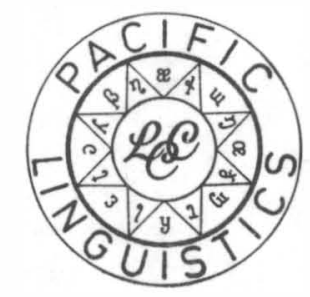

Department of Linguistics

Research School of Pacific Studies

THE AUSTRALIAN NATIONAL UNIVERSITY 
PACIFIC LINGUISTICS is published by the Linguistic Circle of Canberna and consists of four series:

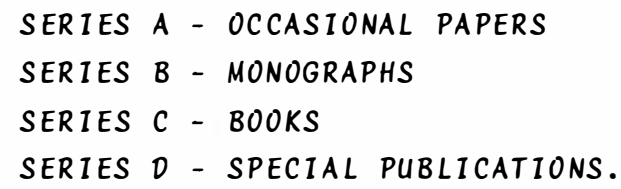

EDITOR: S.A. Wurm. ASSOCIATE EDITORS: D.C. Laycock, C.L. Voorhoeve.

ALL CORRESPONDENCE concerning PACIFIC LINGUISTICS, including orders and subscriptions, should be addressed to:

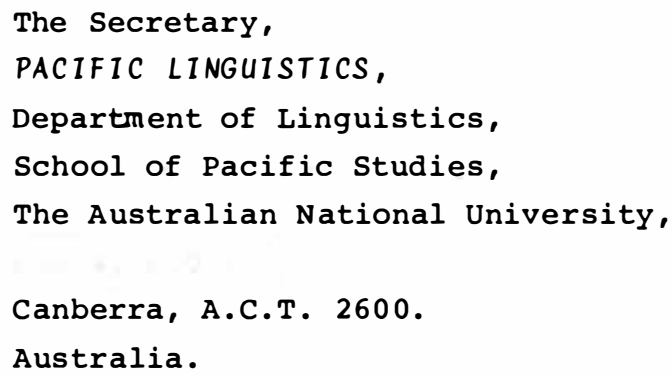

The editors are indebted to the Australian National University for help in the production of this series.

This publication was made possible by an initial grant from the Hunter Douglas Fund.

National Library of Australia card number and ISBN $0 \quad 858831155$ 
TABLE OF CONTENTS

ABSTRACT

LIST OF TERMS AND ABBREVIATIONS

viii

CHAPTER I. INTRODUCTION

1.1. The Tagalog Language 1

1.2. Tagalog Linguistic Studies 1

1.3. Theoretical Orientation 3

$\begin{array}{lll}\text { CHAPTER II. TAGALOG DEEP STRUCTURE CASES } & 15\end{array}$

2.1. The Use of Case in Philippine Studies 15

2.2. Case as Used in this Study 19

2.3. Tagalog Cases 19

2.3.1. Inherent Cases 19

2.3.1.1. The Agentive Case 20

2.3.1.2. The Objective Case 23

2.3.1.3. The Directional Case 30

2.3.1.4. The Locative Case 32

2.3.1.5. The Instrumental Case (Force) 33

2.3.2. Non-inherent Cases 34

2.3.2.1. The Instrumental Case 34

2.3.2.2. The Benefactive Case 39

2.3.2.3. The Affected Case 40

$\begin{array}{ll}2.3 .3 . ~ S u m m a r y & 40\end{array}$

CHAPTER III. BASE RULES 41

3.1. Introduction 41

3.2. Base Rules 43 
CHAPTER IV. SELECTIONAL REDUNDANCY RULES 65

CHAPTER V. THE SUBCATEGORIZATION OF TAGALOG VERBS

CHAPTER VI. SURFACE CASE FORMS IN THE NOUN PHRASES 99

6.1. The Inherent Noun Phrases 100

6.1.1. The Agentive Noun Phrase 100

6.1.2. The Objective Noun Phrase 100

6.1.3. The Directional Noun Phrase 101

6.1.4. The Locative Noun Phrase 101

6.1.5. The Instrumental Noun Phrase (Force) 102

6.2. The Non-inherent Noun Phrases 103

6.2.1. The Instrumental Noun Phrase 103

6.2.2. The Benefactive Noun Phrase 104

6.2.3. The Affected Noun Phrase 105

6.3. Suppressed Noun Phrases in the Surface Structure 105

6.3.1. Built-in Roles 105

6.3.1.1. Incorporated Roles 106

6.3.1.1.1. Incorporated Objects 106

6.3.1.1.2. Incorporated Instruments 106

6.3.1.1.3. Incorporated Directionals 107

6.3.1.2. Lexicalized Roles 107

6.3.1.2.1. Lexicalized Objects 108

6.3.1.2.2. Lexicalized Instruments 109

6.3.1.2.3. Lexicalized Directionals 109

6.3.2. Coreferential Roles 110

6.3.3. Vacant Roles 111

6.3.3.1. Vacant Objective Role 111

6.3.3.2. Vacant Instrumental Role 111

6.4. Surface Realization of Arguments 112

CHAPTER VII. SURFACE MANIFESTATIONS OF TAGALOG CASES 115

7.1. Introduction 115

7.2. Subject as a Surface Phenomenon 115

7.3. Process of Subjectivalization 116

7.3.1. Subject Marking, TR\#1 118

7.3.2. K Case Feature Incorporation, TR\#2 118

7.4. Verbal Affixes as Case Indicators 120

7.4.1. Inherent Cases as Marked in the Verb 120

7.4.1.1. The Agentive Noun Phrase as Subject 120 
7.4.1.2. The Objective Noun Phrase as Subject

7.4.1.2.1. With Agentive Noun Phrases

7.4.1.2.2. Without Agentive Noun Phrases

7.4.1.3. The Directional Noun Phrase as Subject

7.4.1.4. The Locative Noun Phrase as Subject

7.4.1.5. The Instrumental Noun Phrase (Force) as Subject

7.4.2. Non-inherent Cases as Marked in the Verb

128

7.4.2.1. The Instrumental Noun Phrase as Subject

7.4.2.2. The Benefactive Noun Phrase as Subject

7.4.2.3. The Affected Noun Phrase as Subject

129

7.4.3. Surface Realization of Tagalog Cases

130

7.4.4. Problems and Exceptions

130

138

CHAPTER VIII. CONCLUSION

APPENDIX A. SEMANTIC FEATURE DISPLAYS OF THE VERB AND THE CASES 147

APPENDIX B. BASE RULES

APPENDIX C. SELECTIONAL REDUNDANCY RULES

APPENDIX D. MAJOR CLASSES OF TAGALOG VERBS 


\section{ABST RACT}

The Case System of Tagalog Verbs is a study of the underlying case relationships in the sentence, and the dominant role the verb plays in dictating the types of cases 1t allows to co-occur w1th 1t. Th1s linguistic information is used to subcategorlze the verbs of Tagalog in a manner that is sensitive both to the syntact1c and semantic relationships existing between the verb and the cases that occur with 1t. The classification proposed not only takes into consideration the case frame of the verb but also the total semantic reading of a sentence. To formalize the syntact1c-semant1c relationships in the sentence, semant1c features for the verbs have been made prominent, a step in a continuing effort to explain the verb in Philippine languages.

Chapter III gives a modification of Fillmore's case grammar by the use of semant1c features and $1 \mathrm{~s}$ the core of this study. These semant1c features of the verb determine the case frames (case co-occurrence restrictions). The centrality of the verb is emphasized. The noun complements are predictable from the verb rather than vice versa as in F1llmore's view.

Base rules given in Chapter III 1llustrate how the case selectional features of the verb are introduced in a complex symbol, a matrix of speclfled features. To match the verbal case features, nouns also are asslgned case features wh1ch are described in detall in Chapter II. Subcategorlzational and redundancy rules attribute features to both nouns and verbs.

The Tagalog deep structure cases are defined in Chapter II. Most of Fillmore's case designations have been adopted. However, broad case roles have been redefined as having subcase features to capture the fine meanings of case roles intultively percelved for Tagalog as well as in an attempt to formalize Fillmore's prose descriptions of h1s cases. On the other hand, where simllarities have been intultively 
percelved, Fillmore's cases have been collapsed. The result is a small Inventory of broad cases (1.e., f1ve inherent cases) with subcases wh1ch work toward a more adequate and prec1se semant1c and syntact1c description of Tagalog verbal sentences.

Chapter IV deals with the selectional redundancy rules that restrict the types of nouns that occur w1th certaln types of verbs on the basis of the latter's meaning. Case frames are represented as selectional features instead of in terms of category symbols as Fillmore does in h1s grammar. These selectional redundancy rules account for the cooccurrence of the 1nherent types of cases with the verb except for the locat1ves.

Chapter $\mathrm{V}$ presents the major subcategorlzation of the Tagalog verbs. Each of the fifteen classes of verbs is described by matrices consisting of the semant1c features as well as the contextual case features that distinguish each class from the rest.

The first four chapters of this study discuss the underlying semanticsyntact1c case relationships of the Tagalog sentence. The surface case forms (1.e., the case marking particle and the verbal affixes) that mark case relationships in the surface structure are discussed in Chapters VI and VII. The many-to-one correspondence between case function and form 1s emphasized. The process of subject formation, wh1ch is consldered a surface phenomenon in this study, is also described in Chapter VII.

While stressing the 1mportance of features for a more precise description of the behaviour of Tagalog verbs, no clalm is made that the display of verbal and nominal features introduced in this study w1ll completely define all Tagalog verb-noun case relationsh1ps, let alone the total meanings of verbs and nouns. The study needs more emplrical validation, but hás accomplished the following: (1) a more adequate and prec1se subcategorization of Tagalog verbs by the use of features; and (2) a formalization of the introspective judgements of this nat1ve speaker about the case system of Tagalog verbs, thus getting closer to semant1c adequacy. 


\section{LIST OF TERMS AND ABBREVIATIONS}

\author{
1. agent1ve (agt) \\ 2. Agent1ve (A) \\ 3. affected (af) \\ 4. animate (an) \\ 5. Benefact1ve (ben, B) \\ 6. begun (beg) \\ 7. case (c) \\ 8. case marking particle (K) \\ 9. centrifugal ( $c f$ ) \\ 10. change of state (cs) \\ 11. common (com) \\ 12. completed (comp) \\ 13. complex symbol (c.s.) \\ 14. concrete (conc) \\ 15. determiner (det) \\ 16. direction ( $d 1 r$ ) \\ 17. Directional (D1r, D) \\ 18. experiencer (exp) \\ 19. experient1al (exp)
}

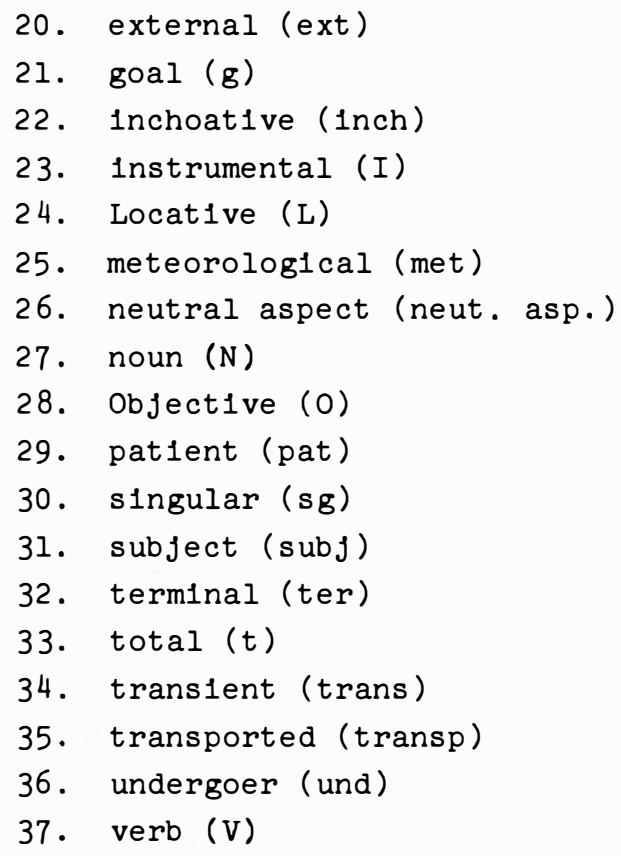




\section{CHAPTER I}

\section{INTRODUCT ION}

\subsection{THE tAGalog language}

Tagalog is one of the elght major languages of the Phllippines. It belongs to the Austronesian or Malayo-polyneslan language famlly as do the rest of the 70 to 150 Phlllppine languages. It 1s regarded by many Phllipplne lingulsts as the dominant language of the country (Llamzon 1968:731). The 1960 Census of the Philippines 1ndicated that at that time $44.4 \%$ of the population were speakers of Tagalog. Constantino (1971:117) later est1mated that th1s percentage had increased to $60 \%$ of the population. One of the major reasons for the rising use of Tagalog over the use of other Ph1l1pplne languages is that in 1937 Tagalog was chosen by the Institute of National Language as the basis of the national language, now called Pilipino.

Tagalog is the native language of the following provinces in the Phllipplnes: Bataan, Bulacan, Batangas, Cavite, Laguna, Marinduque, Occidental Mindoro, Orlental Mindoro, Nueva Ec1ja, Quezon, Rizal, and also Metropolitan Manila. It is also the dominant language in the northern half of Camarlnes Norte in the Blkol Reglon, in some towns of Zambales, Tarlac and Pampanga in Central Luzon, and in some provinces of Mindanao, notably Cotabato and Davao. It $1 \mathrm{~s}$ widely taught in the school system, and is used in the varlous communications media throughout the country.

\subsection{TAGALOG LINGUISTIC STUDIES}

Tagalog is not only the most widely used language in the Philippines, but 1t is probably the most studied from a lingulstic point of view. Ward (1971) surveys the coverage of Ph1lipplne studies, and shows that the greatest concentration of grammatical research has been on the following languages, with Tagalog totalling a full one-third of all the 
works: Tagalog, Cebuano, Ilokano, H1l1gaynon, B1kol, Waray, Kapampangan, and Pangasinan, arranged here in a decreasing order by number of speakers per language. Constantino, in a review of the linguistic research on Phllippine languages, states that Tagalog and the other major languages are the most frequently studied. He writes, 'One can say without exaggerating that the history of Philippine linguistics is largely the history of the study of the major Philippine languages, especially Tagalog' (1971:118).

As early as the 1560's, the Spanish missionarles emphasized the study of the major languages in the Philippines, especially Tagalog. AccordIng to Milner (1963:64), much of the1r work 'rests upon the normative preconceptions and traditional pigeonholes of conventional European grammar.'

During the American occupation of the Philippines (first half of the 20th century), a new era in Philippine lingulstics started. The U.S. army, which brought the first Americans to the Philippines, started the study of Phllippine languages, again notably Tagalog. Among the grammars of Tagalog written at this time, Mackinlay's A Handbook and Grammar of Tagalog is worthy of mention. Three 1mportant grammars of Tagalog were published during this American Perlod: Leonard Bloomfleld's Tagalog Texts with Grammatical Analysis (1917), Frank Blake's A Grammar of the Tagalog Language (1925), and Cec1l1o Lopez's A Manual of the Philippine National Language (1940). Of the three, Bloomfleld's grammar is consldered the first comprehensive and systemat1c analysis of Tagalog. It is also the best known, and the most influential of American studies on any Ph1lipplne language. Blake's grammar 'shows the unmistakable influence of the best spanish grammarians, particularly Totanes' (Constantino 1971:125). Blake's study, though not published unt1l 1925, actually antedates Bloomfleld's 1917 grammar. It is of Importance here since Blake was the first to discuss case relations as expressed by the Tagalog verb. Lopez's manual was Influenced by Bloomfleld's grammatical analysis and also by Jespersen's Philosophy of Grammar (Constantino 1971:131). Though influenced by Bloomfleld, Lopez belleved as did Blake in the 1mportance of semant1c categories as a basis of analysis.

Among the recent works on Tagalog grammar are Kess' doctoral dissertation, A Study of the Syntactic Features of the Tagalog Verb (1967), and Llamzon's Modern Tagalog (1968), the latter a functionalstructural description giving particular attention to the problem of verification. Published recently is a Tagalog Reference Grammar by Schachter and Otanes, the only grammar of Tagalog to date written in a transformational-generat1ve framework. 
The best known and most w1dely used of all Tagalog grammars is Lope K. Santos' Balarila ng Wikang Pambansa, written in Tagalog (or P1lipino, the national language). The Institute of National Language has adopted this work as the offlclal grammar of the Philippines. The Balarila, as It is popularly called, thus has become the 'Blble' for P1lipino teachers all over the country. It deserves more study since Tagalog continues to engage the attention of many scholars of Philippine linguistics.

\subsection{THEORETICAL ORIENTATION}

1.3.1. Previous studies on the verbs of Philippine languages have described verbal affixes and their role in marking which of the noun phrases in the sentence is 'focused' or 'toplcallzed'. Probably under the influence of Bloomfleld, who in the morphology of his Tagalog grammar indicated that an affix indicates one and only one grammatical relation (1917:226 et seq.), most of the Ph1lippine lingulsts (generally S.I.L. lingulsts) had single affixes where actually there are two or more grammatical relations.

Contrary to Bloomfleld's analysis, Constantino cla1ms that 'in many Philippine languages two or more affixes may be used to indicate the same grammatical relation between subject and verb' or that 'one affix may indicate two or more different grammatical relations, not only with different stems but also with the same stems' (1971:139). For example three different affixes may mark the grammatical relation goal (or object).

(I) $[i-]$

(2) $[-a n]$

(3) $[-i n]$

$$
\begin{aligned}
& \text { Itapon mo ang basura. } \\
& \text { throw you garbage } \\
& \text { (You) throw the garbage. }
\end{aligned}
$$

0

Hugasan mo ang pinggan.

wash you plates

(You) wash the plates.

0

Lutuin mo ang ulam.

cook you viand

(You) cook the viand. 
In the next examples, a single verbal affix $i$ - marks three grammat1cal relations between the verb and the focused noun. Th1s affix may be used to mark the object, the beneficlary, or the instrument.

(4) [object1ve]

(5) [Benefact1ve]

(6) [Instrumental]

$$
\begin{aligned}
& \text { Itago mo ang bola. } \\
& \text { keep you ball } \\
& \text { (You) keep the ball. }
\end{aligned}
$$

$$
\begin{aligned}
& \text { Ibili mo siya ng kotse. } \\
& \text { buy you for him car } \\
& \text { (You) buy a car for him. }
\end{aligned}
$$

$$
\begin{aligned}
& \text { Ipunas mo ang trapo. } \\
& \text { wipe you rag } \\
& \text { (You) use the rag to wipe (it). }
\end{aligned}
$$

As Schachter (1961), Constant1no (1971:139), and Cena (1971) noted, the same stems may have two or more interpretations. For example, the noun phrase ang alipin the slave may have two functions in the following sentence.

(7) Binayaran ng lalake ang alipin.

a. The man paid for the slave. (Object-focuser)

b. The man paid the slave. (Indirect-object-focuser)

Schachter (1961:143) in his article shows how the structural amblgulty of the sentence above can be resolved by assigning it two different derlvational histories. He converts the passive sentence Into an active sentence using two transformations, one that marks the noun phrase sa and the other ng. The sentence whlch contains the Object-focuser is transformed to an unambiguous sentence.

$$
\begin{aligned}
& \text { (8) Nagbayad } \frac{\text { ng alipin ang lalaki. }}{\text { slave man }} \\
& \text { The man paid for the slave. }
\end{aligned}
$$

On the other hand, the sentence which contalns the Indirect-objectfocuser is transformed to the following unamblguous sentence.

(9) Nagbayad sa alipin ang lalaki. paid slave man The man paid the slave. 
However, what Schachter clalms as an unamblguous active sentence, Nagbayad ng alipin ang lalaki, can have two interpretations.

a. The man paid for the s lave.

b. The man used the slave for payment.

The second sentence indicates an instrumental function in opposition to the objective function in the first interpretation.

So even case-marking particles can be interpreted as having different functions. For example, the particle ng in Tagalog may mark an agent1ve, an objective, or an instrumental phrase.

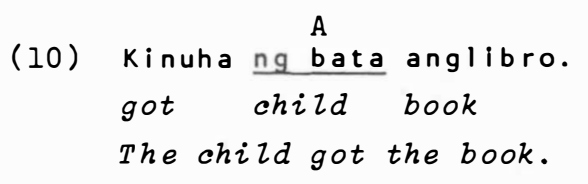

(11) Kumuha ang bata ng libro.

The child got a book.

(12) Gumamit siya ng kutsilyo sa manok. used he knife on the chicken He used a knife on the chicken.

Other lingulsts suggest that another way of disamblguating sentences 1s by 'expanding' the noun phrase (Constantino 1971:139) or by the 'recovery of deleted elements' (Cena 1971:137). For example, sa mesa in the following sentence exhibits a two-way amblgulty between the source and goal function.

(13) nahulog siya sa mesa.

fell he table

a. He fell on the table.

b. He fell from the table.

The phrase sa mesa may be interpreted as the goal (1n \#13a) or the source ( $1 \mathrm{n} \# 13 \mathrm{~b}$ ) of the verbal action.

By expanding sa mesa (or recovering 1ts deleted elements) into patungo (going to) sa mesa 1 t becomes unamblguously the goal of the action or into magmula (coming from) sa mesa unamblguously the source of the action.

All these examples indicate that there is no perfect correlation between surface forms and case functions. They 1llustrate the fact that a consideration of overtly displayed grammatical facts will not 
always lead to the same conclusion about the case of a particular structure as w1ll the use of intultions about the semantic properties of the structure. Chafe (1970:122) states that 'when introspection and surface evidence are contradictory, it is the former which is decisive'. Due to the concentration on a surface syntact1c analysis alone by earlier studies, Tagalog sentences have sometimes been classifled together which are interpreted as different by the native speakers of the language. Kess (1967) trled to classify Tagalog verbs by using the notion of 'focus' and verbal affixes of sentences and was dissat1sfled with the results of his study. He concluded in an unpublished manuscript, the following:

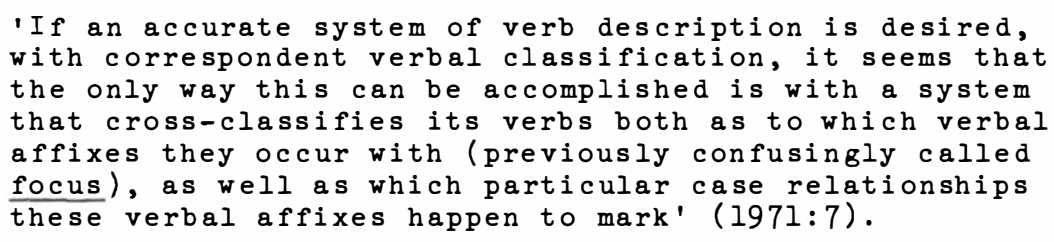

Kess realized that a purely surface structure consideration of focus is not sufficlent for a complete analysis of Tagalog verbal constructions but represents only a partial approach to the problem.

Because a surface syntactic analysis alone is not adequate to explain how sentences are interpreted by nat1ve speakers, a model becomes necessary that can distingulsh two sentences marked similarly on the surface but understood differently due to underlying case distinctions. It seems necessary therefore, to have two levels of analysis to provide an adequate description of Tagalog verbs. While the surface level of analysis of verb structure has been described to some extent for several Phllipplne languages (see publications of SIL lingulsts), very little has been attempted in the way of describing underlying semant1c propert1es of verbs. The only research suggest1ve of this type of analysis is that of $\mathrm{Br}$. Andrew Gonzales (1970) on Kapampangan; though this is not in the framework suggested here. The writer of this study concludes that it is no longer sufficlent for a grammar to classify or subcategorlze verbs on the basis of the surface structures ${ }^{1}$ in wh1ch they occur. Deep structure ${ }^{2}$ information must be considered as well to account for the manner in which sentences are interpreted or understood by the speakers of the language.

\footnotetext{
'Surface structure: Chomsky's term for the structure resulting from the application of all pertinent transformations to a deep structure. The surface structure is the basis for the phonological interpretation of the sentence.

2Deep structure: Chomsky's term for the structure resulting from the insertion of lexical items into the terminal string generated by the phrase structure rules. The deep structure is the basis for the semantic interpretation of the sentence.
} 
A new way of subcategorizing Tagalog verbs not motivated primarily by morpholgical considerations but by syntact1c-semant1c ones is proposed here. This leads the writer, a native speaker of Tagalog, to explain in a systemat1c way the case relationships in a sentence as indicated by the semant1c properties of the verb.

To do this, the grammar model needed must be capable of correlating the observable syntact1c facts w1th a deep structure more semant1c than syntact1c and therefore further removed from the surface structure than the one proposed by Chomsky. Case grammar as envisioned by Fillmore seems to be able to do th1s, but unfortunately th1s model has not been developed far enough to accomplish the goal of explaining adequately the syntact1c-semant1c relationships existing between the verb and the rest of the sentence in wh1ch 1t occurs.

1.3.2. Fillmore's case grammar model is a modification of the standard transformational theory, which relies upon a clear distinction between deep and surface structures (1968:21). The slmple sentence in Fillmore's theory consists of a 'predicator (verb, adjective or noun) in construction with one of the semantic functions known as (deep structure) cases' (1971:246). In short, case grammar 1s a modification having a base component that specifies the case structure of sentences.

It is interesting to note here that Fillmore adopted Blake's (1930) definition of case and case form in his current general theory. Fillmore uses the term case (or deep structure case) to 1dent1fy the 'underlying syntactic-semantic relationship, and the term case form to mean the expression of case relationship in a particular language - whether through affixation, suppletion, use of clitic particles or constraints on word order' (1968a:21). The deep cases 1dent1fy the roles wh1ch the entities serve in the predication, these roles taken from a repertory defined once and for all for human languages.

The case notions comprise a set of universal, presumably innate, concepts wh1ch 1dentify certain types of judgements human beings are capable of making about the events that are going on around them, Judgements about such matters as who did 1t, who 1t happened to, what got changed.

In this study, most of Fillmore's case designations (Agent, Object, Instrument, Source, Goal, Experlencer) have been adopted. However, these designations are too broad to capture the fine meanings of case roles intultively percelved for Tagalog or too similar in function to be consldered separate cases.

For example, Fillmore himself noted three types of agents. He referred to them as 'Agent1ve-as-ojbect1ve', 'Agent1ve-as-goal', and 
'Agent1ve-as-source' (see Cook 1971:15). So where distinctions are present in a case role, subclasses of case are postulated in this study. However, where similarities are detected, the broad case roles have been collapsed into one case role. To 1llustrate, because of their intu1tively percelved similarities (1.e. both being affected or acted on), Fillmore's experlencer and object cases in this study are encompassed by the broad case role of object having the semantic subdivisions of patient and nonpatient types. The result is a small inventory of broad cases w1th subcases wh1ch work toward a more adequate and prec1se semant1c and syntact1c description of Tagalog verbal sentences.

Fillmore too, has notation problems in incorporating case in the base component. Acknowledging this weakness, he says, 'The cases are clearly not categories, though in this notation they are treated just like grammatical categories' (1971:263). The notational problem encountered by Fillmore 1s basically the mixing of function with categorlal elements. He had case relations dominating category symbols, e.g. Case is rewritten as Particle + Noun Phrase. In this study, 1t has been declded to mark case in the lexicon to avold Fillmore's problem of having a relational term (case) dominate categorial elements.

1.3.3. In an attempt to formalize Fillmore's prose descriptions of his cases as well as some semantic generalizations gleaned from the works of Ph1lipplne linguists, particularly Blake (1906), Lopez (1941), Plttman (1966) and Stevens (1969), features ${ }^{2}$ have been postulated for a more precise characterization of case relationships between the predicate (verb) and 1ts arguments. ${ }^{3}$

Aslde from Kess (1967), there has been no analys1s of Tagalog verbs that uses the feature approach. However, his dissertation concentrated on the syntact1c features of the verb whereas th1s study w1ll concentrate on the semantic-syntact1c features of the verb.

The feature notation has been developed in phonology (Halle, Jakobson, etc.), and has been applied to syntax by Chomsky (1965). Syntact1c features (not case features) were used by Chomsky to account for the

\footnotetext{
Robinson (1970), Starosta (1971a, 1972) and Taylor (1971) introduce case in the lexicon. Starosta (1972) has developed to some extent the use of lexical redundancy rules as case marking devices.

2 Feature: a property of a linguistic element according to which the element is classified, or on the basis of which its co-occurrence privileges are stated.

3.Argument' is a term used in a logician sense by Fillmore (1968b:373) to refer to objects (or nouns) concerning which a predicate asserts something.
} 
selectional restrictions governing the co-occurrence of lexical 1tems (1965:75-106). However, there seems to be uncertalnty existing in current transformational grammar about the status and the functions of these selectional features. McCawley states that selectional restrictions are definable solely in terms of properties of semantic representations and that to determine whether a constituent meets or violates a selectional restriction, 1 t is necessary to examine 1 ts semantic representation and nothing else (1968:135).

McCoy (1969:37), who encountered difficulties in setting up her features, says that 'answers are still lacking to such basic questions as how many and which features need to be included in a lexical entry; how the features of a lexical item are to be discovered or how far a grammar needs to go in specifying the features required by the terminal node.' Th1s analys1s, wh1ch is designed to be as semantically adequate as possible and to explain the syntactic characteristics of the verb and 1 ts arguments will hopefully contribute to a solution of these questions.

One of the best treatments on semant1c features that the writer has studied is found in Chafe's Meaning and the Structure of Language (1970). In this study however, the writer 1dentifles binary features, reducing the number of Chafe's features by as much as one-half. Again, some of Chafe's noun types have been collapsed in this study. For example, his patient and experlencer nouns are both referred to here as objects having different governing verbs. The flrst is governed by an agent1ve verb and the second by a nonagentive verb.

In the writer's attempts to formalize the feature approach, Starosta's articles on the case in the lexicon (1971a, 1971b, 1972) have given valuable Insights, as well as McCoy's (1969), Taylor's (1971), and N1lsen's (1971) dissertations. McCoy's work 1s especially 1mportant in the use of subcases in the subcategorization of Spanish verbs.

1.3.4. Linguists disagree on whether to consider the verb or the noun central in the deep structure. Chafe (1970:144) and McKaughan (1958) in his work on Maranao considered the verb central in their analyses. Fillmore (1968:21) and Chomsky (1965) however have thelr nouns select the verbs and not vice versa. Chomsky's strict subcategorlzation rules or Fillmore's case frames give the contexts into which verbs are inserted.

In this study the verb is considered central because one can predict the types of arguments that can co-occur w1th 1 t even when 1 t is not placed in any context with an array of particular nouns. In other words, the syntactic constituents of the sentence are predicted by the semantic 
properties of the verb. 'Verb' in this study is understood in the more general sense of Fillmore's 'predicator'.

The verb, therefore, is composed of a bundle of specifled semant1c features which restrict or dictate the types of case-marked nouns that may co-occur with 1t. The noun, although marked for the potent1al case roles 1 t can perform, can only function in any of these roles if assigned by the semant1c properties of the verb. These properties or features are inherent to the verb and const1tute part of 1 ts total meaning.

The semant1c features of a particular verb select the types of nouns that the verb allows to occur w1th 1t. The 1nherent semant1c features In the verb and the types of nouns that co-occur with 1 f further 1mpose a classification on the verb similar to Fillmore's 'case frame'. However, Fillmore's frames consist only of the cases that may select a verb, wh1le th1s study adds the inherent semant1c features of the verb and refers to both the case frame and the semant1c properties as features of the verb, with the former predictable from the latter.

For example, [texternal] verbs require more than one argument. These arguments are Agent and object. The [+external] feature of the verb Indicates a type of action having an agent external to that action. The features of this verb class would include [texternal], requiring $[+\mathrm{A}]$, and $[+0]$. Example:

(14)

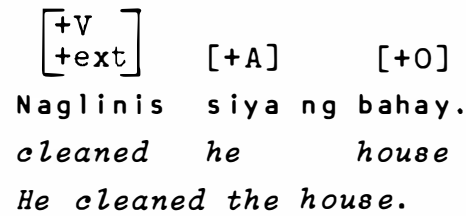

A verb marked [-external] often requires the presence of just one argument, that of Agent. The action is internal and therefore does not affect an outside object. Such a verb would include the feature [-external], requiring $[+A]$. Example:

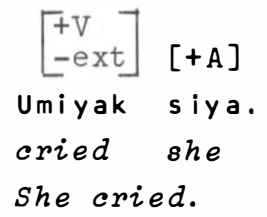

The case frames or case co-occurrence restrictions are actually determined by the semantic features of the verb. The case environment of the verb, or sald in another way, the nouns co-occurring with the verb, therefore, do not determine the type of verb to be used. The verb has as part of 1ts total meaning the array of cases that 1 ts very 
meaning requires or permits in 1ts environment. The verb 'governs' the introduction of cases into the sentence. The verb's central sense or meaning thus includes 1 ts case environment. Th1s 1mportant observation seems to be verlfied in that the classiflcation of the verbs has been found to be possible without having to put them into a context.

It is of interest as an aside to note that when the investigator initially posited semantic features for the verb, no thought was given to a one-to-one correspondence with surface representations. However, some semantic features posited, such as [tcentrifugal], have helped to explain surface forms heretofore inadequately described. For example, most MAG-verbs correspond to the verbal feature [+centrifugal], meaning action away from the agent, and the majorlty of UM-verbs correspond to the [-centrifugal] feature, meaning action toward or benefiting the agent (P1ttman 1966:12). Th1s seems to directly support the cla1ms here (1) that the semant1c features chosen are not purely aribtrary or ad hoc but do correspond to actual inherent semant1c properties of Tagalog verbs, and (2) that some formal features of grammar can be accounted for in terms of meaning (cf. Lakoff 1970).

1.3.5. In this study, following Chomsky's notational system in h1s standard transformational model (1965), the case selectional features of the verb are introduced in the base by a complex symbol, a matrix of specified features. As indicated above, and repeated here for emphas1s, verbs have semant1c features wh1ch define the basic or central sense of the verb, and they have also contextual (1.e., case environment) features. Specifically, the types of verbal features discussed here focus on their noun selection function.

To match the verbal case features, nouns also are assigned case features in this study, called 'nominal case features'. These are in addition to the 'Inherent features' of nouns such as 'animate-1nanimate', 'proper-common', etc. But as mentioned before, nouns as lexical units do not have flxed case roles as do the verbs. Nouns assume case roles in propositions, the case role being determined by the verb. These roles are assigned to nouns by case-related redundancy rules similar to those Taylor used (1971:264). Subcategorizational and redundancy rules in this approach thus attribute features to both nouns and verbs.

To capture the relational character of case (see Anderson 1971:28), selectional redundancy rules (see Chapter IV) restrict the types of nouns that occur with certain types of verbs on the basis of the latter's meaning. In other words these rules show how the semantic properties of the verb dictate what kind of cases may occur with 1 t.

Case frames are represented as selectional features instead of 
category symbols as Fillmore does in his grammar. According to Starosta,

'This has an advantage over Fillmore's pseudo-strict-

subcategorizational case frames in that the case frame need not be handled as a single unanalysable unit, but

can be broken up into components which can be handled

by redundancy rules in accordance with usual conventions

for feature rules.' (1972:1101).

At the risk of further redundancy, the alm here is to describe the core feature matrix for verb classes recognized intultively by nat1ve speakers of Tagalog, but needing a formalization in order to describe th1s intultive knowledge. Th1s has been done by noting the inherent features of verbs using a model that will explain why a nat1ve speaker can tell what the verb's co-occurrence restrlctions are, or what array of nouns a verb demands even when the verb is out of context.

Inltially, the writer examined about 800 verb bases for obligatory case environments and checked the results with another native speaker of Tagalog. Flllmore's universal case list was used for the purpose. It was discovered that a majority of the verbs cluster around a few case frames. When subjectlvallzed however, the same frame was found to have different verbal afflxes marking it in the surface structure. In some instances different case frames were marked by the same verbal afflxes. To eliminate some of these overlaps, it was declded to study the meanings of the verbs. The semantic properties of the verbs as well as the avallable syntactic information about them were then formallzed into features. It was observed that Fillmore's case roles were too broad to handle the finer meanings of the relationship between the verb and 1ts noun phrases so these were divided into subcases wh1ch were selected by the verbal features.

Most of the semant1c features of verbs have been derived from descriptions of the Tagalog verb by Lopez and Plttman and concepts for the case features from Blake, Flllmore and Chafe's descriptions. Whenever necessary, new features (semant1c or case) have been posited, based upon the writer's intultions as a nat1ve speaker of the language. The result is an analysis which explains some of the '1diosyncratic' behaviour of the verbs; some, not all, for there are exceptions which w1ll be discussed in detall in Chapter VII.

Before continuing to a description of deep cases and their meanings in Tagalog, it should be sald that this study makes no cla1m to being the best approach to case determination. The use of features as an attempt to formalize the varlous case relationships present in a sentence may not be the perfect solution, but unt1l a better system is found, features appear to be a convenient shorthand 'to express the similarities and differences existing among various cases' (McCoy 1969: 37). The writer has tried to approximate her intultive understanding 
of the total meaning of the verb by positing the features relevant to an adequate description of the case system in Tagalog. It should also be sald that no cla1m is made elther that the display of verbal and nominal features introduced in this study w1ll completely define all Tagalog verb-noun case relationships, let alone the total meanings of verbs and nouns. The study is experimental, almed toward an ultimate explanation of the underlying case system and consequently how this lingulst1c knowledge can help in the subcategorlzation of Tagalog verbs. The writer belleves that the semantic features postulated in this study subcategorize verbs w1th more exact1tude than has been possible earlier. Since the surface realization machinery is not developed to a point where one can make precise predictions, the ultimate emplrical validity st1ll remalns to be tested.

In summary, this study attempts (1) to explain why a deep structure analysis is necessary to make an adequate description of the case system of Tagalog verbs; (2) to explain why a particular verb has a particular case frame in terms of semant1c features of verbs; (3) to explain the intultively percelved differences in case constituents in terms of subcases, thus getting closer to semant1c adequacy; and (4) to formalize the system in a way which avolds the notational problems of Fillmore's case grammar and Chafe's semant1c case model. None of the previous works of Tagalog have undertaken any one of these object1ves. It may be mentioned in this connection that others recently have attempted the use of subcases in thelr analyses, but none on Tagalog: see McCoy 1969; N1lsen 1971; Anderson 1971; Taylor 1971; and Harrison 1971 . 



\section{CHAPTER II}

\section{TAGALOG DEEP STRUCTURE CASES}

As postulated in the introduction, the verb is central to the Tagalog sentence. Nouns are perlpheral and tied to the verb center by relations such as agent1ve, objective, instrumental, directional, locative, and the like. The nature of these case relationships of the nouns to the verb will be discussed in some detall in this chapter.

\subsection{THE USE OF CASE IN PHILIPPINE STUDIES}

The notion of 'case' is not new in the analysis of Ph1lippine languages. In 1906 F.R. Blake wrote a paper ent1tled 'Expression of Case by the Verb in Tagalog'. In 1930 he wrote another paper in which he defined his use of case very clearly. He says, 'the term case as regularly used refers primarily to form and has to do with meaning only insofar as that is denoted by the form' (1930:34). But this use of the term, Blake points out, 1 s limlted and does not denote the relationship 1tself. Blake goes on to clarify by using the phrase case form for 'case' In 1ts usual sense, 1.e., the inflections, and the term case for the relationsh1p without regard to 1 ts means of expression. Fillmore emphasizes this clarification in his current general theory of case grammar and adopts Blake's usage by, he says, 'using the term case to identify the underlying syntactic-semantic relationship, and the term case form to mean the expression of case relationship in a particular language - whether through affixation, suppletion, use of clitic particles, or constraints on word order' (1968:2l).

Bloomfleld did not use the term case since affixes on nouns' in Tagalog do not occur to mark such relationships. In general, the term has been avolded by others writing on Phllippine languages.

However, avolding the use of the term case does not do away with the type of relationships often indicated by noun affixes (case forms). 
These relationships tylng noun phrases in the Tagalog sentence to verb centers are 1ndicated by affixes in the verb rather than on the noun and by particles introducing noun phrases. Affixes in Tagalog verbs mark case relationships between the verb and the subject of the sentence, while the particles introducing noun phrases mark the same kind of relationships, but do so between verbs and non-subject noun phrases.

At least three terms have been used to describe the verb affixes referred to above: focus, volce and case. Summer Institute of Lingulst1cs' personnel introduced the term focus for these affixes (Healey 1960:103). Kerr expla1ns that the verb, by these affixes, 'has an implied focus of attention on the entire expression marked as topic' (1965:17). Others have deslgnated these afflxes by the term voice, Including Bloomfleld (1917, 1933), Lopez (1937), and McKaughan (1958, 1962). McKaughan in h1s earlier writing preferred volce to focus to emphasize that the relationship was verb to subject (he called 1t 'top1c' then) rather than a relationship of emphasis seemingly conveyed by the SIL term 'focus'. Others using the term 'focus' in their descriptions of Ph1lippine languages include Dean (1958), P1ke (1963) and other SIL lingulsts, Capell (1964) and Bowen (1965). Those who have followed Blake (1906, 1930) in h1s use of the term case include Kerr (1965), McKaughan (1970) and Gonzales (1971).

Wh1le most Ph1lippine lingulsts avolded the term case ent1rely, McKaughan did refer to 'pronouns inflected for case relations, and case marking particles' whlch 'indicate various case-like relations to the verb center' in his monograph on the Inflection and Syntax of Maranao verbs (1958:7-15). In a footnote (1958:16) he says, 'these caserelations remind us of the following: nominative, ergative, accusative, and dative (locative and benefactive).' But in the 1958 monograph, McKaughan used the term 'volce' for verbal affixes that indicate the 'specific syntactic relations between the topic.... and the verb' (1958: 19). In a later article, though not using the term case he obviously referred to case-like relations between the verb and the topic as well as the (case) relations between the (case) particles and the non-toplc nominal expressions. In 'Overt Relation Markers in Maranao' he says, 'verbal affixes thus mark grammatical relations between verb and topic which intersect the relations marked by particles used with other than topic substantives' (1962:47).

Taking up from McKaughan's Maranao study, Kerr concluded that 'the case-like relationships marked by the verb voice affixes are the same types of relationship as those obtaining between the non-topic nominal expressions and the verb' (1965:16). He noted that verb volce affixes have case-marking functions. This parallels to a certain extent what 
Blake wrote in the 1906 article mentioned above. In his article, Blake stated that 'the case relations of a noun may be expressed by a verb' and that verbs have 'case indicating functions' (1906:183). Kerr also used case to encompass both types of relationships: the case-like relations marked in the verb between the verb and 1ts topic and the case-like relations between the verb and the non-toplc nominal expresslons. Unlike Blake however, Kerr did not distingulsh clearly between case form and case (meanling).

F1llmore turned to Blake's use of case in his conceptual framework. In 1968, he postulated that with each underlying predicate expression there is an unordered set of arguments. Each of these arguments is labelled according to 1 ts semant1c role (or 'case' relationsh1p) with the predlcate word. The role types are themselves unanalyzables corresponding to elementary perceptions on the part of human beings concerning matters relative to an action. The roles include relations to actions such as who did 1t, who experlenced 1t, where 1 t happened, what the result was, and a few others. A number of these role notions may be universal, and can be grouped in each language into a limited number of cases, namely agent, instrument, object, directional, location and so forth. In this study, these role types and thelr groupings are used to describe the semantic structure of predicates and their arguments.

F1llmore's case grammar model thus has two levels: the deep structure and the surface structure (1968:21). According to McKaughan, this difference between deep and surface structure helps to clarlfy the 'problem of conceptualizing the cross cutting of the cases marked by verbal affixes and those marked by particles or pronouns' (1970:294). He argues that with the avallabllity of a model that moves from deep to surface structure, instead of just describing what is found on the surface all at one t1me, 'we can discuss the underlying cases in one step and then move toward the surface in another step, topicalizing one of the NP's with resultant changes' (1970:295).

In discussing deep structure, Fillmore describes the underlying sentence as consisting of $a$ 'verb and one or more noun phrases, each associated with the verb in a particular case relationship' (1968:21). Using McKaughan's description of Maranao, he describes 'primary toplcallzation' for that language as follows: 'one NP is chosen as topic for every sentence, and this choice is recorded in the following way: 
its original case preposition is replaced by so and an affix is inserted into the $V$ which indicates the case category of the chosen NP' (1968:55). The resultant surface structure indicates what the top1c is by the preposed particle so, and in turn what the underlying case relationship of the top1c to the verb is by an affix in the verb rather than in the noun. McKaughan says that Fillmore's process of toplcalization (or subjectivalization) 'immediately clarifies what has confused our descriptions for so long, and what has made us unintelligible to nonPhilippinists in our discussions of voice, focus, case, topic, etc.' (1970:295).

It is interesting to note that the surface structure of a Tagalog sentence is actually quite simliar to the deep structure representation of a sentence proposed by Flllmore. The Tagalog verbal sentence on the surface often consists of a verb followed by a serles of noun phrases related to the verb as agent, object, instrument, source or goal. The thesis in this study is that the deep structure of a sentence may be stated in terms of these underlying role relationships rather than starting with surface syntactic relationships, the role relationships underlying the surface arrangements.

Probably because of the striking resemblance of a surface Ph1lippine language sentence to Fillmore's suggested universal structure, recent studies on Phllipplne languages are heavily influenced by his case grammar model. Gonzales (1971) worked on the semant1c structure of Kapampangan, using Chafe's generat1ve-semant1c model (1968:70). Chafe's model as used by Gonzales, bears a striking resemblance to Fillmore's (1968) case grammar and Chafe acknowledges h1s debt to F1llmore's work (Chafe 1970:10). The main difference between the two is that Fillmore's $V ' s$ and C's (cases) are primitives of deep structure in syntax, distinct from the interpretat1ve semant1c component, whereas chafe's $\sqrt{\mathrm{N}}$ configurations are meant to be semant1c, syntax belng incorporated into semant1cs. So in Gonzales' study, $V$ (verb) is used as the nucleus of a sentence with accompanying role-marked N's (nouns). On the basis of the specifications of $V$, co-occurring $N$ 's are postulated which stand in the following possible (case) relations to $\mathrm{V}$ : agent, agent1ve beneficlary, assoclate, complement, experlencer, goal, 1nstrument, location, materlal, measure, mot1ve, norm, part1t1ve, pat1ent, source, t1me.

M1r1k1tan1 (1971), on Kapampangan, Introduced semant1c relationsh1ps taken from Fillmore's case grammar, but in general used Chomsky's generative-transformational model instead of Fillmore's. The resultant difference is in the notational approach, since Mirikitani introduced case relationships through subcategorizational rules (1971:14) to avold mixing relational and categorlal functions, a weakness which fillmore notes in his model (1971:35). 


\subsection{CASE AS USED IN THIS STUDY}

Case as used in this study is adopted from Blake's use of the term (1930:35) to 1dent1fy a syntact1c-semant1c relationsh1p without regard to 1 ts means of expression. The reason for emphasis upon the relationsh1p without regard to 1ts means of expression comes from the fact that for Phllipplne languages, surface forms do not always reveal easily the underlying case relations. Surface expressions which indicate case relationships, are called case forms.

Following Fillmore, the deep structure relationshlps between verbs and the nominal constituents of a sentence are stated in terms of semantic role relationships in this study other than purely syntactic relationships. The description proceeds from these deep structure relationships to the ultimate surface syntact1c realizations by transformational rules. Since 'every language has approximately the same case relationships though they differ widely in their use of case forms' (Blake 1930:34), a study of these relationsh1ps in Tagalog may also furnish an excellent basis for a comparison of languages of widely differing types. Further, if these relationships can be shown to be comparable across languages, then there would be strong evidence for consldering case to be a unlversal category of language, and for clalming greater explanatory adequacy for grammars written within a case grammar framework (F1llmore 1968:20) with 1ts underly1ng semant1c structure. In the following sections, the underlying case relations in Tagalog are discussed.

\subsection{TAGALOG CASES}

There are two types of cases in Tagalog, inherent cases and noninherent cases. The flrst, the inherent or nuclear cases are determined by the central meaning of the verb whlle the others, the non-1nherent or the perlpheral cases, are predictable from the existence of certain inherent cases in the sentence.

\subsubsection{Inherent Cases}

As stated above, certain cases are conceptually 1nherent to the basic sense of the Tagalog verb. These arrays of 1nherent cases have the effect of 1mposing a classiflcation on the verbs according to the sentence types in which they may be inserted. Case, then, functions in the subcategorization of Tagalog verbs. Verbs may be classified, in other words, according to the Inherent cases with which they are closely assoclated in the deep structure.

The cases inherent to the verb are 1mplied by the meaning of the 
verb. Th1s may be 1llustrated as follows: In Tagalog, the verb bili to buy in 1ts semant1c 1mplications (or features) designates or assumes (1) an inftiator and performer of the action which also benefits from the performance of the action (1s the recelver of that action), and (2) an object that is affected by the action, 1.e., 1s purchased, and transferred to the agent (purchaser). On the other hand, bigay to give assumes (1) an inftiator of the action who is not the goal or recelver, though that inftiator is the source from which the action emanates, (2) an object that is transported away from the agent, and (3) a referent to whom the object 1s transported (a directional goal of the action).

The roles actants may perform are grouped in Tagalog into five Inherent case relationships in the deep structure: the agent1ve case $(A)$, the objective case ( 0 ), the directional case ( $1 \mathrm{r}$ ), the locative case ( $L$ ) and the instrumental case (I). These flve cases are further subcategorlzed according to the semantic roles involved in each. A single case may designate more than one semantic role. As indicated above, an agent may perform the action and be the reciplent thereof (bili to buy) or the agent may perform an action and be the source of the action without being affected thereby (tapon to throw).

The following sections indlcate what the inherent cases are in Tagalog and thelr semantic characteristics.

\subsubsection{The Agentive Case}

The agent1ve (A) case is the case of the 'typically animate perceived instigator of the action identified by the verb' (F1llmore 1968a:24). Th1s case applies to the actant who performs the action.

There are two subclasses of the agent1ve case: the agent1ve-asundergoer and the agent1ve-as-nonundergoer. Other analysts have not subdivided this case, referring to the agent as the actor whether or not that actor is the source, goal or undergoer of the action (part1cularly Bloomfield and various SIL linguists).

The first subclass of the agent1ve case, the agent1ve-as-undergoer, designates a performer that undergoes the action he initiates. Here the agentive case is coreferential in that the agent both performs the action and is also affected by that action, 1.e., is the undergoer of the action. For example, the verb lakad to walk takes an agent that (1) performs the action and (2) is the one in the action that is directly affected by 1 t; $1 . e$. , the agent undergoes the action of walking and 1s therefore both performer and object. Anderson (1971:50) describes

the same type of agent as one wh1ch 'operates in some sense upon 1tself'. Th1s type of agent1ve case cannot take a separate object case since the 
agent 1s both performer and the object of the action. Fillmore (see Cook 1971:14) refers to these dual roles as 'coreferential roles' because there are two distinct underlying functions performed by the same referent. ${ }^{1}$ The following sentences 1llustrate this subcase. ${ }^{2}$

(1) Umakyat siya.

climbed he

He climbed up.

Note: If punung kahoy tree is added, it cannot be the object of the verb. The agent involves himself in the action, he does not make the tree climb. Rather, the tree would be the goal of the action and would necessar1ly be in the directional case (Section 2.3.1.3).

\section{A}

(2) Tumayo siya.

stood he

He stood up.

Note: He is the agent-undergoer of the standing action. As in the sentence above, the agent involves himself in the action indicated by the verb.

Other verbs that require this type of agent are langoy to $8 w i m$, lakad to walk, tawa to laugh, iyak to cry, and ngiti to smile.

The second subclass of the agent1ve case, the agent1ve-as-nonundergoer, designates an agent that inftiates and performs the action designated by the verb, but that agent does not undergo the action; the action relates to an object outside of the agent. There are two subclasses of this second type of agent1ve case. One 1s coreferential with the source of the action only, whereas the other 1s coreferentlal with the goal or beneflclary of the action.

The first subclass of the agentive-as-nonundergoer case may be called the agent-as-source case since the agent inftlates and performs the action on an object outside of that agent. The agent is both the performer and the source of the action with the two roles carried out by one individual. The following sentences lllustrate this subclass.

\footnotetext{
'Using the notion of 'coreferential roles', Fillmore analyzes the subjects of verbs like walk, mon, swim as having two case functions: Agentive and Objective. What he terms as 'agentive-as-objective' is similar to the 'agentive-as-undergoer' in this study. Huddleston (1970:507) analyzes the same set of intransitive verbs as having subjects which occur twice in the deep structure, once as objective, and once as Causer.

${ }^{2}$ In the sentences illustrating the different cases, the verbs are cited with their affixes.
} 


$$
\begin{aligned}
& \text { (3) Magluluto ang nanay } \mathrm{ng}^{\mathrm{I}} \text { ulam. } \\
& \text { wizl-cook mother main dish } \\
& \text { Mother wizl cook the main dish. }
\end{aligned}
$$

Note: Mother inftiates and performs the action of cooking and is the source of the action. The action relates to the main dish, in no way affecting Mother.

$$
\begin{aligned}
& \text { (4) Itatapon ng bata ang basura sa labas. } \\
& \text { wizl-throw child garbage outside } \\
& \text { The child will throw the garbage outside. }
\end{aligned}
$$

Note: The child 1n1tiates and performs the action, wh1ch, though 1t emanates from the child, in no way affects this child. Rather, the action affects the garbage.

Other verbs that require this type of agent are laba to launder, linis to clean, hugas to put, place, abot to hand over, and walis to sweep.

The second subclass of the agent1ve-as-nonundergoer case may be called the agent-as-goal case. Here the inftlator and performer of the action 1s also the recelver or goal. That 1s, the agent 1 s the source of the action, but the action also benefits the inftiator. In this Instance, the agent case again subsumes coreferential roles in that the terminal goal of the action is also the performer. P1ttman (1966:12) refers to this type of action as 'centripetal' (moving object toward actor) as opposed to 'centrifugal' (removing object away from actor). The centrifugal action takes the agent1ve-as-source case as opposed to the centripetal action here, which takes the agent1ve-as-goal case. The objects in the following examples move toward the performer of the action and the performer is the goal of that movement.

A

(5) Kumuha siya ng pagkain.

got he some food

He got some food.
(6) Umabot siya ng saging.
reached-for he banana
He reached for a banana.

Other verbs that require this type of agent are bili to buy, hiram to borrow, kain to eat, inom to drink, ubos to consume, higop to gulp down, lulon to swallow and hingi to ask for.

\footnotetext{
$\overline{l_{\text {The symbol }}}$ ng stands for the particle nang according to the accepted orthography of Tagalog.
} 
The following feature tree gives a display of the agent1ve case and 1 ts subcases (or features).

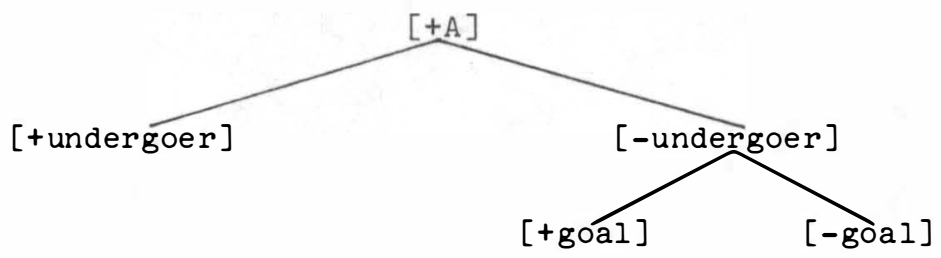

\subsubsection{The objective case}

The objective (0) case is the most neutral case semant1cally. According to Fillmore (1968a:25) it is the case of anything representable by a noun whose role in the action or state is 1dentifled by the semantic interpretation of the verb, limited probably to things affected by the action or state 1dentified by the verb. Where Fillmore limits the concept to Inanimate objects, the objective case in Tagalog includes experlencer anlmate ent1ties too. The term objectlve here, therefore, encompasses both Fillmore's objective and experiencer cases.

There are two major subdivisions of the objective case in Tagalog, one with agent1ve involvement and the other with no such agent1ve involvement. The first type of object acts as the patient or is the recelver of an externally induced action and the other type is not the patient but the experiencer of an internally induced action.

The case referred to as the object in previous analyses is here termed the objective-as-patient. The following sentence 1llustrates this type of object.

\section{(7) Naglinis ang babae $\left\{\frac{\text { ng bahay }}{\text { nito }}\right.$. cleaned the woman $\begin{aligned} & \text { house } \\ & \text { this place }\end{aligned}$ \\ The woman cleaned the house/this place.}

When an object1ve case obligatorlly occurs with an agent1ve-as-source or an agent1ve-as-goal case, the verb affects the object in four different ways: (1) if motion is involved, it transports the object away from or toward the agent; (2) In such instances 1t transports toward or away from a directional source or goal; (3) if motion is not Involved, the verb changes or does not change the object and (4) when It changes the object, the change is elther partial of total.

The object-as-patient is in turn subdivided between centripetal and centrifugal objects referred to above. The centripetal object 1s brought toward the agent when acted upon, the agent being in the underlying 
agent-as-goal subclass. There are two types of centripetal objects: the nontransported centripetal object and the transported centripetal object. The first is acted upon by the agent and 1s moved directly towards 1t (agent) as goal.

The following sentence lllustrates:

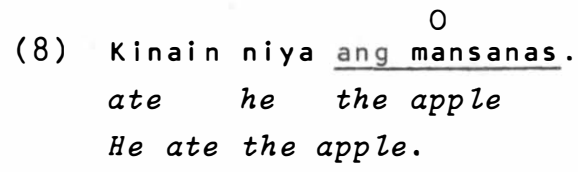

The following verbs also show that the direction of the object is toward the performer: inom to drink, lunok to swallow, kagat to bite, tawag to call, igib to fetch water, ampon to adopt and kabig to draw towards self.

The second type of centripetal object is acted upon and brought towards the agent from a third argument that 1s the source of the act1on. The following sentence exemplifies this kind of object.

(9) Kinuha niya ang mansanas sa mesa.
got he tapple
He got the apple from the table.

The following verbs also show that the direction of the object is toward the performer from a directional source: abot to reach for, hingi to ask from, dukot to draw out from, bunot to pluck out, baltak to pulz toward source of force, tanggap to receive from, agaw to snatch from, and hiram to borrow from.

Unlike the action of the verb on the centripetal object, the action of some verbs does not move the object toward the agent. Th1s type of object is referred to as the centrifugal object. The two types of centrifugal objects are the non-transported centrifugal object and the transported centrifugal object.

The flrst of these is not carried from the agent to a third argument. The action terminates with the object. The following sentence exemplifles this type of object.

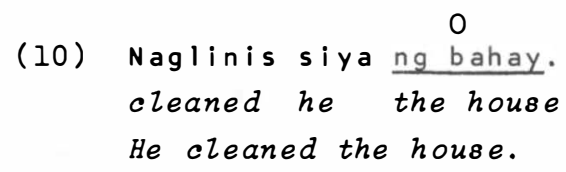

Other verbs that take this type of object are: alaga to take care of someone, akay to lead someone, aksaya to waste something, halungkat to ransack something and ayos to arrange something. 
When not transported, the centrifugal objects may or may not undergo a process of change in physical condition when acted upon by some verbs. The action terminates with the object. The agent with these objects is the source of the action.

If there is change, that change of the physical condition of the object may be of two kinds. One type of change is total and the other 1s partial. Note the following examples.

\section{(11) Binali niya ang sanga. broke he the branch He broke the branch.}

Here the branch is no longer in 1ts original condition. The agent that performs the action is 1 ts source, but 1t 1s not the goal or object of the action. Changes of this sort are considered total (see also sentence \#12) in contrast to partial change 1llustrated in sentence \#13 - \#15 below.

\section{(12) Tinadtad niya ang karne chopped he the meat}

He chopped the meat.

Other verbs that take this type of object are: durog to pulverize, sira to destroy, punit to tear up, hiwa to cut, slice, gillng to grind, giba to demolish, putul to cut, piraso to take a piece of, basag to break, tunaw to melt, pitas to pick.

W1th some verbs the object does not undergo a complete change of state. It 1 s generally an object which is handled by an agent-as-source of the action. The following sentences illustrate.

\footnotetext{
(13) Hinugasan niya ang pinggan. washed he the plate He washed the plate.
(14) Binuksan niya ang radyo. turned-on he the radio He turned on the radio.
(15) Linabhan niya ang damit. laundered he the clothes He laundered the clothes.


Other verbs that take this type of object are: punas to wipe off, hilamos to wash (face), banlaw to rinse, sara to close, bukas to open, tali to tie and pahid to wipe.

W1th some verbs, the object does not undergo any change at all. The following sentences lllustrate.

\section{0}

(16) Inipun niya ang pera.

saved he money

He saved the money.

(17) Hinalungkat niya ang bahay.

ransacked he house

He ransacked the house.

Some centrifugal objects are carrled away from the agent toward a third argument that is the recelver where the action terminates.

Examples :

(18) Itinapon niya ang basura sa ilog.

threw he the garbage in river

He threw the garbage in the river.

(19) Ibinigay niya ang pera sa akin.

gave he the money to me

He gave me the money.

Other verbs that take this type of object are: tanim to plant, tago

to hide, hulog to drop, hatid to deliver, balik to return, hagis to hurl, throw and latag to spread.

The following feature tree gives a display of the patient subcase of the objective case.

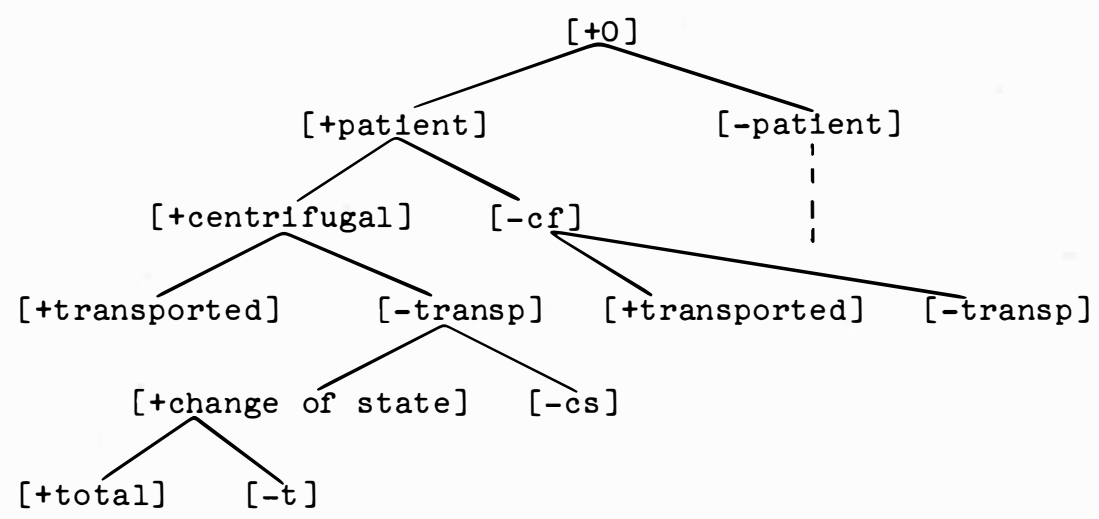


As indicated earlier, the object case baslcally divides between those that recelve an externally induced action (patient) and those that do not. The latter undergoes some k1nd of process stated by the verb w1thout the presence of an 'animate instigator' of the action. Under this subclass, object-as-nonpatient case there are two types of objects, one that 'experiences' a sensation or that is affected by a psychological event, and the other which does not 'experlence' or 'feel' the process stated by the verb.

Certaln verbs require the experiencer case as referents. These referents 'suffer' or 'feel' psychological effects from the action designated. Earlier analysts have not distingulshed this case from the actor or agent case (see Bloomfleld and SIL lingulsts). The semantic differences are, however, clear. The experlencer does not perform an action. He is affected by the action, but not because he inftiates 1 . The syntact1c 1mplications are also different in that this case is often the only case in the sentence. The following sentence 1llustrates.

(20) Nagutom ang mama/pusa.

felt-hungry man cat

The man/cat felt hungry.

Other mental state or psychological verbs that take this case are as follows: hilo to be dizzy, uhaw to be thirsty, lungkot to be sad and tuwa to be happy.

There are two types of non-experiencer objects. One undergoes a process of 'becoming' and is called here the 'Inchoat1ve' object to emphasize the beginning of a change, and the other undergoes a general process stated by the verb.

These objects marked 'Inchoat1ve' go through a process of 'becoming' something other than thelr orlginal state. Note the following examples.

(21) Gumanda si Neneng.

become-beautiful Neneng

Neneng became beautifur.

(22) Pumuti ang buhok niya. became-white the hair his His hair became white.

(23) Lumiit ang tinapay. became-small the bread The bread became small. 
Although adjectival concepts appear here, this subclass of the objective case actants differs from the actants of ordinary adjectives by having been once in a different state, and not being in a particular non-changling state or condition as are the latter actants. The actants in the 1nchoative subcase must undergo a process of change, and this process is conveyed by the notion of 'becoming'.

Other verbs that take this kind of object are: laki to become big, tigas to harden, become hard, lambot to soften, become soft, bait to become good, yaman to become rich, taas to become tall, taba to become stout, hirap to become difficult, lago to become Zuxuriant, kinis to become smooth and $k i s l a p$ to sparkle.

A subset of the same class of object indicates change of a temporary or transient nature.

Examples :

(24) Namula ang pisngi niya.

became-red the cheeks her

she blushed.

(25) Namutla siya.

became-pale she

She became pale.

Other verbs that take this type of object are: puti to become white, payat to become thin, to lose weight, itim to become black/gray, dilaw to become yezrow, tigas to become stiff, to faint, ngalumata to develop dark rings around the eyes, hina to become weak, nginig to tremble, kupas to fade, etc.

Objective actants that undergo the process indicated by non-stative types of verbs are called here non-1nchoatlve objects. These objects are usually 1nanimate. Again, no agent is involved overtly in the action upon this type of object.

There are two subclasses of the non-1nchoative object. One.type is transported and the other 1s not. The latter is 1llustrated by the following sentences.

0

(26) Bumukas ang pinto.

opened the door

The door opened. 
0

(27) Kumukulo ang tubig.

boiling the water

The water is boiling.

Other verbs that take this type of object are: sara to close, buka to bloom, to open, hinto to stop, galaw to move and kaluskos to make a rustling sound.

A transported non-inchoative object is carrled to a second argument where the action terminates. The following sentences lllustrate.

(28) Bumagsak ang bola sa pir $\begin{gathered}0 \\ \text { putik. }\end{gathered}$

fell ball mud

The ball fell into the mud.

$0 \quad$ Dir

Bumuhos ang tubig sa lata.

The water poured into the can.

Other verbs that take this type of object are: tulo to trickle, taob to turn over, lubog to sink, litaw to appear, lutang to float, tilapon to be thrown out and tapon to spizl.

A certain type of object seems to have the characteristic features of the 'becoming' types of objects and the 'process-undergoer' types. Like the first type of object, this object frequently occurs with stative types of verbs but instead of undergoing an internal process of 'becoming', similar to the second type, 1t undergoes a general process stated by the verb.

Example:

0
(30) Nabasa ang sahig.

wet floor

The floor got wet.

Other examples are: sunog to get burned, luto to get/be cooked, bali to get broken, tuyo to dry up, pis a to get crushed and baluktot to be bent.

However further analysis indicates that these objects actually allow an external causer to occur with them. The potentlal causer may be e1ther instrumental or agentive.

Examples :

(31) Nabasa $\begin{aligned} & \text { ng ulan ang sahig. } \\ & \text { wet fain floor }\end{aligned}$
The raingot the floor wet.


(32) Nabasa $\frac{\text { Ag bata }}{\text { chizd }}$ ang sahig. I

The child got the floor wet.

When a causer is present, an element of unintentional or accidental meaning is added to the sentence and the object has unexpected events happen to 1t. Th1s object was first thought to be a subclass of objects not allowing agent1ve involvement. However, 1 t has been dropped from this classification because causers may occur w1th 1 t.

The following feature tree glves a display of the non-patient subcase of the objective case.

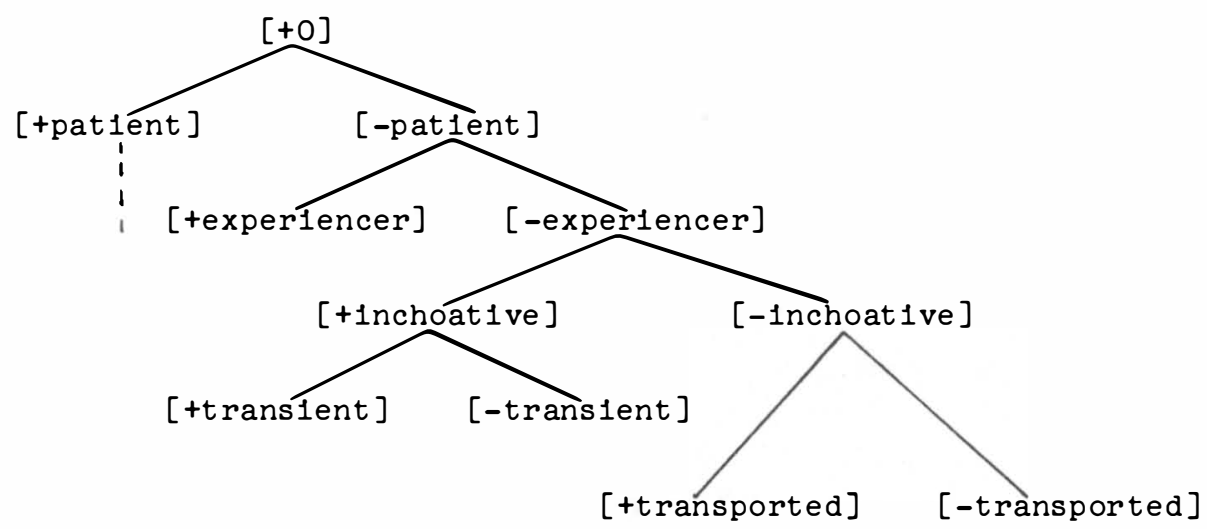

\subsubsection{The Directional case}

The directional ( $D 1 r$ ) case is the case of the animate or inanimate object from or toward which the action of the verb is directed. Th1s case actant occurs with verbs of motion. The directional case has been previously analyzed as locative or referent (see SIL papers on Philipplne linguist1cs, 1964).

As with other cases, this one may also be subdivided. The first subdivision is the directional goal, designating an actant toward which the action of the verb is directed, or the place where the action terminates or is terminated. The following sentences exemplify the. first subdivision of the directional case.

\footnotetext{
The first example with the instrumental force as causer always has the unintentional interpretation. However, with the agentive causer present, the sentence gets two readings. One is accidental and the other abilitative. Some native speakers differentiate the two interpretations by stressing the affix of the verb of the sentence having the accidential meaning. However, most native speakers of Tagalog do not make this distinction.

The second sentence having an agentive causer has the following readings:
}

a. (Accidental) The child got the floor wet unintentionally.

b. (Abilitative) The child was able to get the floor wet. 
Directional Goals with Agents

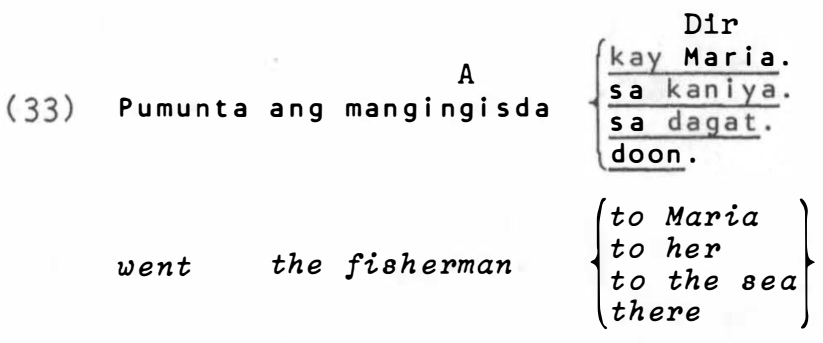

$$
\begin{aligned}
& \text { The fisherman went }\left\{\begin{array}{l}
\text { to Maria. } \\
\text { to her. } \\
\text { to the sea. } \\
\text { there. }
\end{array}\right.
\end{aligned}
$$

Other verbs that require these cases are: dapo to alight on, kapit to hold on to, lipat to transfer, pasok to enter into and tingin to look at.

Directional Goals with Agent and objects

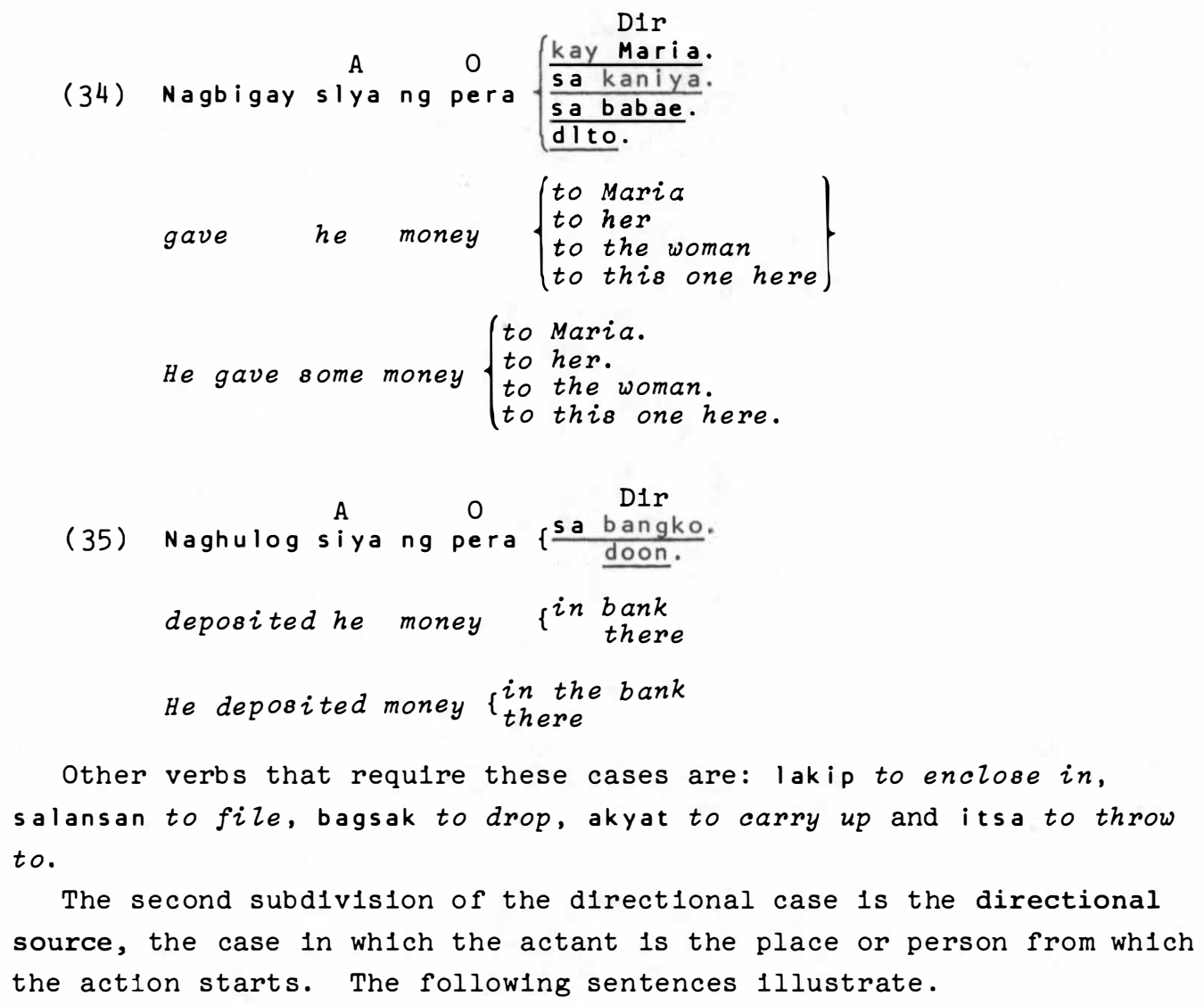


Directional Source with Agents

$$
\begin{aligned}
& \text { D1r } \\
& \text { siya }\left\{\frac{\frac{\text { sa amin. }}{\text { kina Pedro. }}}{\frac{\text { sabahay }}{\text { dito. }}}\right. \\
& \text { came he }\left\{\begin{array}{l}
\text { from us (our place) } \\
\text { from Pedro's (place) } \\
\text { from the house } \\
\text { from here }
\end{array}\right\} \\
& \text { He came }\left\{\begin{array}{l}
\text { from our place } \\
\text { from Pedro's place. } \\
\text { from the house. } \\
\text { from here. }
\end{array}\right.
\end{aligned}
$$

Other verbs that require these cases are the following: umpisa to start from, mula to come from, simula to begin from, and buhat to come from.

The only difference between the directional goal actant and the directional source actant is the direction of the action. Generally only the agent-as-goal co-occurs with the directional source actant.

Examples of verbs that require these cases are: agaw to snatch, hila to pulz, sunggab to grab, bunot to pulz out, kaladkad to drag, supsop to sip, kagat to bite, hingi to ask for, hiram to borrow, abot to reach for and pasan to carry on one's back.

The following feature tree gives a display of the directional case and 1 ts subcases.

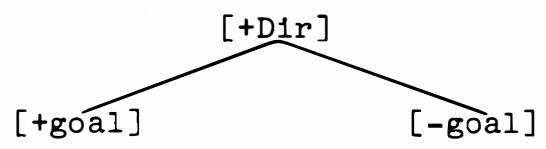

(source)

\subsubsection{The Locative Case}

The locative (L) case is the place where the action occurs. In contrast with adverbial expressions of place which can occur with all verb types, this case 1s required by a limlted set of verbs. 'The following sentences lllustrate.

$$
\begin{aligned}
& \text { Lumangoy ako sa } \mathrm{i} \text { log. } \\
& \text { swam I in river } \\
& \text { I swam in the river. }
\end{aligned}
$$


L

(38) Tumira ako sa bahay niya.

lived $I$ in house his

I lived in his house.

A directional case can occur with a locative case in a sentence as seen in the example below.

(39) Naghalo akong gatas Da kape sa kapetera.

mixed I milk with coffee in coffee pot

I mixed milk with coffee in the coffee pot.

In this sentence, the agent $I$ inltiates and performs the action of mixing the object, milk, with a reclplent, the coffee which is 1 ts directional goal, in a container which is the location where the action of mixing takes place.

There are very few verbs that take both the directional and the locative case.

Examples of verbs that take the locative case are: lipad to fly, tigil to stay (at a place), luto to cook (in a utensil), babad to soak, laba to Zaunder, hintay to wait, duyan to swing (in a swing, hammock), tampisaw to play in water, laga to boil and sakay to ride.

\title{
2.3.1.5. The Instrumental case (Force)
}

Among all the cases discussed here, the instrumental (I) case is classifled as belonging to both inherent and non-1nherent types of cases. However, only a very small set of the I case belongs to the inherent category. Words in this set are limited to the forces of nature that are causally involved in the action stated by the verb. The natural phenomena nouns such as ulan rain, araw sun, kidlat lightning, when classlfied as inherent I cases, are lmplied in the meaning or semantic properties of the verb. Section 6.3.1.1.2 describes these actants as 'Incorporated instruments' because unlike the1r non-1nherent force counterpart, these actants never surface.

Examples :

\author{
I (force) \\ (40) Humahangin. ( $\frac{\text { ang hangin) }}{\text { wind }}$ \\ The wind is blowing. \\ (41) Umaaraw. (ang araw) \\ shining sun \\ The sun is shining.
}




\subsubsection{Non-inherent Cases}

The 1nherent cases that have been discussed are 1mplied in the semant1c features of the verbs. They subclassify verbs and are obligatory In that the semant1c 1mplications, even if they are not brought to the surface, are 'understood' by the speakers of the language. On the other hand, there are certain cases that also subclassify the verbs but in contrast with the first type of cases, these are predictable. Their occurrence is dependent upon the occurrence of one or the other of the inherent cases. For example, the occurrence of benefactive phrases in the sentence seems more directly dependent upon whether the agent1ve phrase 1s present than upon the semant1c properties of the verb. These are the cases 'compatible w1th the cases originally chosen' or required by the verb (F1llmore 1968:87). Cook states that these cases are 'peripheral to the analysis and simply add in clrcumstantial detall of the verbal action' (1971:12). Three non-1nherent cases are treated here, the instrumental, the benefactive and the affected cases.

\subsubsection{The Instrumental case}

The Instrumental (I) case expresses the 'force or object causally involved in the action or state 1dentifled by the verb' (F1llmore 1968:24). In Tagalog there are two subclasses of the instrumental case: the instrumental tool and the instrumental force.

The first subclass of the instrumental case, the instrumental tool, is typically an inanimate object which acts as a tool to bring about the action 1dentified by the verb. Its presence in the sentence is dependent upon the presence of the agentive case. Most Philippine lingulsts limit the use of the instrumental role to this subclass. (See publications of SIL linguists; Constantino 1965; Bowen 1965.)

Examples:

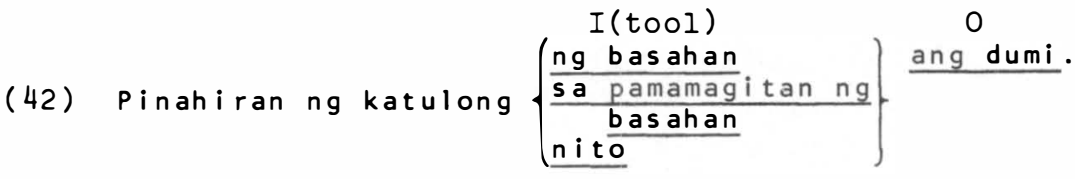

$$
\begin{aligned}
& \text { wiped helper }\left\{\begin{array}{l}
\text { with rag } \\
\text { by means of a rag } \\
\text { with this }
\end{array}\right. \text { the dirt } \\
& \text { The helper wiped off the dirt }\left\{\begin{array}{l}
\text { with a rag. } \\
\text { by means of a rag. } \\
\text { with } \text { this. }
\end{array}\right.
\end{aligned}
$$


(43) Binasag ko ang salamin $\left\{\begin{array}{l}\text { I(tool) } \\ \frac{\frac{\text { ng martilyo. }}{\text { samamagitan ng martilyo. }}}{\text { nito. }}\end{array}\right.$

$$
\begin{aligned}
& \text { broke I the glass }\left\{\begin{array}{l}
\text { with hammer } \\
\text { by means of a hammer } \\
\text { with this }
\end{array}\right. \\
& \text { I broke the glass }\left\{\begin{array}{l}
\text { with a hammer } \\
b y \text { means of a hammer } \\
\text { with this }
\end{array}\right.
\end{aligned}
$$

Verbs w1th wh1ch this case occurs are: hiwa to cut, slice, hampas to hit, sampal to slap, wasak to destroy, palo to spank, pukpuk to pound, linis to clean, ipit to press, durug to pulverize, walis to sweep (with a broom), sinturon to hit (with a belt), talop to peel, punas to wipe and hugas to wash.

The second subclass of the Instrumental case corresponds to the case called 'Force' In other case grammar studies (see Huddleston 1970; F1llmore 1971). It refers to the inanimate unintentional performer or non-responsible causer of an event. The occurrence of this case is dependent upon the presence of the objective case in a proposition where no agency involvement is present. It therefore never co-occurs w1th agents.

The force subclass of the instrumental case can be expressed by Impersonal ent1ties l1mited to the forces of nature or natural phenomena like ulan rain, bagyo storm, baha flood, kidlat lightning, araw sun, ambon drizzle, kulog thunder, hangin wind, alon wave and other 1 mpersonal ent1ties like diseases, plants, fire and rock, which cause an event to occur.

Examples:

(44) Nabasa siya $\mathrm{I}$ (force)

wet he by rain

He was drenched by the rain.

(45) Naanod ang bakya ng baha.

carried-away the wooden shoes by flood

The wooden shoes were carried away by the flood.

(46) Nabuksan ang pinto ng hangin.

forced-open the door by wind

The wind forced the door to open, or

The wind opened the door. 
$\begin{array}{ccc}0 & I \text { (force) } \\ \text { (47) Nalason siya ng kabuti. }\end{array}$ poisoned he by mushroom

He was poisoned by mushrooms.

$\begin{array}{ccc}0 & I(\text { force) } \\ \text { (48) Napatay siya ng tuberkulosis. }\end{array}$

kizled he by tuberculosis

He was killed by tuberculosis.

The 1mpersonal ent1ties may refer to inanimate objects that cause an event to happen. Because of the presence of non-responsible causers of the action, an element of unintentional or accidental meaning is Implied in the sentence.

Examples:

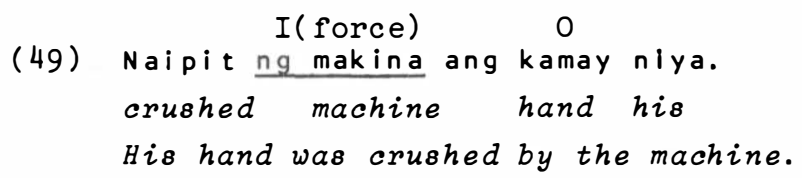

$\begin{array}{lll} & 0 & I \text { (force) } \\ \text { (50) Nasagajan } & \text { ang mama } & \frac{n g \text { trak. }}{\text { truck }}\end{array}$

The man was run over by the truck.

The instrumental force too may function as the stimulus which causes an object to undergo or experlence some kind of psychological or mental event. It could be an animate or inanimate cause of the experience. Examples:

(51) Natakot siya $\left\{\begin{array}{l}\text { I(force) } \\ \frac{\text { sa palabas }}{\text { sakin }} .\end{array}\right.$

frightened she $\left\{\begin{array}{l}\text { of the movie } \\ \text { of me } \\ \text { of the cat }\end{array}\right.$

She was frightened $\left\{\begin{array}{l}\text { of the movie. } \\ \text { of me. } \\ \text { of the cat. }\end{array}\right.$

0
(52) Nabuwisit siya sa inggay.

irritated she noise

She was irritated by the noise. 
Again, as in the above mentloned examples, there is no willful or purposeful agent involved in the sentence.

Th1s type of instrumental force differs from the one marked by ng in that 1t is more a passive cause rather than the active causer of the event. The following sentences show the contrast.

O I (force)

frightened she thunder

She was frightened by the thunder.

(54) Natakot siya sa kuler)

frightened she thunder

She was frightened of the thunder.

Fillmore regards thunder in the second sentence as the instrument which is the 'stimulus or reacted-to situation in the description of a mental event' (1971:262).

The writer is of the opinion that $s$ a in the sentence above is actually the reduced form of dahil sa because of. But this needs more testing. The role of phrases marked by dahil sa was treated previously in this study as 'causal case' 1 and defined as the case wh1ch gives the nonagent1ve cause of an action.

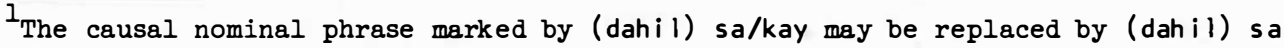
pronouns or demonstratives.
}

Example:

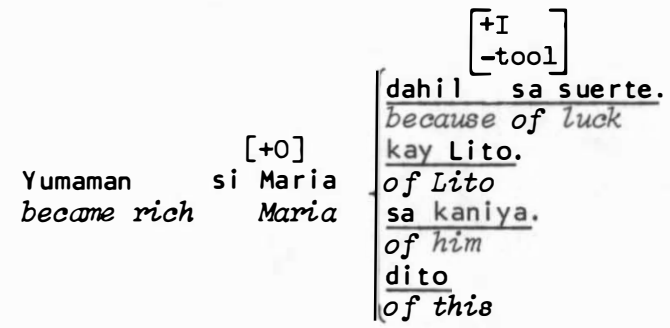

$$
\begin{aligned}
& \text { Maria got rich because of }\left\{\begin{array}{l}
\text { luck. } \\
\text { lito. } \\
\text { him. } \\
\text { this. }
\end{array}\right.
\end{aligned}
$$

When this case is subjectivalized, the verb takes the $i-k a-$ compound affix. Example :

$$
[+0] \quad\left[\begin{array}{l}
+\mathrm{I} \\
-\mathrm{t} 001
\end{array}\right]
$$

Ikinayaman ni Maria ang mabuting suerte. caused to become rich Maria $\frac{\text { good fortune }}{\text { cod }}$

Good fortione caused Maria to become rich or Maria became rich because of good fortune. 
Examples:

$$
\begin{aligned}
& \text { I (force) } \\
& \text { sa suerte. } \\
& \text { (55) Yumaman si Maria }\left\{\begin{array}{l}
\text { dahil sa suerte. } \\
\text { became rich Maria }
\end{array}\right. \\
& \frac{\text { dahil sa nagkaroon siya ng suerte. }}{\text { because got }} \\
& \text { Maria became rich }\left\{\begin{array}{l}
(\text { because) of luck. } \\
\text { because of luck. } \\
\text { because she was lucky }
\end{array}\right. \\
& \text { I (force) } \\
& \text { sa a lak. } \\
& \text { (56) } \begin{array}{l}
\text { Namatay si Juan } \\
\text { died }
\end{array} \quad\left\{\begin{array}{l}
\frac{\text { Juan alcohol }}{\text { of }} \\
\text { dahil sa }
\end{array}\right. \\
& \text { dahil sa paginom niya ng alak. } \\
& \text { because of drinking he alcohol }
\end{aligned}
$$

It is noted that this instrumental cause occurs more frequently in non-agent1ve sentences but it can occur in agent1ve sentences too. Example:

(57) Nagipon siya ng pera $\begin{aligned} & \text { sahil sa asawa niya. } \\ & \text { saved he money }\end{aligned}\left\{\begin{array}{l}\text { beause of wife his } \\ \text { dahil sa gusto ng asawa niya. } \\ \text { because of like wife his }\end{array}\right.$

He saved money $\begin{aligned} & \text { because of his wife. } \\ & \text { because his wife wants him to. }\end{aligned}$

Fillmore limited his examples to sentences with the experlencer case only.

Non-agent1ve cause or 'causal case' has been dropped from this study because the writer noted that the dahil sa phrase could possibly be derlved from a sentence. Th1s part of the study 1s limited to the analys1s represented by noun phrases only. So, although mentioned here, this type of case which has an event-causing function is not discussed further.

The following feature tree gives a display of the instrumental case and 1 ts subcases.

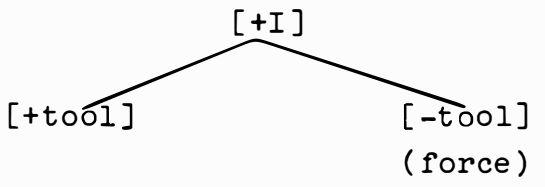




\subsubsection{The Benefactive case}

The benefact1ve ( $B$ ) case is dependent on the presence of an agent1ve case in the sentence, 1.e., the benefactive case cannot occur unless the agent1ve case also occurs. The benefactlve case expresses the anlmate or Inanimate ent1ty for whom or for wh1ch, the action of the verb takes place.

Examples :

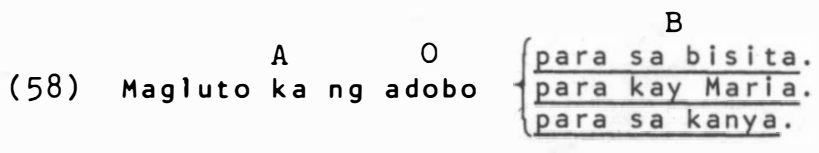

$$
\begin{aligned}
& \text { cook you adobo }\left\{\begin{array}{l}
\text { for the visitor } \\
\text { for Maria } \\
\text { for her. }
\end{array}\right. \\
& \text { (You) cook adobo }\left\{\begin{array}{l}
\text { for the visitor. } \\
\text { for Maria. } \\
\text { for her. }
\end{array}\right.
\end{aligned}
$$

(59) Bumili siya ng kurtina para sa bahay.

$$
\text { bought she curtains for the house }
$$

She bought some curtains for the house.

In some verbs the benefactive case indicates that the agent performs an action in place of the benefactor. Th1s happens usually in sentences where there are no objects.

Examples:

$$
\begin{aligned}
& \text { Kumain ka sa handaan para sa akin. } \\
& \text { eat you at party for } \\
& \text { (You) eat at the party in my place. }
\end{aligned}
$$

(61) Kumanta siya sa palatuntunan para sa akin.
(6)

$$
\text { sang he at program in-place-of me }
$$

He sang in the program in place of me (or for me).

(62) Nagluto siya para sa akin.

cooked he for me

He cooked in place of me. 


\subsubsection{The Affected case}

The affected (Af) actant '1s generally human and suffers (adversely) from a patient's action or his state of belng' (Sasak1 1971:68). The occurrence of this case in Tagalog is dependent upon the presence of an objective case which has undergone some kind of process, the whole event affecting the second actant adversely. The following palred sentences lllustrate.

Process Undergone by object

(63) Namatay ang tatay niya.
died the father his
His father died.

0

(64) Nawala ang pera niya. lost the money his His money was lost.

\section{0}

(65) Nasunog ang bahay niya.

burned the house his

His house was burned down.

\section{Affected Sentence}

Namatayan siya ng tatay.
died he $\quad$ father
He was adversely affected by his
father's dying/death.

Nawalan siya ng pera.
Lost he $\quad$ money
He was adversely affected by his
money being lost.

Nasunugan siya ng bahay.
burned he house
He was adversely affected by the
burning of his house.

\subsubsection{Summary}

In this chapter we have discussed the meaning of the Tagalog cases, subdividing them when necessary to specify those meanings. Five inherent cases and three non-1nherent cases have been discussed. Subdivisions are made in order to fully understand the intult1ve information a speaker of the language has at his command. Ten oppositions, for example, are needed to characterize the meaning of just the object case relation.

We now turn to a formalization of this information. To do so, the Tagalog verb must be put into a framework of generative rules that will show baslcally how to account for sentences with these centers. 


\section{CHAPTER III}

\section{BASE RULES}

\subsection{INTRODUCTION}

The base rules needed specifically for a description of the case system of Tagalog are presented in this chapter. The rules are general and include only the noun categories pertinent to the subcategorization of the verbs. Adverblal phrases of t1me, manner and extent are not discussed since they involve complications beyond the scope of this study. With some modifications, the rules follow Fillmore's general 1dea of a grammar model, being a 'transformational grammar whose base component specifies the case structure of sentences' (F1llmore 1971:247).

Case relationships are incorporated in the base component as features of lexical 1tems of the grammar in this study rather than as dominating category symbols. In this cholce, the writer agrees with Robinson who claims that the lexical component appears to be the 'loglcal place' where 'formative (terminal) categories are subcategorized and selectional restrictions defined, either by syntactic redundancy rules if they are general, or by entries in the lexicon if they are specific' (1969:70). Taylor's dissertation on 'Case in Japanese' (1971) is a descriptive exemplification of how case is incorporated in the base component as features of lexical items.

Instead of rewriting the sentence as a verbal element followed by a serles of cases (1.e., $S \rightarrow V+C_{1} \ldots C_{n}$ ) as Fillmore does (1970), KP, a term introduced by Robinson in her article on 'Case, Category and Configuration' (1969:10), has been subst1tuted here for $C_{1} \ldots C_{n}$. This gives $\mathrm{S} \longrightarrow \mathrm{V}+\mathrm{KP}_{1} \ldots \mathrm{KP}_{\mathrm{n}}$ where in turn $\mathrm{KP}$ rewrites as $\mathrm{K}+\mathrm{NP}:$ The objection to rewriting $C_{1}$ (case) as $K$ (preposition or case marker) plus an NP (noun phrase) is the problem of $\mathrm{mlxing}$ relational (functional) notions (case) with categorial notions (case particle $+N P$ ), a notational weakness of Fillmore's model (see Fillmore 1971:35). 
The model used in this study is a modifled generative transformational model incorporating case in the base component as features of lexical 1tems. To do this, Chomsky's use of subcategorization rules and complex symbols has been adopted. The use of complex symbols and features described in this study assumes Chomsky's first of two possible formats of the base component of a grammar as presented in Aspects (1965:84-111). The base component consists of two subcomponents: (a) a constituent structure subcomponent, consisting of context-free 'rewriting rules that apply to category symbols and that generally involve branching, and rules that apply to symbols for lexical categories and that introduce or operate on complex symbols (sets of specified syntactic features)' (Chomsky 1965:84); and (b) a lexicon subcomponent, wh1ch is simply an unordered list of all lexical formatives and some redundancy rules. More preclsely, the lexicon is a set of 'dictionary entries', each dictionary entry beling a complex of syntact1c, phonological and semant1c information.

The constituent structure subcomponent defines a set of trees, whose terminal nodes are labeled by 'complex symbols'. Lexical categorles dominate complex symbols. The features of these complex symbols are assigned by subcategorization rules which include context-free rules (usually referred to by Chomsky as 'redundancy rules') and contextsensitive rules. The context-sensitive subcategorlzation rules consist of two subtypes, namely "strict subcategorization rules" which subcategorize a lexical category in terms of the frame of sister category symbols in which it appears and "selectional rules" which subcategorize a lexical category in terms of syntactic features that appear in specified positions in the sentence' (Chomsky 1965:112-113).

The lexicon subcomponent contains a similar or 1dentical set of subcategorization rules as well as a set of redundancy rules, which predict the existence of one feature in the lexical entry in terms of another. Such redundancy rules may predict context-sensitive features such as $[+\ldots[+\mathrm{A}]]$ as well as context-free features such as [+animate].

Lexical insertion then follows Chomsky's lexical rule:

If $Q$ is a complex symbol of a pre-terminal string and $(D, C)$ is a lexical entry, where $C$ is not distinct from $Q$, then $Q$ can be replaced by D.' (1965:84)

G1ven, therefore, a lexical entry $(D, C)$, where $D$ is a phonological distinctive feature matrix 'spelling' a certain lexical formative and C a collection of specifled syntact1c features (a complex symbol), the lexical rule above permits substitution of $\mathrm{D}$ for any complex symbol $\mathrm{K}$ that is not distinct from $C$.

The lexical rule simply means that a complex symbol may be replaced by a lexical 1tem if their feature matrices are non-distinct. Consequently, Chomsky says that 'lexical entries must be specified negatively 
for features corresponding to contexts in which they may not occur' (1965:110).

In this work, all context-free subcategorlzation rules will be assumed to operate both in the categorlal component and in the lexicon. Context-sensitive rules operate only in the const1tuent structure subcomponent, not in the lexicon.

The 1mportant amplification of the base rules given here, is an expanded specification of the 'complex symbol' rewriting the verb to include case-related semant1c and contextual features and the complex symbol rewriting the noun to include case features (Taylor 1971).

As has been stated earlier, certain semant1c features of the Tagalog verb govern the cholce of the arguments (nominal expressions) that may occur w1th 1t. These (nominal expressions) in turn must be specifiable w1th semant1c features compatible w1th the verbs. The verbs are subcategorlzed by the semant1c features they contain which in turn determine the nominal expressions with which they can occur. Thus, the caserelated semant1c features of the verb can be determined by analyzing the potent1al argument(s) w1th which 1t may occur. The possible base structure conflgurations can be specifled by rewrite rules which include both the complex symbol (semant1c features) for the verbs and the complex symbol for the nouns.

The following base rules for Tagalog formalize and expand as well as particularize the information given in the previous chapter. The allowable semantic underlying cases of the sentence are specified as part of the meaning of the verb. Semantic information other than that of case is also needed to rewrite the verb, and will also be given in the complex symbol suggested in this chapter. Selectional redundancy rules for the nouns must be specified to indicate the cholces possible when the verb center has been chosen. The selectional redundancy rules are given in Chapter IV.

\subsection{BASE RULES}

A typlcal Tagalog verbal sentence consists of a verb (V) accompanied by one or more actants, or case-marked phrases (KP). ${ }^{1}$

$$
\text { BR\# I. } \quad \mathrm{S} \longrightarrow \mathrm{V}+(\mathrm{KP})^{5}
$$

Case-marked phrases (KP) are verbal complements. Constantino referred to these KP's as 'complement phrases' (1965:10) and Kerr called them 'nominal expressions' (1965:16). Maximally, flve KP's can occur in a single sentence.

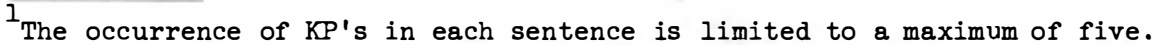




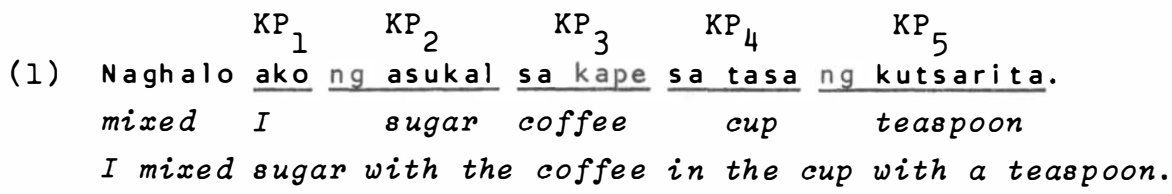

A verb in turn 1s specifled by BR\#2, belng composed of a complex symbol. In this study, only the semant1c characterlstics of non-stative verbs (1.e., verbs that express an activity or a process) are described. 'Causat1ves', 'aptat1ves', 'd1stribut1ves', referred to as 'aspect' by McKaughan (1958:26), w1ll not be treated as part of the basic semant1c structure of the verb.

BR\#2. $\quad \mathrm{V} \rightarrow \mathrm{c} . \mathrm{s}$.

W1th Base Rule \#2, the verb 1s rewritten as a complex symbol wh1ch is then marked by subcategorization and selectional rules for semantic features specifying 1 ts aspectual features and types of case relationshlps 1t can enter 1nto. Baslcally then, the verb may be marked for [+agent1ve] or [-agent1ve], ${ }^{1}$ and for [+neutral aspect] or [-neutral aspect]. Th1s information is contained in the feature symbolization following.

$$
2.1[+\mathrm{V}] \longrightarrow\left[\begin{array}{l} 
\pm \text { agent1ve } \\
\text { tneutral aspect }
\end{array}\right]
$$

The marking of [tagent1ve] and [ tneutral aspect] are 1ndependent of each other.

The [+agent1ve] feature expresses an act1vity wh1ch somebody does, typically the particlpant which Fillmore refers to as the 'animate inst1gator'. The [+agent1ve] verbs always require the co-occurrence of agents.

Example:

The [-agent1ve] feature expresses an act1vity wh1ch 1s characterized as a process undergone by the referent of a non-dynamlc type of nominal expression which is affected by the action rather than being 1ts inftator.

\footnotetext{
The verbal feature [-agentive] corresponds to Chafe's selectional unit, 'process' while [tagentive] corresponds to Chafe's 'action and process-action' selectional units. Miller (1970:497) divides his active verbs the same way, agentives and non-agentives.
} 
Examples:

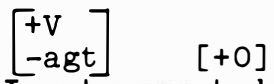

(3) Tumubo ang halaman.

grew plant

The plant grew.

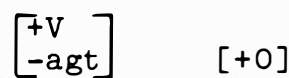

(4) Bumukas ang pinto.

opened door

The door opened.

We now turn to the full expansion of the features specifled in 2.1 . 2.11 [+agent1ve] $\longrightarrow$ [texternal]

The [+agent1ve] verbs are elther specified as [+external] or [-external].

Verbs having a [+external] feature express an activity or verbal action which occurs outside of the agent. It is an action externally induced by an agent.

Example:

$$
\left[\begin{array}{l}
+\mathrm{V} \\
+e x t
\end{array}\right][+\mathrm{A}] \quad[+\mathrm{O}]
$$

(5) Nagtayo siya ng bahay.

built he a house

He built a house.

Verbs having a [-external] feature express inner motion or an internally induced action by an agent. Lopez called this type of agent an 'agent or actor (1nternal)' wh1ch inftlates 'Inner mot1on' or motion restricted to 'Inner parts of the body' or 'putting the whole body in motion' (1941:94).

Example:

(6)

$$
\left[\begin{array}{l}
+\mathrm{V} \\
-\mathrm{ext}
\end{array}\right][+\mathrm{A}]
$$

Tumayo siya.

stood he

He stood.

$2.111[$ texternal $] \longrightarrow\left[\begin{array}{l} \pm \text { centrifugal } \\ \pm \text { terminal }\end{array}\right]$

Verbs having the [texternal] feature have a [tcentrifugal] feature and a [tterminal] feature. 
The verbs that have the [+centrifugal] feature portray a type of action that moves in a direction away from the agentive source.

Example:

$$
\left[\begin{array}{l}
+\mathrm{V} \\
+\mathrm{cf}
\end{array}\right] \quad[+\mathrm{A}] \quad[+\mathrm{O}]
$$

(7) Nagbili siya ng gulay.

sold she vegetables

She sold vegetables.

Verbs with the [-centrifugal] feature specify a type of action which goes back toward 1ts source.

Example:

$$
\begin{aligned}
& {\left[\begin{array}{l}
\mathrm{H} \\
-\mathrm{cf}
\end{array}\right],[+\mathrm{A}] \quad[+0]} \\
& \frac{\text { Bumili }}{\text { bought she }} \frac{\text { siya gulay }}{\text { (some) vegetables }} \\
& \text { She bought some vegetables. }
\end{aligned}
$$

When the verb is marked [+terminal], the action terminates with the object1ve argument.

Examples:

(9) $\left[\begin{array}{l}+\mathrm{V} \\
\text { ter }\end{array}\right]$\begin{tabular}{ll}
{$[+\mathrm{A}]$} & {$[+\mathrm{O}]$} \\
\hline
\end{tabular}

$$
\text { saved he money }
$$

He saved some money.

$\left[\begin{array}{l}+\mathrm{V} \\ +\mathrm{ter}\end{array}\right][+\mathrm{A}] \quad[+0]$

(10) Kumain siya ng mansanas.

$$
\text { ate she an apple }
$$

She ate an apple.

If specifled as [-terminal], the verbal action goes beyond the object1ve argument to the directional argument where 1t terminates. The object is thus transported to or from the directional argument. Examples:

$$
\left[\begin{array}{l}
+\mathrm{V} \\
-\mathrm{ter}
\end{array}\right] \quad[+\mathrm{A}] \quad[+0] \quad[+\mathrm{D} 1 \mathrm{r}]
$$

(11) Nagtapon siya ng dumi sa basurahan. threw she dirt in garbage can

She threw some dirt into the garbage can. 


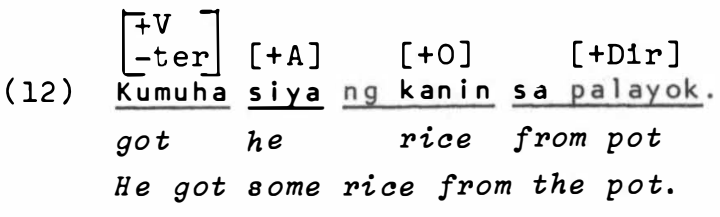

$2.1 \mathrm{v}[$ tterminal $] \longrightarrow$ [tchange of state]

Verbs having the [+terminal] feature manifest a type of action which may or may not cause the object to change in physical condition.

Some [+terminal] verbs do not affect the physical condition of the object at all.

Example:

$$
\begin{aligned}
& {\left[\begin{array}{l}
+\mathrm{V} \\
-\mathrm{Cs}
\end{array}\right] \quad[+\mathrm{A}] \quad[+\mathrm{O}]} \\
& \text { (13) } \frac{\text { sinalansan }}{\text { fiziyd }} \frac{\text { ang libro. }}{\text { he }} \frac{\text { books }}{\text { bed }} \\
& \text { He filed the books. } \\
& 2: v \quad[+ \text { change of state] } \longrightarrow[ \pm t o t a l]
\end{aligned}
$$

Example :

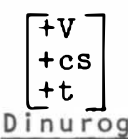

$$
[+A]
$$$$
[+0]
$$

Dinurog niya ang paminta.

crushed he

pepper

He crushed the pepper.

(A pepper after being crushed is no longer a pepper.)

When the change is partial, the effect of the action of the verb on the object is superficlal.

Example:

$$
\begin{aligned}
& {\left[\begin{array}{l}
+\mathrm{V} \\
+\mathrm{cs} \\
-\mathrm{t}
\end{array}\right] \quad[+\mathrm{A}] \quad[+\mathrm{D} 1 \mathrm{r}]} \\
& \text { (15) Pinunasan niya angmesa. } \\
& \text { He wiped the table. } \\
& \text { (A table after belng wiped is st1ll a table.) } \\
& \text { 2.v1 [-external] } \longrightarrow \text { [ } \text { [direction }]
\end{aligned}
$$


The [-external] feature can be elther [+direction] or [-direction]. A verb specified with the [+direction] feature is characterized by movement .

Example:

$$
\begin{aligned}
& {\left[\begin{array}{l}
+\mathrm{V} \\
+\mathrm{d} 1 \mathrm{r}
\end{array}\right]} \\
& \frac{\text { Tumakbo }}{\text { ran }} \frac{\text { siya }}{\text { he }} \\
& \text { He ran. }
\end{aligned}
$$

The [-direction] feature indicates non-movement.

Example:

$$
\begin{aligned}
& {\left[\begin{array}{l}
+\mathrm{V} \\
-\mathrm{d} 1 \mathrm{r}
\end{array}\right][+\mathrm{A}]} \\
& \text { Umiyak siya. } \\
& \text { cried she } \\
& \text { she cried. }
\end{aligned}
$$

\section{2.v11 [tdirection] $\longrightarrow$ [tcentrifugal]}

The [+direction] feature may be elther [+centrifugal] or [-centrifugal]. Though these features are simliar in name and function to the features specifying action related to the agent in 2.111, they are interpreted somewhat differently when they are assoclated w1th a directional argument. The [+centrifugal] feature indicates that the direction of the action is toward the directional argument which acts as the goal of the action, whereas the [-centrifugal] feature 1ndicates that the direction of the action is away from the directional argument instead of toward 1 t.

Examples :

$$
\begin{aligned}
& {\left[\begin{array}{l}
+\mathrm{V} \\
+\mathrm{dir} \\
+\mathrm{cf}
\end{array}\right]} \\
& \begin{array}{l}
\text { Pumunta } \\
\text { went }
\end{array} \frac{\text { siya sa bayan }}{\text { he to town }} \\
& \text { He went to town. }
\end{aligned}
$$

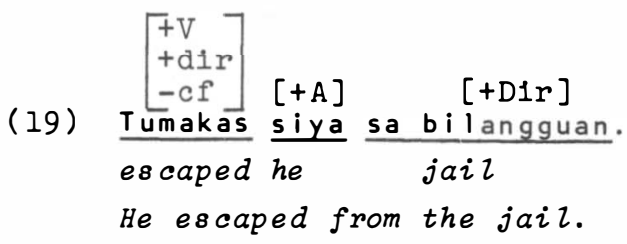

The following partial tree shows the different features of the [+agent1ve] type of verbs discussed In BR\#2.1 to 2.v11. Verbs are 
listed below w1th their respective features and thelr places in the tree speclfled by numbers corresponding to each verb.

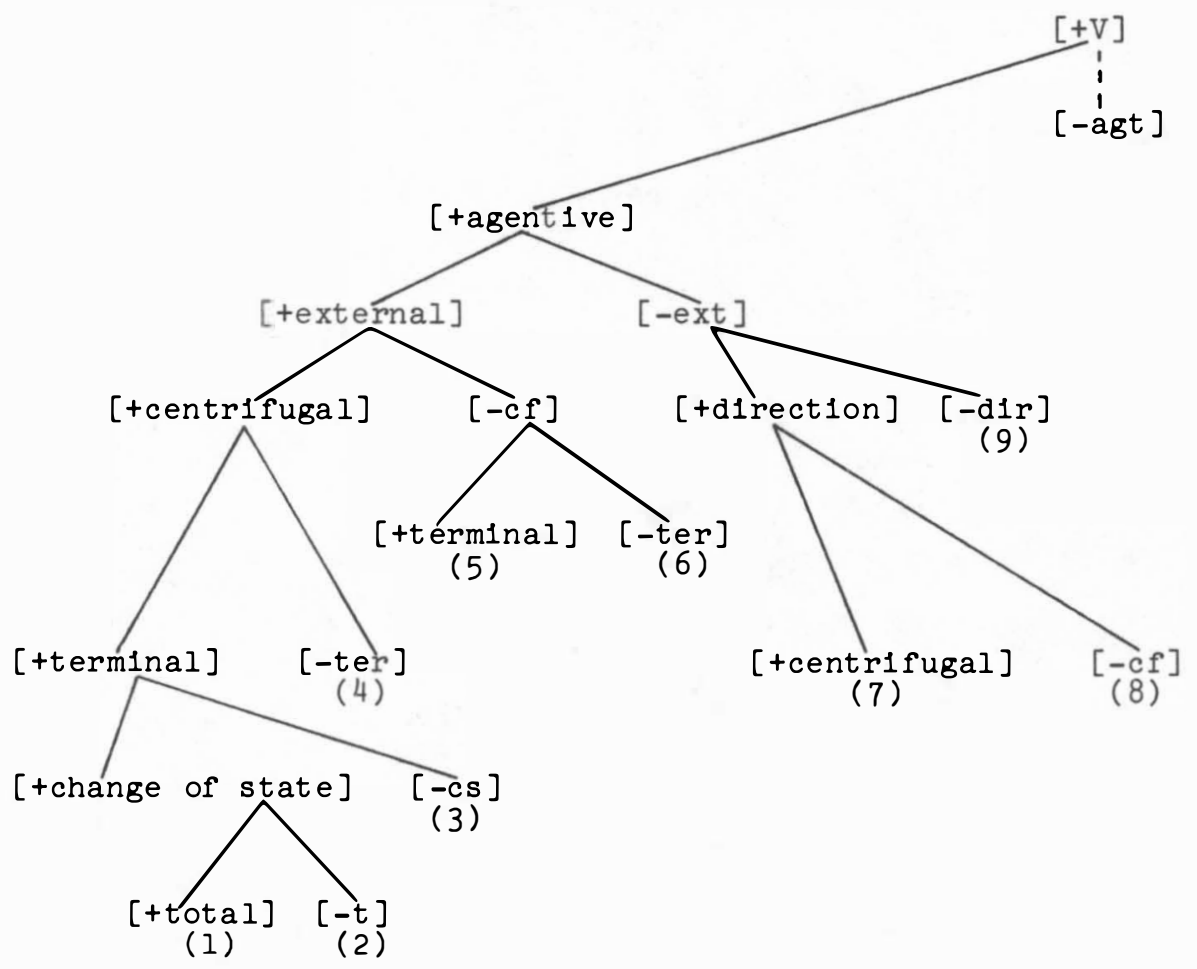

(1) luto to cook [+v, tagt, +ext, +cf, +ter, +cs, +t]

(2) hugas to wash [ $+\mathrm{V}$, +agt, +ext, +cf, +ter, +cs, -t]

(3) ipon to collect [ $+\mathrm{v}$, +agt, text, +cf, +ter, -cs]

(4) tapon to throw $[+\mathrm{V}$, tagt, +ext, +cf, -ter]

(5) kain to eat $[+\mathrm{V}$, +agt, +ext, $-\mathrm{cf}$, +ter $]$

(6) kuha to get $[+\mathrm{V}$, tagt, +ext, $-c f,-t e r]$

(7) punta to go $[+\mathrm{V}$, +agt, -ext, +dir, -ter, +cf]

(8) takas to escape from [ $\mathrm{V}$, tagt, -ext, +dir, -ter, -cf]

(9) iyak to cry [+V, tagt, -ext, -dir]

$$
\text { 2.v111 [-agent1ve] } \longrightarrow \text { [texperient1al] }
$$

The [-agent1ve] verbs are elther specifled [texperlential] or [-experiential]. Verbs marked [texperient1al] express a psychological event resulting in a particular mental state in the referent of 1 ts nominal expression. 
Example:

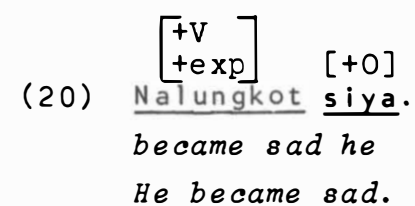

The [-experiential] feature expresses a non-psychological change of state or condition of the referent of the [+0] nominal expression occurring with the verb.

Example :

$$
\begin{aligned}
& {\left[\begin{array}{l}
+\mathrm{V} \\
-\mathrm{exp}
\end{array}\right]} \\
& \frac{\text { Lumaki }}{\text { grew }} \text { ang } \\
& \text { bata } \\
& \text { The child } \\
& \text { child }
\end{aligned}
$$

Note that this approach does not require the separate experiencer case discussed by Fillmore. Instead, the experiential aspect of such sentences is (more approprlately, I belleve) treated as a semantic feature of the verb and a subcase of objects on nouns.

$$
\text { 2.1x [-experiential] } \longrightarrow \text { [IInchoative] }
$$

Verbs marked [-experiential] may be elther specified [+1nchoative] or [-inchoative]. When specified as having the inchoative feature, the verbal action expresses a process of 'becoming', of a change of state in physical condition.

\section{2. $x \quad[+$ inchoat1ve $] \longrightarrow[ \pm$ transient $]$}

The process of 'becoming' may be elther of a transient or permanent nature. The following sentences lllustrate these kinds of changes.

Examples:

(22) Gumanda ang bata.

became beautiful the child

The child became beautiful.

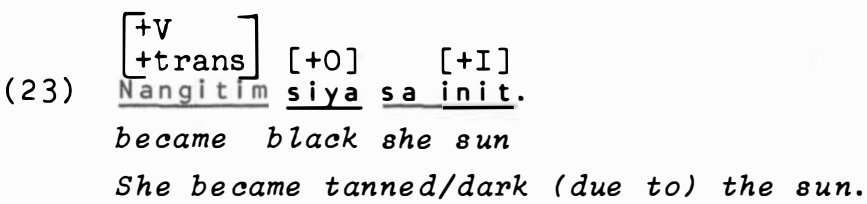


When specifled as having the [-1nchoat1ve] feature, the verbal action expresses any kind of non-agent1ve process of activity that does not express a state of 'becoming'.

Example :

$$
\left[\begin{array}{l}
+\mathrm{V} \\
-1 \mathrm{nch}
\end{array}\right] \quad[+0]
$$

(24) Umikot ang gulong.

rotated the wheel

The wheel rotated.

2.x1 [-Inchoat1ve] $\longrightarrow[$ [meteorological $]$

A verbal action specifled as [-1nchoative] may be further specified as elther [+meteorological] or [-meteorological]. A [+meteorological] feature of the verbal action is restricted to acts of natural phenomena. Example:

(25)

$$
\begin{aligned}
& {\left[\begin{array}{l}
+\mathrm{V} \\
+\mathrm{meteorological}
\end{array}\right]} \\
& \frac{U \mathrm{mu} l \mathrm{an}}{\text { Ut }} \text {. } \\
& \text { It rained } \\
& \text { It rained. }
\end{aligned}
$$

The [-meteorological] feature marks all other types of verbal activ1ty.

Example:

(26)

$$
\begin{aligned}
& {\left[\begin{array}{l}
+\mathrm{V} \\
\text {-meteorological }
\end{array}\right]} \\
& \frac{\text { Kumulo }}{\text { boiled }}
\end{aligned}
$$

The water boiled.

$$
\text { 2.x11 [-meteorological] } \longrightarrow \text { [tterminal] }
$$

The [-meteorological] feature may be elther [+terminal] or [-terminal]. The [+terminal] feature indicates that the verb does not require a directional argument to complete 1 ts meaning.

Example:

$$
\begin{aligned}
& {\left[\begin{array}{l}
+\mathrm{V} \\
\text { ter }
\end{array}\right] \text { [+0] }} \\
& \text { sumara ang bintana. } \\
& \text { closed the window } \\
& \text { The window closed. }
\end{aligned}
$$

The [-terminal] feature requires a directional actant to complete the meaning of the verb. 
Example :

(28)

$$
\left[\begin{array}{l}
+\mathrm{V} \\
-\mathrm{ter}
\end{array}\right] \quad[+0] \quad[+\mathrm{D} 1 \mathrm{r}]
$$

Bumagsak ang ibon sa lupa.

fell the bird on ground

The bird fell on the ground.

The following partial tree shows the features described in BR\#2.v111x11 (pp.49-51) to complete the plcture given earlier.

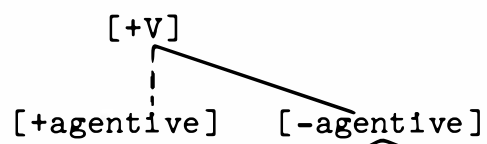

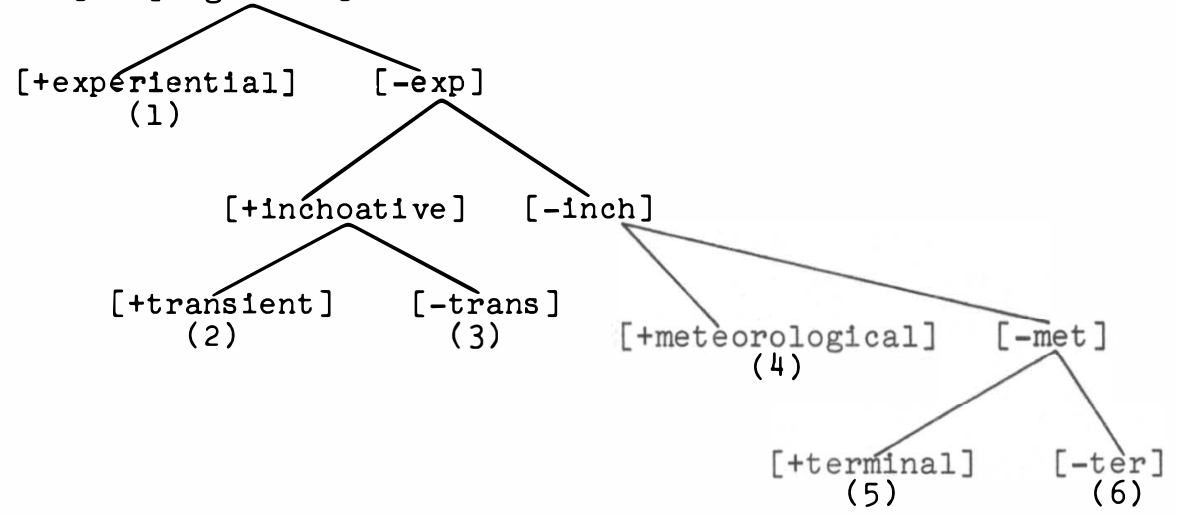

(1) lungkot to be sad [+V, -agt, texp]

(2) pula to blush, become red temporarily [+V, -agt, -exp, +Inch, +trans]

(3) pula to become red [ $+\mathrm{V},-$ agt, -exp, +1nch, -trans]

(4) ulan to rain $[+\mathrm{V},-a g t,-$ inch, +met]

(5) kulo to boil [+V, -agt, -exp, -inch, -met, +ter]

(6) bagsak to falz [+V, -agt, -exp, -1nch, -met, -ter]

All verbs have aspect. Pel defines this verbal feature as the action or state denoted by the verb...vvlewed as completed or in progress, instantaneous or enduring, momentary or habitual' (1969:19).

The term 'aspect' as used in this study is often referred to in previous studies as tense (Blake 1916, 1925; Constantino 1965, 1971, etc.). Aspect is used here to differentiate Tagalog from other nonPhllippine languages that use tense to indicate a different system of axis orlentation. Stockwell (1957:C-47-48) gives a good distinction between the Tagalog aspect system and the English tense system when he says :

\footnotetext{
'All Tagalog ( $T$ ) verb forms are oriented toward a single temporal axis, what Bull (1960:17) has called the Point Present ( $P P$ ), the instant of speaking. T has no verb forms oriented to the Retrospective Axis (RP), a recollected moment of speaking. Since English verb forms are
} 
oriented toward both of these axes (present or non-
past and past tenses), the most fundamental difference
between $T$ and E verb systems is evidently at this point.
The T verbal distinctions should not be confused with
a system that has more than a single axis of orientation."

Bowen used the term aspect for Tagalog and described 1 t as 'somewhat slmilar to the tense system of English....but the system is not closely tied to t1me, as tense systems are' (1965:113).

Otanes (1970:37) gave an excellent feature analysis of aspect in Tagalog verbs and, except for a few modiflcations, her analysis has been adopted in this study.

Verbs are e1ther not marked for aspect [+neutral] or marked for aspect [-neutral aspect].

Examples :

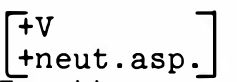

You run.

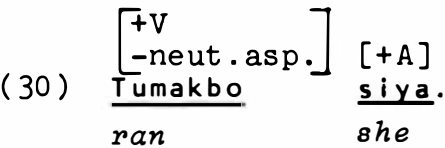

She ran.

(31)

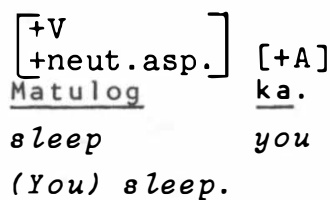

(32)

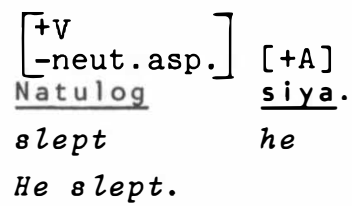

Features specifying verbal aspect are described in rules $2 . x 111-$ 2. $\mathrm{xv}$ below.

$$
\text { 2.x111 [-neut.asp.] } \longrightarrow \text { [ }
$$

When marked for aspect, the verbal action 1 s elther begun or not begun. 
Examples :

\begin{tabular}{|c|c|c|}
\hline $\begin{array}{l}\text { [+begun] } \\
\text { naglinis } \\
\end{array}$ & $\begin{array}{l}{[-b e g u n]} \\
\text { maglilinis }\end{array}$ & $\begin{array}{c}\text { [+begun] } \\
\text { naglilinis } \\
\end{array}$ \\
\hline cleaned & wizl clean & is/are cleaning \\
\hline
\end{tabular}

2. $x 1 \mathrm{v} \quad[+$ begun $] \longrightarrow[ \pm$ completed $]$

Forms speclfled with the feature [+begun] are of two kinds: completed or non-completed.

Example:

$$
\begin{array}{lc}
{[+ \text { comp }]} & {[- \text { comp }]} \\
\text { naglinis } & \text { naglilinis } \\
\text { cleaned } & \text { is/are cleaning }
\end{array}
$$

2.xv [+completed $] \longrightarrow[$ trecent $]$

Completed forms further subdivide into recently completed and nonrecently completed. The feature [-recent] here means 'unspecifled with respect to recentness.'

Example:

$\begin{array}{ll}\text { [+recent] } & {[\text {-recent] }} \\ \text { kalilinis } & \text { naglinis } \\ \text { just cleaned } & \text { cleaned }\end{array}$

The following tree shows the different aspectual forms of the verb maglinis to clean:
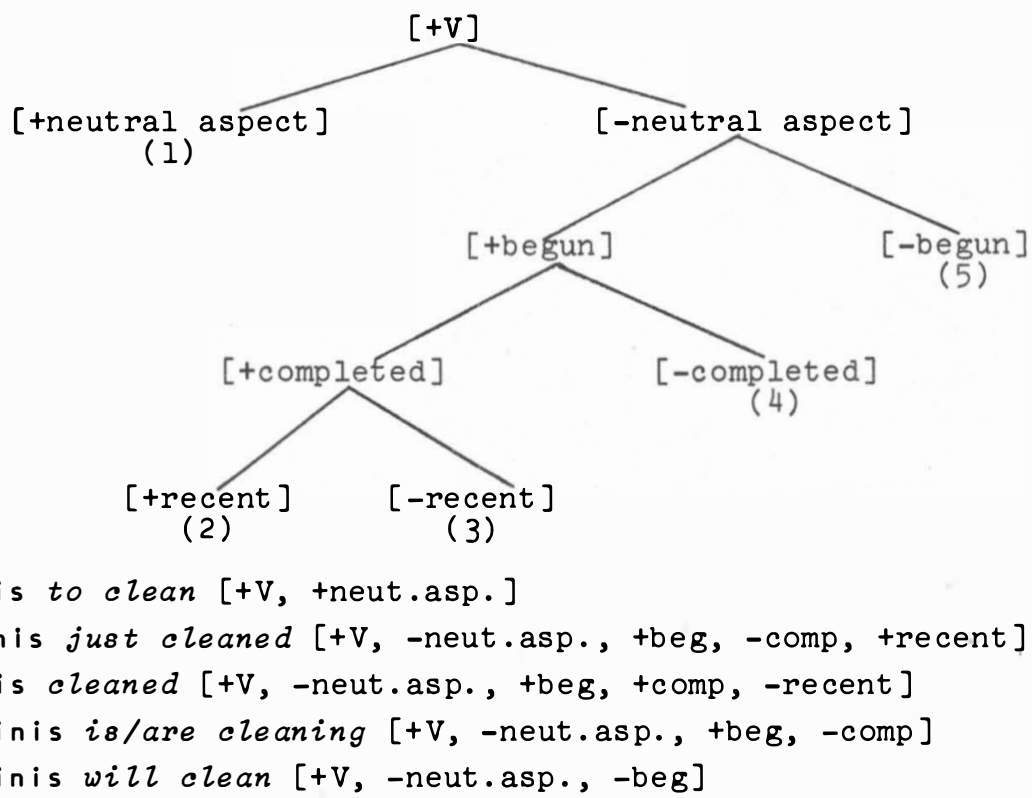

(1) maglinis to clean [+V, +neut.asp.]

(2) kalilinis just cleaned [+V, -neut.asp., +beg, -comp, +recent]

(3) naglinis cleaned [ $+\mathrm{V}$, -neut.asp., +beg, +comp, -recent]

(4) naglilinis is/are cleaning [+V, -neut.asp., +beg, -comp]

(5) maglilinis will clean [+V, -neut.asp., -beg] 
Base Rule \#3 rewrites the case phrase (KP).

$\mathrm{BR \# 3.} \mathrm{KP} \longrightarrow \mathrm{K}+\mathrm{NP}$

The KP expands into 1ts categorlal constituents consisting of a casemarking particle $(K)$ and a noun phrase (NP). The case-marking particle (McKaughan 1958), called a 'preposition' by F1llmore (1966a) and a 'complement marker' by Constantino (1965), signals the surface relation of a nominal element to the verb. In his 1970 model, Fillmore eliminated the $K$ and directly adjolned 1 t to the noun phrase by means of preposition selection rules. (See Cook 1971:11.) Its retention is preferred here as simpler and more directly representative of the facts in Tagalog.

Every NP is rewritten as an optional determiner (Det) and a noun (N). Relative clauses and other $\mathrm{N}$ attributes will not be treated in this work.

$\mathrm{BR \# 4}$. NP $\longrightarrow($ Det $) \mathrm{N}$

The Noun in turn is rewritten by a complex symbol.

BR\#5. $\quad \mathrm{N} \longrightarrow$ c.s.

The complex symbol for nouns includes at least the inherent features glven below which follow generally the matrix of features of the English nouns given by Chomsky in 1965.

$5.1[+\mathrm{N}] \longrightarrow[ \pm$ common $]$

$5.11[+$ common $] \longrightarrow[ \pm$ concrete $]$

$5.111[+$ concrete $] \longrightarrow[ \pm$ count $]$

$5.1 \mathrm{v}[$ +count $] \longrightarrow\left[\begin{array}{l} \pm \text { animate } \\ \pm \text { singular }\end{array}\right]$

$5 . \mathrm{v} \quad[-$ common $] \longrightarrow\left[\begin{array}{l}\text { tanimate } \\ \pm \text { singular }\end{array}\right]$

These Inherent features of the nouns in Tagalog are necessary for the selectional restrictions of nouns with verbs to avold deviant sentences. For example, [+agent1ve] verbs occur with [+anlmate] N's as agents; [-agent1ve] verbs may occur with [+anlmate] nouns as experlencers. Verbs may occur with [tanimate] N's as objects and directionals.

The following tree shows these inherent features of the nouns. 


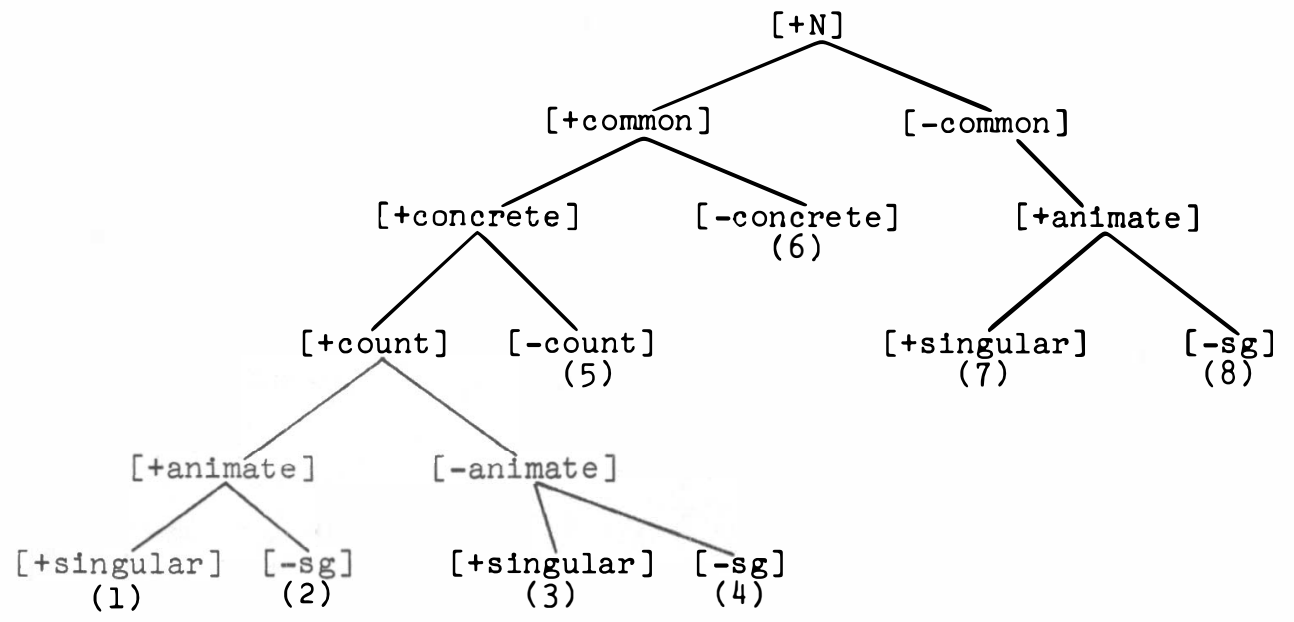

(1) tao person $[+\mathrm{N},+\mathrm{com},+\mathrm{conc},+$ count, tan, $+\mathrm{sg}]$

(2) tao persons $[+\mathrm{N},+\mathrm{com},+\mathrm{con} c$, +count, +an, $-\mathrm{sg}]$

(3) halaman plant $[+\mathrm{N},+\mathrm{com},+$ conc, +count, $-\mathrm{an},+\mathrm{sg}]$

(4) halaman plants [ $+\mathrm{N},+\mathrm{com},+$ conc, +count, -an, -sg]

(5) asin salt [ $\mathrm{N},+$ com, +conc, -count]

(6) kaligayahan happiness $[+\mathrm{N},+$ com, -conc]

(7) Pedro Peter [+N, -com, tan, +sg]

(8) Pedro Pedro and his companions [ $+\mathrm{N},-\mathrm{com},+\mathrm{an},-\mathrm{sg}]$

The subcategorization rules below assign case features to all $\mathrm{N}$ matrices. Chomsky's 'Aspects' model seems to require that this and other subcategorizational rules appear both in the base rules and the lexicon, whereas such rules in Taylor's approach appear only once, in the lexicon. Taylor called these 'case-related redundancy rules' in his description of case in Japanese (1971:258). There are five case features that may characterize the noun in Tagalog.

$$
\begin{array}{ll}
5 . v 1 & {[+N] \longrightarrow[ \pm O]} \\
5 . v 11 & {[+O] \longrightarrow[-A,-I,-D i r,-L]} \\
5 . v 111 & {[-O] \longrightarrow[ \pm A]} \\
5.1 x & {[+A] \longrightarrow[-I,-D i r,-L]} \\
5 . x & {[-A] \longrightarrow[ \pm D i r]} \\
5 . x 1 & {[+D 1 r] \longrightarrow[-I,-L]} \\
5 . x 11 & {[-D 1 r] \longrightarrow[ \pm I]} \\
5 . x 111 & {[+I] \longrightarrow[-L]} \\
5 . x 1 v & {[-I] \longrightarrow[ \pm L]}
\end{array}
$$


After these rules apply, all $\mathrm{N}$ matrices are distinct from all others in at least one feature. Each matrix or segment has a distinctive feature that differentlates or marks 1 as different from the others.

Chomsky referred to a 'distinctive-feature matrix' as representing each lexical format1ve (1965:81).

W1th the application of these rules, a given $N$ matrix has at most one of the case features marked positively and each also ther has the other four features marked negatively. The following dlagram shows these rules applied to $[\mathrm{N}]$.

Note that this specifles one matrix whlch is marked negatively for all cases. In Taylor's work, this corresponds to the predicate of an equational sentence. That sentence type however is beyond the scope of the present study, and w1ll not be discussed further.

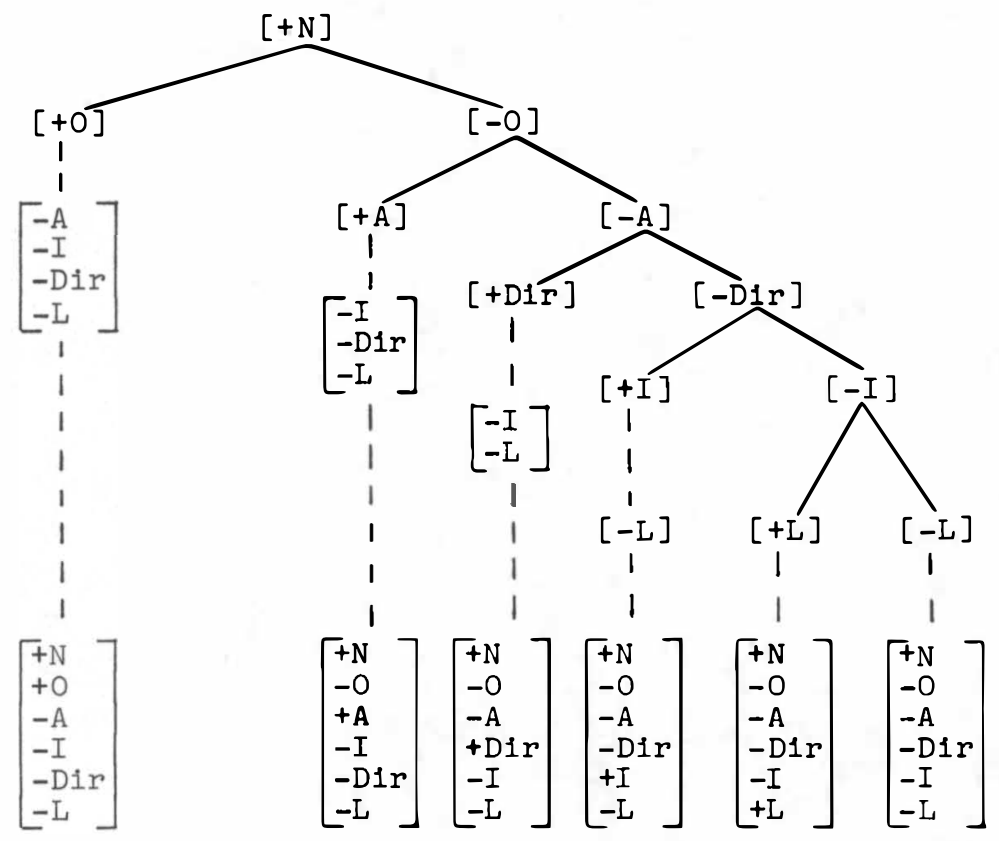

The next set of subcategorizational rules assign different caserelated semant1c features to nouns marked for each of the five cases assigned to the noun by rules $5 . v 1-5 . x 1 v$. The features are the same as those already described in chapter II, and so, no further explanation is given here. Only the rules relevant to this part of the complex symbol for nouns are listed with accompanying 1llustrations.

$$
5 . \mathrm{xv} \quad[+0] \longrightarrow[\text { tpatient }]
$$


(33) Nagluto siya ng adobo. cooked she adobo

She cooked adobo.

$5 . x v 1[$ patient $] \longrightarrow\left[\begin{array}{l} \pm \text { centrifuga } 1 \\ \pm \text { transported }\end{array}\right]$

$$
[+A]\left[\begin{array}{l}
+0 \\
+c f \\
-t r a n s p
\end{array}\right]
$$

(34) Naglaba siya ng damlt. washed she the clothes

She washed the clothes.

(35) Kumain siya ng mansanas.

$$
\text { ate he apple }
$$

He ate an apple.

$$
[+A]\left[\begin{array}{l}
+0 \\
-c f \\
+t r a n s p
\end{array}\right] \text { [+Dir] }
$$

(36) Kumuha siya ng kendi sa kahon.

got he candy from box

He got some candy from the box.

$$
[+A]\left[\begin{array}{l}
+0 \\
+c f \\
+ \text { transp }
\end{array}\right][+ \text { D1r }]
$$

(37) Naglagay siya ng pera sa bintana.

$$
\text { put he money at window }
$$

He put some money at the window.

5.xv11 [-transp] $\longrightarrow$ [ \pm change of state]

(38) $\frac{\text { Inipon niya ang pera niya. }}{\text { saved }}$ he

$$
\begin{aligned}
& {[+\mathrm{A}]} \\
& \text { hiya ang } \frac{\left[\begin{array}{l}
+0 \\
- \text { tran } \\
-\mathrm{cs}
\end{array}\right.}{\text { mone }} \\
& \text { he his money. }
\end{aligned}
$$

$5 . x v 111[$ tchange of state $] \longrightarrow[$ ttotal $]$ 
(39) $[+\mathrm{V}] \quad[+\mathrm{A}] \quad\left[\begin{array}{l}+0 \\ +\mathrm{t}\end{array}\right]$

(39) Binali niya ang sanga.

broke he branch

He broke the branch.

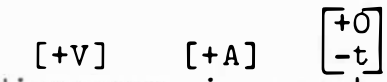

(40) Hinugasan niya ang baso.

washed she glass

She washed the glass.

$5 \cdot x 1 x\left[\begin{array}{c}\text { tanimate } \\ \text {-patient }\end{array}\right] \longrightarrow[$ texperiencer $]$

$[+\mathrm{V}]\left[\begin{array}{l}\text { to } \\ + \text { an } \\ - \text { pat } \\ \text { texp }\end{array}\right]$

(41) Nasuya siya.

got disgusted he

He got disgusted.

5.xx $\left[\begin{array}{l}\text {-animate } \\ \text {-patient }\end{array}\right] \longrightarrow[$-experiencer $]$

$5 . x \times 1 \quad[$-experiencer $] \longrightarrow[ \pm$ inchoat1ve $]$

$5 . x \times 11 \quad[+$ inchoat1ve $] \longrightarrow[ \pm$ transient $]$

$[+\mathrm{V}]\left[\begin{array}{l}+0 \\ + \text { inch } \\ \text { ttrans }\end{array}\right]$

(42) Namuti siya.

became-white she

she turned pale.

$[+\mathrm{V}]\left[\begin{array}{l}+0 \\ + \text { inch } \\ \text { trans }\end{array}\right] \quad[+\mathrm{L}]$

(43) Pumuti siya sa Amerika.

became-fair she America

she became fair (complexion) in America.

5.xx111 [-1nchoat1ve $] \longrightarrow[$ ttransported $]$ 
(44) $\frac{\text { Bumagsak }}{\text { felz }} \frac{\text { ang eroplano }}{\text { the airplane ground }}$

The airplane fell to the ground.

(45) Kumulo ang tubig.

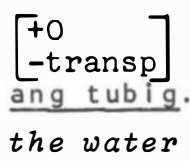

The water boiled.

$5 . x \times 1 v\left[\begin{array}{l}+\mathrm{N} \\ + \text { animate }\end{array}\right] \rightarrow[ \pm \mathrm{A}]$

$5 \cdot x x v \quad\left[\begin{array}{l}+\mathrm{N} \\ \text {-animate }\end{array}\right] \longrightarrow[-\mathrm{A}]$

5.xxv1 $[+\mathrm{A}] \longrightarrow[$ tundergoer $]$

(46) Tumalon siya.

jumped he

He jumped.

(47) $\frac{\text { Naglinis }}{\text { cleaned }} \frac{\left[\begin{array}{l}\tan \\ +\mathrm{A} \\ \text {-und }\end{array}\right]}{\text { se }} \frac{\text { ng sapatos }}{\text { shoes }}$.

He cleaned the shoes.

5.xxv11 [-undergoer $] \longrightarrow$ [ tgoal]

(48) Bumili siya ng tinapay.

$$
\left[\begin{array}{l}
+ \text { an } \\
+A \\
- \text { und } \\
+g
\end{array}\right]
$$

bought he bread

He bought some bread. 
$\left[\begin{array}{l}+ \text { an } \\ +\mathrm{A} \\ - \text { und } \\ -\mathrm{g}\end{array}\right]$

(49) Nagayos siya ng silya.

arranged he chair

He arranged the chair(s).

$5 . \operatorname{xxv111}[+\mathrm{D} 1 \mathrm{r}] \longrightarrow[ \pm \mathrm{goal}]$

(50) $\frac{\text { Pumunta }}{\text { went }} \frac{\text { siya sa tindahan. }}{\text { he }}$ to store

He went to the store.

(51) Nagitsa siya ng bola sa akin.

threw he ball to me

He threw the ball to me.

(52) Nanggaling siya sa bahay.

came he from house

He came from the house.

(53) Kumuha siya ng pagkain sa kusina.

got he food from kitchen

He got some food from the kitchen.

$5 . x \times 1 x \quad[+I] \longrightarrow[ \pm t \circ 01]$

$$
[+A] \quad\left[\begin{array}{l}
+I \\
+t o 01
\end{array}\right] \quad[+0]
$$

(54) Hiniwa niya ng kutsilyo ang karne.

sliced he knife the meat

He sliced the meat with the knife.

(55) $\frac{\text { Nabuksan }}{\text { opened }} \frac{\left[\begin{array}{l}+\mathrm{I} \\ - \text { tool }\end{array}\right]}{\text { wind }} \frac{\left.\begin{array}{c}{[+0]} \\ \text { hing }\end{array}\right]}{\text { the window }}$

The wind opened the window. 
The determiner, optional in BR\#5, is also rewritten by a complex symbol.

BR\#6. Det $\longrightarrow$ c.s .

The determiner always has the plurality feature [-sg].

$$
6.1[+ \text { Det }] \longrightarrow[-\mathrm{sg}]
$$

The determiner can only occur with a noun if the latter is marked $[-\mathrm{sg}]$. If $\mathrm{N}$ is marked [tsg], then the determiner does not occur.

6.11

$$
\left[\begin{array}{l}
+\mathrm{N} \\
+\mathrm{sg}
\end{array}\right] \longrightarrow[-[+ \text { Det }]
$$

Example:

$$
\begin{aligned}
& {[+ \text { Det }]\left[\begin{array}{l}
+\mathrm{N} \\
-\mathrm{Sg}
\end{array}\right]} \\
& \text { Kumakanta ang mga bata. } \\
& \text { singing child (pl) } \\
& \text { The children are singing. }
\end{aligned}
$$

The K (Kasus) that stands for the case marker, or more generally, the category of morphemes that are reallzations of the case system, is rewritten as a complex symbol.

$$
\text { BR\# 7. } \quad \mathrm{K} \longrightarrow \mathrm{c.s} \text {. }
$$

$$
7.1[+\mathrm{K}] \longrightarrow\left[\begin{array}{l}
\alpha c o m m o n \\
\beta C
\end{array}\right] /\left[\begin{array}{l}
+\mathrm{N} \\
\alpha c o m \\
\beta C
\end{array}\right]
$$

where $C$ is a case feature and is a member of $[+A,+0,+D 1 r,+I,+L]$.

Th1s states that the lexical category $(K)$ agrees w1th the noun in 1 ts case feature (C) as well as in 1 ts inherent property feature [ \pm common].
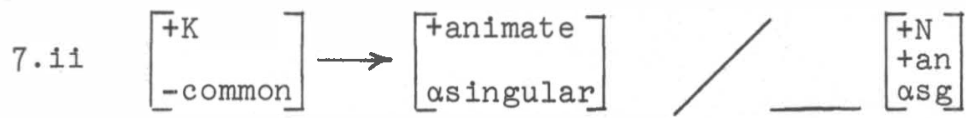

When marked [-common], the $K$ is animate (such as for names) following the feature [tan1mate] of the proper noun that follows 1t. When marked [tanimate], the $K$ is elther [tsingular] depending on the number of the animate proper noun that follows 1t. The [tcommon], [+animate] and [tsingular] features of the $K$ may be represented graphically as follows. 


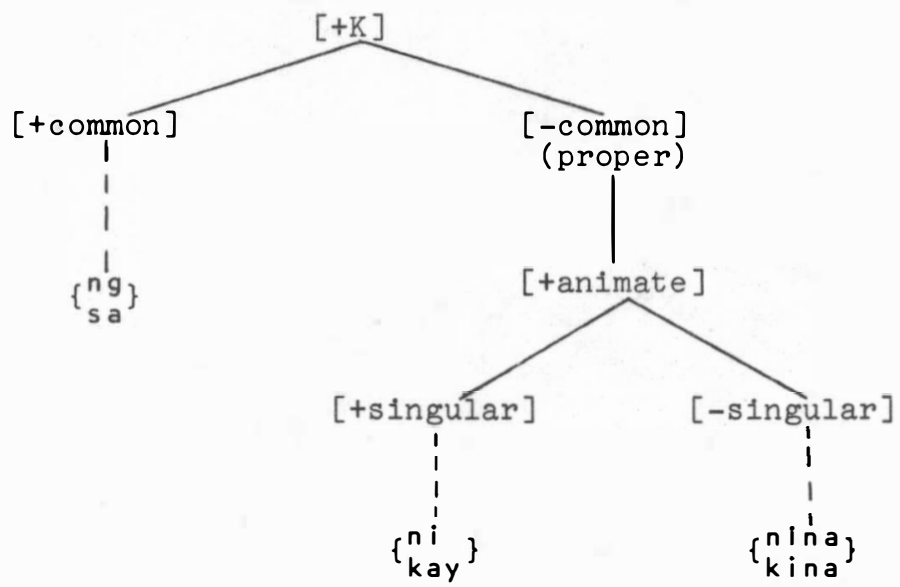

The cholce of ng or sa depends on the case of the noun that follows 1 t.

$\mathrm{Ng}$ does not occur before locatives and directlonals. Ni/nina does not occur before objects, locatives and directionals. They are entered in the lexicon as follows:

ng<smiles>[R10][14c]1[14cH][14cH][14cH][14cH][14cH]1</smiles>

ni

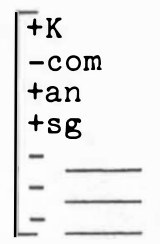

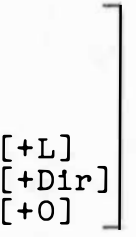

nina

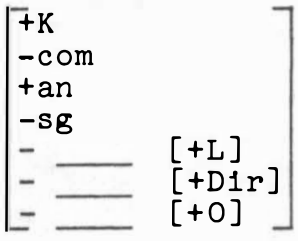

Sa does not occur before objects, agents and 1nstruments. Kay/kina does not occur before agents and instruments. They are entered in the lexicon as follows:

s a

$\left[\begin{array}{ll}+\mathrm{K} & \\ +\mathrm{com} & \\ - & {[+O]} \\ -\square & {[+\mathrm{A}]} \\ -\square & {[+\mathrm{I}]}\end{array}\right]$ kay

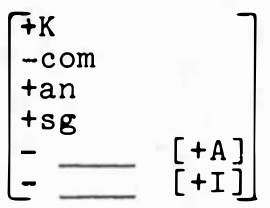

kina

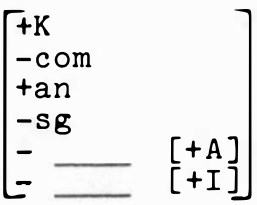





\section{CHAPTER IV}

\section{SELECTIONAL REDUNDANCY RULES}

The verb in this study is selectionally dominant. Selectional ties exist between the verb and the arguments that occur w1th 1t. These ties are expressed by semant1c features which are inherent to the verb, features which determine and restrict the selection of the nouns occurring with 1t. These restrictions of co-occurrence between the verb and the agents, objects, directionals and instrumentals that may occur w1th 1 t are generallzed by selectional redundancy rules. These rules function like Taylor's redundancy rules which 'predict the co-existence of $Y$ and $X$ on the basis of the existence of X alone' (1972:203). Chomsky defines such a rule as a 'selectional relation between two positions in a sentence' (1965:113). These rules predict one feature uniquely on the basis of the presence of another.

Selectional redundancy rules specifled in this chapter are perhaps some kind of agreement rules since features in the verb agree with those in the nouns that complete the proposition in which they occur. It may be that one could conclude even that these rules are of government because on the one hand only those nouns may occur w1th verbs that are permitted by the verbs' complex symbol. A selection, in other words, of the possible features assigned to nouns is made by the cholce of the verb in a given sentence. On the other hand, through later transformational rules, it is the selection of a particular nominal expression to be subject of the sentence that causes certain changes in the surface structure of both nominal and verbal expressions. The selectional redundancy rules follow.

SRR\#1 contains the following information. 


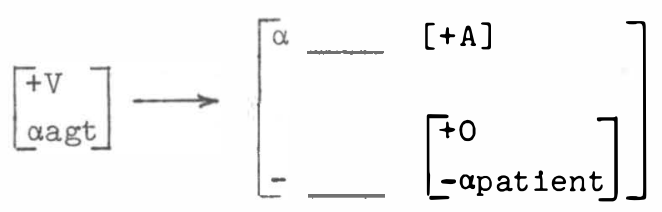

SRR\#l generalizes the relationship between verbs and the agents and objects which may occur with them. All verbs are specified for [+agentive] or [-agentive]. Verbs having a positively specified agentive feature occur obligatorily with agents. Those having a negatively specified feature agentive must have objects but not agents.

The symbol alpha $(\alpha)$ stands for $(+)$ and $(-)$ values of features. An $\alpha$ symbol on the left side of the arrow and an $\alpha$ on the right side of the arrow agree in their $+/-$ feature specifications. In the rule above, a verb having a positively specified agentive feature requires a [+ [+A] ] or an agentive type of noun while one having a negatively spec1 fled agentive feature does not permit an agentive noun to occur with 1 t.

When present therefore, the $\alpha$ indicates agreement or disagreement of values in various parts of the rule (Harms 1968:59).

SRR\#I is a combination of the following rules.

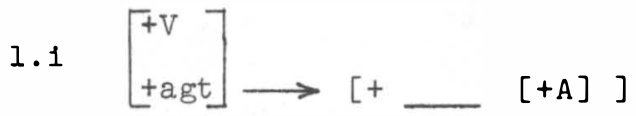

Agent1ve verbs always occur with agents.

Example :

$\left[\begin{array}{l}+\mathrm{V} \\ +\mathrm{agt}\end{array}\right] \quad[+\mathrm{A}] \quad[+\mathrm{O}]$

(1) $\frac{\text { Nagmaneho }}{\text { drove }} \frac{\text { siya }}{\text { he }} \frac{\text { ng kotse. }}{\text { the car }}$

He drove the car.

1.11

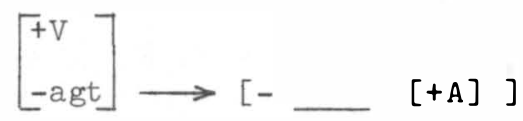

Non-agentive verbs never occur with agents. The following is therefore not possible. (See subrule l.1v below.)

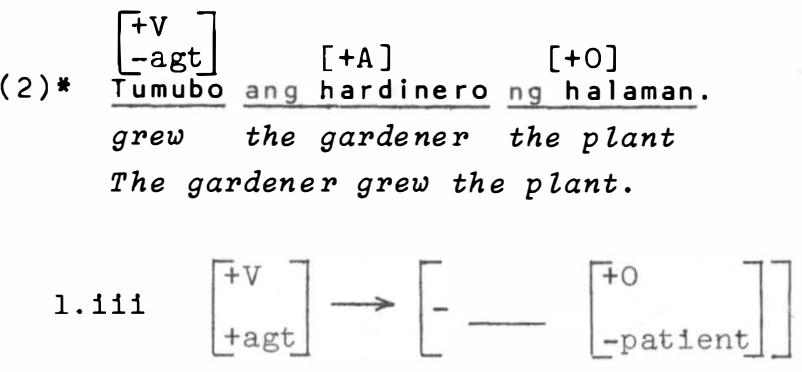


Agent1ve verbs do not occur w1th objects interpreted as non-patients. Th1s 1mplies that agent1ve verbs may occur only w1th objects interpreted as patients.

Example :

(3) Nagt $[+A]$ tanim siya ng mais.
tagtant

planted he corn

He planted corn.

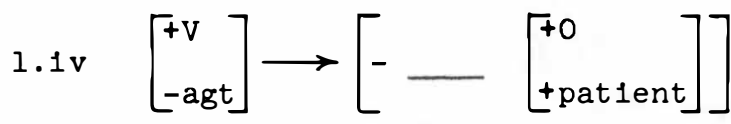

Non-agent1ve verbs never occur w1th objects marked by the feature [+patient]. Th1s 1mplies that non-agent1ve verbs can only co-occur with objects interpreted as non-patients.

Example:

(4)

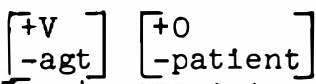

Tumaba ang tuta.

grew fat puppy

The puppy grew fat.

SRR\#2 contains the following information.

$$
\left[\begin{array}{ll}
+\mathrm{V} \\
\text { aexternal }
\end{array}\right] \longrightarrow\left[\begin{array}{ll}
- & \left.\begin{array}{l}
+\mathrm{A} \\
\text { aundergoer }
\end{array}\right] \\
\alpha & \left.\begin{array}{l}
+0 \\
\text { tpatient }
\end{array}\right]
\end{array}\right]
$$

SRR\#2 generallzes the relationsh1p between verbs marked [external] and the types of agents and objects that co-occur with them. Verbs having a positively specified feature [+external] require the presence of [+patient] objects. Verbs marked [-external] do not allow [+patient] objects.

SRR\#2 is a combination of the following rules.

$$
2.1
$$

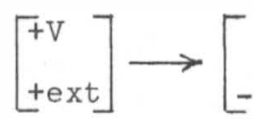

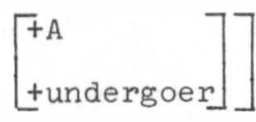

Verbs marked [+external] never occur w1th agents marked w1th the feature [+undergoer]. It follows from SRR\#l that these verbs always occur w1th agents marked [-undergoer]. 
2.11

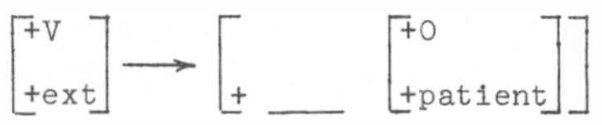

Verbs having a positively specifled feature [external] must occur with objects marked by the feature [+patient].

Example for \#2.1 and 2.11 .

Lext $\left[\begin{array}{l}+\mathrm{V} \\ \text { tex } \\ \text {-und }\end{array}\right]\left[\begin{array}{l}+0 \\ \text { tpatient }\end{array}\right]$

(5) Naghugas siya ng baso.

washed she glass

She washed the glass.

2.111

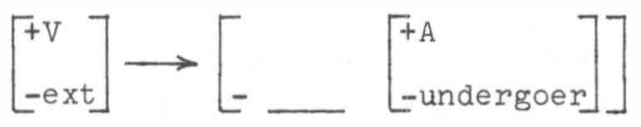

Verbs marked [-external] never co-occur w1th agents marked [-undergoer]. By Implication, they occur with agents marked [+undergoer].

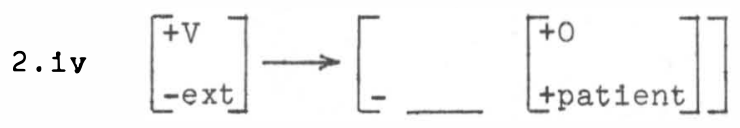

Verbs negat1vely specifled for the feature [external] do not occur with objects marked by the feature [+patient].

Example for \#2.111 and 2.1v.

(6) $\frac{\left[\begin{array}{l}+\mathrm{V} \\ -e x t\end{array}\right]}{\text { Tumakbo }} \frac{\left[\begin{array}{l}\text { t } \\ \text { tund }\end{array}\right]}{\text { siya }}$

He ran.

SRR\#3 contains the following information.

$$
\left[\begin{array}{l}
+\mathrm{V} \\
\alpha c f
\end{array}\right] \rightarrow\left[\begin{array}{ll}
-\left[\begin{array}{l}
+\mathrm{A} \\
\alpha g \circ a l
\end{array}\right] \\
-\left[\begin{array}{l}
+0 \\
-\alpha c \mathrm{f}
\end{array}\right] \\
-\left[\begin{array}{l}
+\mathrm{DIr} \\
-\alpha g \circ a 1
\end{array}\right]
\end{array}\right]
$$

SRR\#3 generalizes the relationsh1p between verbs marked for centrifugal and the types of agents, objects and directionals that may occur w1th them.

SRR\#3 is a combination of the following rules. 
$3.1\left[\begin{array}{l}+\mathrm{V} \\ +\mathrm{Cr}\end{array}\right] \rightarrow\left[\begin{array}{ll}- & {\left[\begin{array}{ll}\mathrm{A} \\ +\mathrm{goal}\end{array}\right]}\end{array}\right]$

Verbs marked with the semant1c feature [+centrifugal] never occur with agents marked with the semant1c feature [+goal]. By 1mplication, this type of verb can take agents marked [-goal].

3.11<smiles>C=CC1[CH][CH][CH]1</smiles><smiles>C1C2CC3CC1OC3C2</smiles>

Verbs marked [+centrifugal] do not co-occur with objects marked [-centrifugal]. Th1s 1mplies that they can only occur with objects marked [+centrifugal].

3.111<smiles>C=CC1[C]C=[C+]C1</smiles>
$\left.\left[\begin{array}{c}\text { Dir } \\ \text {-goal }\end{array}\right]\right]$

Verbs positively specified for the feature [centrifugal] cannot cooccur with directionals marked [-goal]. By 1mplication, they can only occur with directionals marked [+goal].

Example for \#3.1, 3.11 and 3.111 above.

$$
\left[\begin{array}{l}
+\mathrm{V} \\
+\mathrm{Cf}
\end{array}\right]\left[\begin{array}{l}
+\mathrm{A} \\
-\mathrm{g} O \mathrm{Oal}
\end{array}\right]\left[\begin{array}{l}
+0 \\
+\mathrm{cf}
\end{array}\right]\left[\begin{array}{l}
+\mathrm{D} 1 \mathrm{r} \\
+\mathrm{goal}
\end{array}\right]
$$

(7) Naghagis siya ngbato sa ahas. hurled he stone at snake He hurled a stone at the snake.

$3.1 \mathrm{v}$

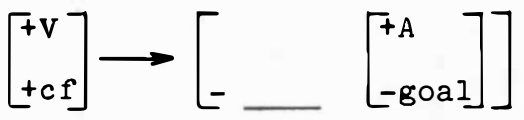

Verbs marked w1th the semant1c feature [-centrifugal] never occur with agents marked[-goal]. By Implication, they occur with agents marked [+goal].

$3 \cdot v$<smiles>C#CCC1CC2C=CC1C2</smiles><smiles>C1C2[C@@H]3C[C@H]1[C@@H]2O3</smiles>

Verbs marked [-centrifugal] do not co-occur w1th objects marked [+centrifugal]. Th1s 1mplies that they can only co-occur with objects marked [-centrifugal].

3.v1

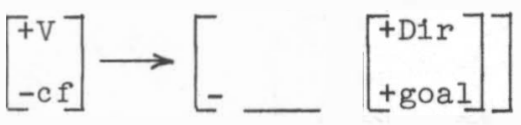

Verbs negatively specifled for the feature centrifugal cannot co-occur with directionals marked [+goal]. By 1mplication, it can occur with directionals marked [-goal]. 
Example to 1llustrate \#3.1v, 3.v, and 3.v1 above.

$\left[\begin{array}{l}+V \\ -c f\end{array}\right]\left[\begin{array}{l}\text { ta } \\ \text { tgoal }\end{array}\right]\left[\begin{array}{l}+0 \\ -c f\end{array}\right]\left[\begin{array}{l}\text { Dir } \\ \text {-goal }\end{array}\right]$

(8) Kumuha siya ng pera sa nanay niya.

got he money from mother his

He got money from his mother.

SRR\#4 generalizes the relationsh1p between verbs marked [tterminal] and the directionals that may occur with them.

SRR\# 4. $\left[\begin{array}{l}+\mathrm{V} \\ \alpha t e r\end{array}\right] \rightarrow\left[\begin{array}{lll}-\alpha & \\ -\alpha 1 r]\end{array}\right]$

SRR\#4 is a combination of the following rules.

$4.1\left[\begin{array}{l}+\mathrm{V} \\ t \mathrm{ter}\end{array}\right] \rightarrow\left[\begin{array}{ll}- & {[+\mathrm{D} 1 \mathrm{r}]}\end{array}\right]$

Verbs marked with the semant1c feature of [+terminal] do not allow directionals.

Example:

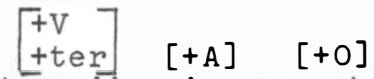

(9) Nagwalis siya ng sahig.

swept she the floor

She swept the floor.

4.ii $\left[\begin{array}{l}+\mathrm{V} \\ \text {-ter }\end{array}\right] \rightarrow\left[\begin{array}{ll}+ & \\ + & {[\mathrm{Dir}]}\end{array}\right]$

All verbs having a negatively specifled feature [-terminal] require directionals.

Examples :

(10)

$\left[\begin{array}{l}+\mathrm{V} \\ -\mathrm{ter}\end{array}\right][+\mathrm{A}] \quad[+\mathrm{O}] \quad[+\mathrm{D} 1 \mathrm{r}]$

$\frac{\text { Itapon }}{\text { throw }}$ you garbage $\frac{\text { ang basura sa ilog. }}{\text { in river }}$

(You) throw the garbage in the river.

$\left[\begin{array}{l}\text { tV } \\ \text {-ter }\end{array}\right][+A] \quad[+0] \quad[+D 1 r]$

(II) Kumuha ka ng pagkain sa mesa.

get you food from table

(You) get (some) food from the table. 


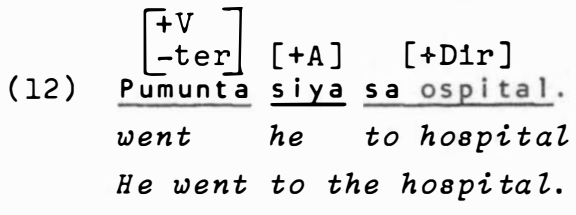

SRR\#5.

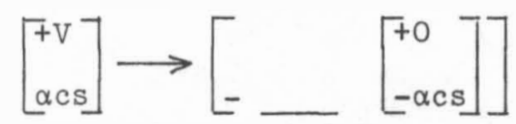

SRR\#5 1ndicates that verbs marked [+change of state] can only occur with objects having the same semant1c feature; conversely, verbs marked negat1vely for the same feature only allow objects also negatively specifled for the sald feature.

SRR\#5 is a combination of the following rules.

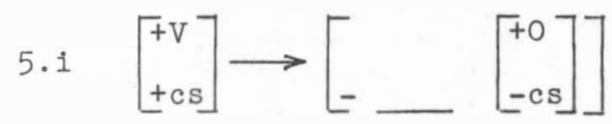

Example:

(13) Binali niya ang sanga.

broke he branch

He broke the branch.

5.11
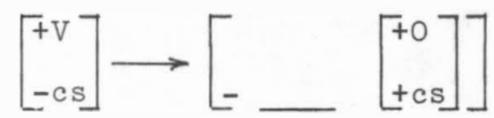

Example:

$\left[\begin{array}{l}+\mathrm{V} \\ -\mathrm{Cs}\end{array}\right][+\mathrm{A}] \quad\left[\begin{array}{l}+0 \\ -\mathrm{CS}\end{array}\right]$

(14) Inipun niya ang silya.

collected he chair(s)

$H e$ collected the chairs.

SRR\# 6 .

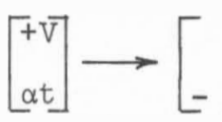

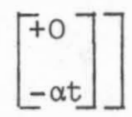

SRR\#6 Indicates that verb.s marked [+total] (change) occur with objects having the same semant1c feature. On the other hand, verbs marked negat1vely for the same feature do not allow objects positively specified for the sald feature.

SRR\#6 is a combination of the following rules.

6.1

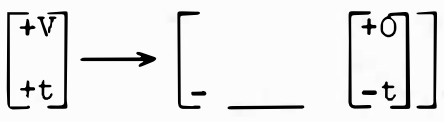


Example:

(15) $\frac{\text { pinitpit }}{\left[\begin{array}{l}+\mathrm{V} \\ +\mathrm{t}\end{array}\right]} \frac{[+\mathrm{A}]}{\text { niyashed }} \frac{\left[\begin{array}{l}+\mathrm{O} \\ +\mathrm{t}\end{array}\right]}{\text { she }} \frac{\text { ang bauang }}{\text { garlic }}$.

She crushed the garlic.

6.11

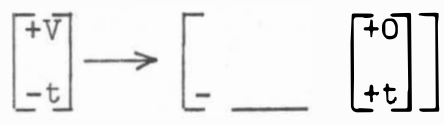

Example:

( 16)

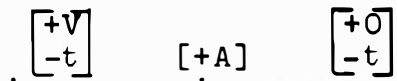

Pinunasan niya ang mesa.

wiped she table

She wiped the table.

SRR\# 7 .
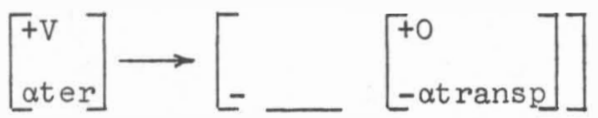

SRR\#7 1nd1cates that verbs marked [+terminal] cannot occur w1th objects having the semant1c feature [+transported]; verbs marked negat1vely for 'terminal' cannot occur with objects having the feature [-transported].

SRR\#7 is a combination of the following rules.

7.1
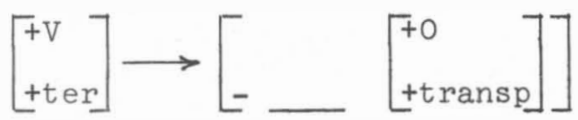

Terminal verbs never occur w1th objects marked [+transported]. By Implication, only objects marked [-transported] occur with terminal verbs.

Example:

$$
\left[\begin{array}{l}
+\mathrm{V} \\
\text { tter }
\end{array}\right] \quad[+\mathrm{A}]\left[\begin{array}{l}
+\mathrm{O} \\
- \text { transp }
\end{array}\right]
$$

(17) Nagbunot siya ng sahig.

polished he floor

(husked)

He polished the floor (with a husk).

7.11

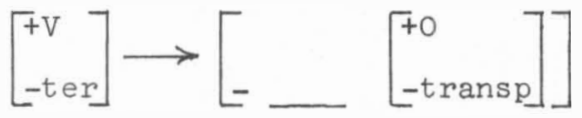

Non-terminal verbs never occur w1th objects marked [-transported]. This 1mplies that this type of verb can occur only with objects marked [ttransported]. 
Example:

$\left[\begin{array}{l}+\mathrm{V} \\ -\operatorname{ter}\end{array}\right] \quad[+\mathrm{A}]\left[\begin{array}{l}+\mathrm{O} \\ + \text { transp }\end{array}\right] \quad[+\mathrm{D} 1 \mathrm{r}]$

Nagsabit siya ng kulambo sa pako.

hung he mosquito net nail

He hung the mosquito net on the nail.

SRR\#8 contains the following information.

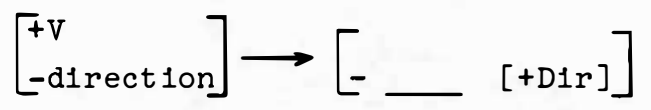

SRR\#8 states that verbs marked [-direct1on] do not allow directionals. Example :

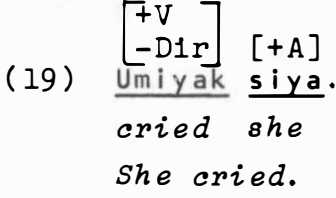

SRR\#9. $\left[\begin{array}{l}+\mathrm{V} \\ \text { aexperient1al }\end{array}\right] \rightarrow\left[-\left[\begin{array}{l}+0 \\ \text {-aexperiencer }\end{array}\right]\right]$

SRR\#9 generalizes the relationsh1p between verbs and objects marked [+experiential] or [-experiential].

SRR\#9 is a combination of the following rules.

$\left.9.1\left[\begin{array}{l}+\mathrm{V} \\ \text { texperient1al }\end{array}\right] \rightarrow\left[\begin{array}{l}+\mathrm{O} \\ \text {-experiencer }\end{array}\right]\right]$

Verbs having a positively specifled feature [+experient1al] do not co-occur with objects having the semantic feature [-experiencer]. Th1s rule 1mplies that experlentlal verbs can co-occur with objects marked with the feature [+experiencer].

Example :

$$
\left[\begin{array}{l}
+\mathrm{V} \\
+\exp
\end{array}\right]\left[\begin{array}{l}
+\mathrm{O} \\
+\mathrm{exp}
\end{array}\right]
$$

Nagutom siya.

got hungry he

He got hungry.

9.11

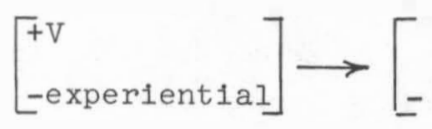

$\left.\left[\begin{array}{l}+0 \\ \text { texperiencer }\end{array}\right]\right]$

Verbs having a negat1vely specified feature [-experient1al] do not co-occur with objects having the semant1c feature [+experiencer]. Th1s rule 1mplies that non-experlentlal verbs can occur with objects having the feature [-experiencer]. 
Example:

$$
\left[\begin{array}{l}
+\mathrm{V} \\
-\mathrm{exp}
\end{array}\right]\left[\begin{array}{l}
+\mathrm{O} \\
-\mathrm{exp}
\end{array}\right]
$$

(21) Lumago ang damo.

grew (Luxuriantly) the grass

The grass grew luxuriantly.

SRR\#10 contalns the following information.

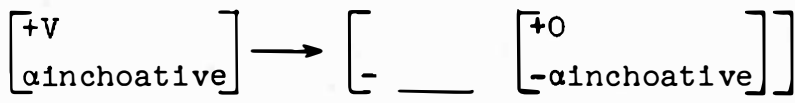

SRR\#10 generalizes the relationsh1p between verbs and objects marked [+1nchoat1ve] or [-1nchoat1ve]. Th1s rule 1mplies that 1nchoat1ve verbs can co-occur w1th objects marked with the feature [+1nchoat1ve].

Example :

(22)

$$
\begin{aligned}
& \left.\left[\begin{array}{l}
+\mathrm{V} \\
\text { +inch }
\end{array}\right] \begin{array}{l}
\text { +o } \\
\text { +1nch }
\end{array}\right] \\
& \frac{\text { Lumak }}{\text { ang bata. }} . \\
& \text { grew the chizd } \\
& \text { The chizd grew. }
\end{aligned}
$$

10.11
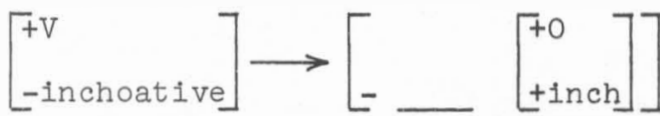

Verbs having a negatively specifled feature [-1nchoative] do not cooccur with objects having the semant1c feature [+1nchoat1ve]. Th1s rule Implies that non-1nchoat1ve verbs can co-occur with objects having the feature [-1nchoat1ve].

Examples:

$$
\left[\begin{array}{l}
+\mathrm{V} \\
-1 \mathrm{nch}
\end{array}\right]\left[\begin{array}{l}
+\mathrm{O} \\
-1 \mathrm{nch}
\end{array}\right]
$$

Kumulo ang tubig.

boiled the water

The water boiled.

SRR\#ll contalns the following information.

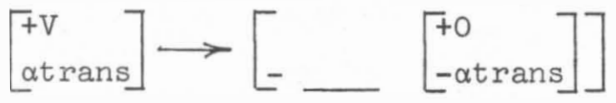

SRR\#ll shows that verbs marked [+translent] never occur w1th objects marked [-transient] and vice versa. Th1s 1mplies that transient verbs require only objects marked [+transient] and non-transient verbs can occur only with objects marked [-transient].

SRR\#ll is a combination of the following rules. 
11.1

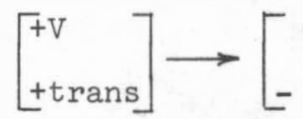

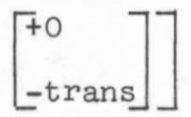

By 1mplication, translent verbs occur only with translent objects. Example :

(24)

$$
\begin{aligned}
& {\left[\begin{array}{l}
+\mathrm{V} \\
+ \text { trans }
\end{array}\right]\left[\begin{array}{l}
+0 \\
\text { trans }
\end{array}\right]} \\
& \text { Namuti } \text { siya. } \\
& \text { became-white she } \\
& \text { She lost color/she became pale. }
\end{aligned}
$$

11.11
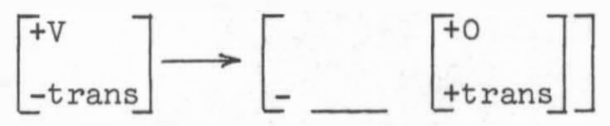

The rule above 1mplies that non-translent verbs occur only with nontransient objects.

Example:

$$
\begin{aligned}
& {\left[\begin{array}{l}
+\mathrm{V} \\
- \text { trans }
\end{array}\right]\left[\begin{array}{l}
+0 \\
- \text { trans }
\end{array}\right]} \\
& \text { Pumut } \mathrm{siya} \\
& \text { became fair she } \\
& \text { She became fair. }
\end{aligned}
$$

SRR\#12 contains the following information.

$$
\left.\left[\begin{array}{l}
+\mathrm{V} \\
\alpha \text { agentive }
\end{array}\right] \rightarrow\left[\begin{array}{l}
+\mathrm{I} \\
-\alpha \mathrm{t} \circ \mathrm{ol}
\end{array}\right]\right]
$$

SRR\#12 generalizes the relationsh1p between verbs marked [-agent1ve] or [+agent1ve] and the instrumentals that may occur with them, except for verbs marked [-direction] which never take instrumentals specified [t tool].

The following rule expresses this general fact necessary to SRR\#12.

$12 \mathrm{a}$<smiles>C1CCC2CCCC2C1</smiles>

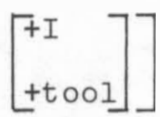

Example:

$$
\begin{aligned}
& {\left[\begin{array}{l}
+\mathrm{V} \\
-\mathrm{d} 1 \mathrm{r}
\end{array}\right][+\mathrm{A}]} \\
& \text { Ngumit siya. } \\
& \text { smiled she } \\
& \text { She smiled. }
\end{aligned}
$$

SRR\#12 is a combination of the following rules.

12.1

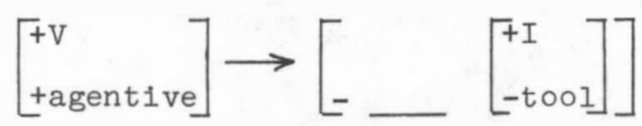


Verbs having a positively specifled feature [+agent1ve] may co-occur with instrumentals interpreted as [+tool].

Example:

$$
\left[\begin{array}{l}
+\mathrm{V} \\
+a g t
\end{array}\right][+\mathrm{A}] \quad\left[\begin{array}{l}
+\mathrm{I} \\
+\mathrm{t} \text { ool }
\end{array}\right]
$$

(27) $\frac{\text { Binasag niya }}{\text { broke }} \frac{(\text { ng bato) }}{\text { stone }} \frac{\text { ang salamin. }}{\text { glass }}$

He broke the glass (with a stone).

12.11

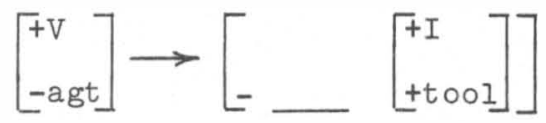

Verbs having a negatively spec1fled feature [-agent1ve] may co-occur with instrumentals that are marked by the semant1c feature [-tool].

Example :

(28)

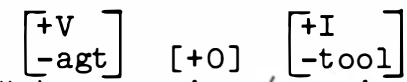

Nabasa siya (ng uian).

drenched he rain

He was drenched (by the rain).

Except for the locatives, ${ }^{1}$ these selectlonal redundancy rules account for the co-occurrence of the Inherent types of cases with the verbs.

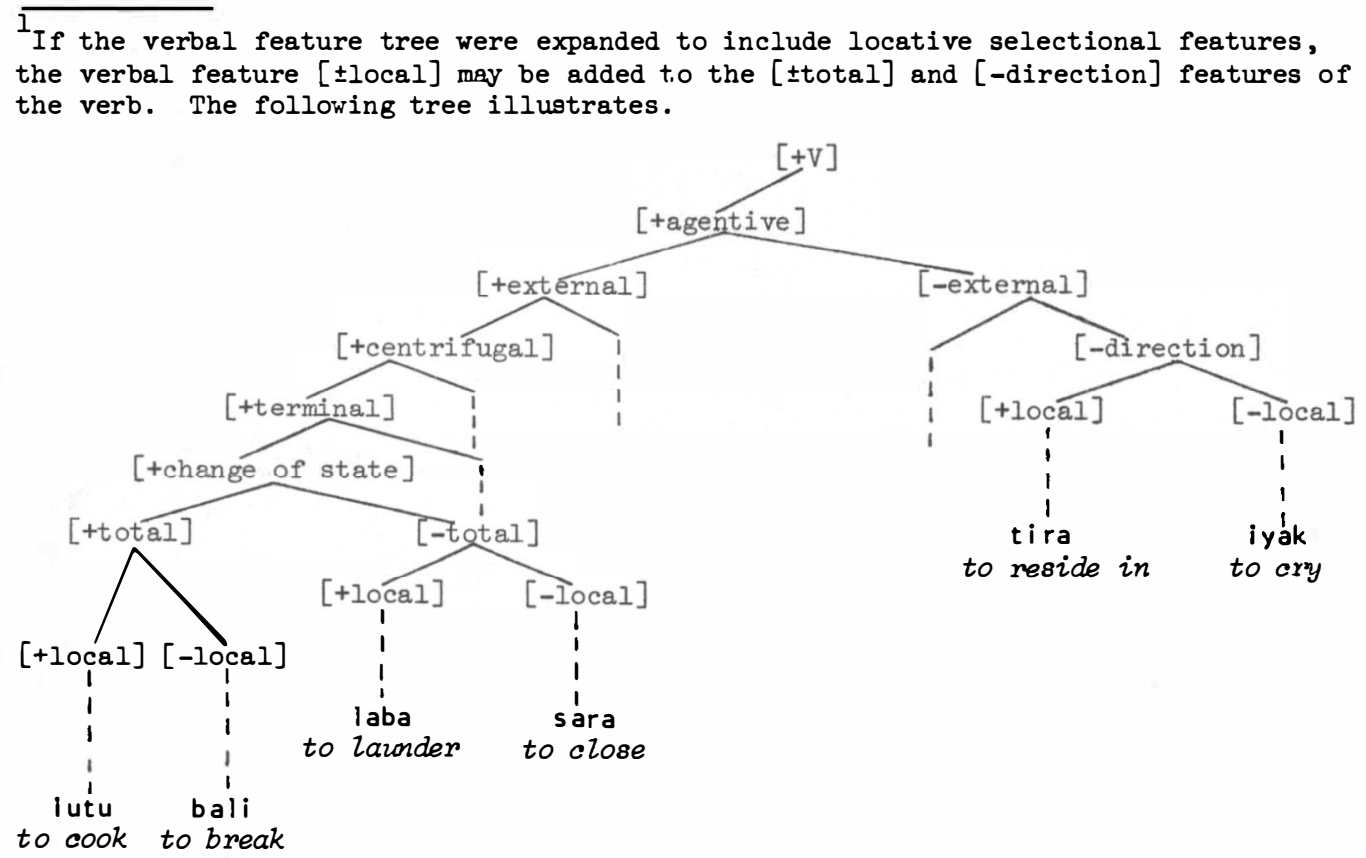

(Continued opposite) 
The following rules may be added to the base rules.

$$
\left.\begin{array}{l}
{[- \text { direction }]} \\
{[ \pm \text { total }]}
\end{array}\right\} \rightarrow[ \pm \text { local }]
$$

Any verb having the semantic feature [+local] dictates the presence of a locative actant to complete its meaning.

$$
\left[\begin{array}{ll}
+\mathrm{V} & \\
+ \text { local }
\end{array}\right] \rightarrow\left[\begin{array}{ll} 
& \\
+ & {[+\mathrm{L}]}
\end{array}\right]
$$





\section{CHAPTER V}

\section{THE SUBCATEGORIZATION OF THE TAGALOG VERBS}

As has been indicated earlier, the feature characterlstics of Tagalog verbs 1mpose a classification on those verbs. The major subcategorization of the verbs presented in this chapter is based upon the semantic features as well as the contextual case features that make up verbal matrices. The semant1c features that make up the complex symbol of the verb are given in Chapter III. Given certain baslc properties of verbs, all thelr other grammatical properties can be supplied by the application of the selectional restriction rules discussed in the previous chapter. Chapter IV also explains how the semant1c properties of the verb dictate what kind of cases may occur with 1t. The characterlstics of these cases which are properties of the nouns are discussed in Chapter II. Th1s chapter describes the verbal matrices as consisting of two types of features, the semantic features and the contextual case features. The verbal matrices of fifteen classes of verbs to whlch the majority of Tagalog verbs belong will thus be defined in this chapter.

In F1llmore's case grammar of 1968, verbs were defined in terms of 'case frames', that 1s, according to the case environments which the sentence provides (1968a:26). In h1s 1969 article on lexical information (1969:76), he used the term 'case structure' to refer to the comb1nation of cases that might be assoclated with a given predicate. The arrays of cases defining the sentence types of a language, according to $\mathrm{hlm}$, have the effect of 1mposing a classification on the verbs in the language (1968a:21). Contrary to F1llmore's view, in this study the arrays of cases in the nouns do not 1mpose a subclassiflcation on the verbs of Tagalog. The array of cases is not sufficlent in 1tself to do this. Besides, the verb is considered as central in this study, not the noun. Therefore, the semant1c and selectional features of the verbs predict the types of cases that may occur with them. Ult1mately these semant1c 
and selectional features subclassify the verbs.

Whereas Fillmore's case frames consist of category symbols, the selectional rules here represent case frames in terms of selectional features. Thus $[+$ A 0 Dir] in Fillmore's system corresponds to

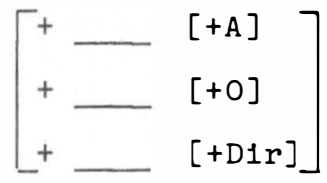

In the system presented here, though the latter notation does not require the cases to be introduced in some arbitrary order.

Each case, however, is well defined by a cluster of features. Th1s 1s similar to Fillmore's 'coreferential roles'. But the features go beyond dual roles to capture more distinctions in their use.

For example, F1llmore (see Cook 1971:15) talks of the agent1ve case as being sometimes coreferential with the source, and sometimes with the goal case. In th1s study, these features are dominated by st1ll another feature called [-undergoer] whlch has a positively specifled [+undergoer] counterpart. The [+undergoer] type of agent is nelther the goal nor the source of the action but both. It undergoes the action 1t originates. The action of swimming, walking, running or moving, for instance, dictates the single positive subfeature [+undergoer] for the agent. The verb kuha to get requires two subfeatures for the agent [-undergoer, +goal], since 1t is the non-undergoer reclplent or goal of the action. Tapon to throw, on the other hand, also requires two agentive subfeatures but 1t contrasts with the verb kuha to get, in that the agent is not the goal of the action. It has the subfeatures [-undergoer, -goal]. The following verbs then require three types of agents.

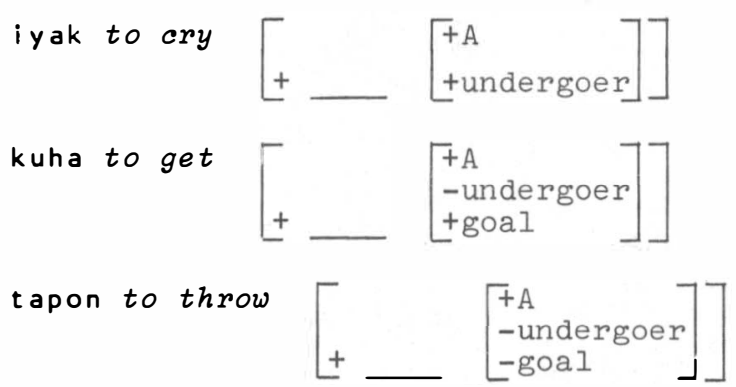

In the following paragraphs inherent and contextual features necessary to distinguish each class of verbs are listed for each type of verb. The branching feature dlagrams in Chapter III (see also Append1x A-1), give a graphic view of how the features are arranged in hierarchical order. The verbs listed below these diagrams are thus representative of the verbs for the different classes. 
The semant1c features are summarlzed, and these features are those subcategorlzing the verbs. These contextual features of each type of verb have been determined in the selectional redundancy rules given in Chapter IV.

There are fifteen classes of verbs resulting from the contrasting matrices exhibited in the following paragraphs.

1. The flrst type of verb has the following semant1c and contextual features.

$$
\left[\begin{array}{l}
+\mathrm{V} \\
+ \text { agentive } \\
\text { +external } \\
\text { +centrifugal } \\
\text { +terminal } \\
\text { +change of state } \\
+ \text { total } \\
+-\left[\begin{array}{l}
+\mathrm{A} \\
\text {-undergoer } \\
\text {-goal }
\end{array}\right] \\
+\left[\begin{array}{l}
\text { to } \\
\text { +pat1ent } \\
\text { +centrifugal } \\
\text {-transported } \\
\text { +change of state } \\
\text { total }
\end{array}\right]
\end{array}\right]
$$

The [+agent1ve] feature indicates that this type of verb requires an agent wh1ch 1s the source of the action performed externally (outside of that agent). The [+centrifugal] feature indicates that the action 1s directed away from the agent toward an object (required also by the [+external] feature) where the action terminates. The [+terminal] feature indicates that the action is not carried beyond the object. The verb's action upon the object causes a change in physical condition. In this class of verb, the effect of the change upon the object 1 s total.

Th1s type of verb then requires two arguments, one having an agent1ve case feature which 1s only the source of the action and an objective case feature which is not moved toward the agent, [+centrifugal], nor 1s 1 transported anywhere. It is a stat1c object, [+patient], that acts as the reciplent of the action which causes it to change in physical condition totally. Thus the verb baluktot to bend from this set has the meaning (someone) bends (something).

Examples :

(1) Binaluktot ng magnanakaw ang rehas. bent burglar iron bars

The burglar bent the iron bars. 
(2) Winasak ng loko-loko ang kotse. destroyed madman car

The madman destroyed the car.

(3) $\frac{\mathrm{N}\left[\begin{array}{l}+\mathrm{V} \\ +\mathrm{t}\end{array}\right]}{\text { cooked mother }} \frac{\left[\begin{array}{l}+\mathrm{A} \\ -\mathrm{g}\end{array}\right]}{\text { vegetables }}$ ang
Mother cooked the vegetables.

Other verbs that belong to this class are: pitpit (someone) crushes (something), tastas (someone) rips (something), patay (someone) slaughters (something), yupi (someone) dents (something), buhay (someone) keeps alive (something), linis (someone) cleans (something), ihaw (someone) broils (something), tuwid (someone) straightens out (something), laga (someone) boils (something), buro (someone) pickles (something), init (someone) heats (something), unat (someone) removes the crease from (something), gupit (someone) cuts (something), ahit (someone) shaves (someone) and basa (someone) wets (something).

2. The second type of verb has the following semantic and contextual features.

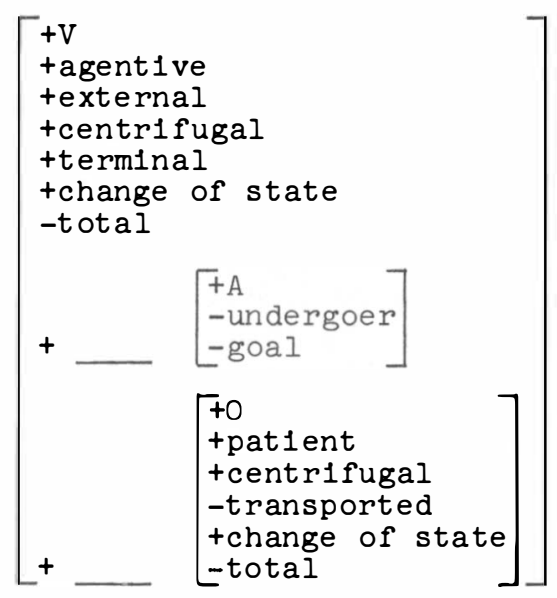

This type of verb differs from the first one in that the effect of the verbal action of the verb upon the object is not to change 1ts condition totally but partially. Otherwise, all the other features function fust like those characterlizing the first type of verb.

This type of verb, then, requires two arguments, one having the agentive case feature and the other the objective case feature. The verb hugas to wash belongs to this type of verb class and has the meaning (someone) washes (something). 
Examples:

(4)

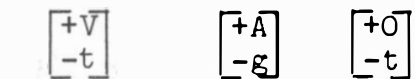

Binantawan niya ang damit.

rinsed she clothes

She rinsed the clothes.

(5) Pinunasan $\frac{\text { niya ang mesa. }}{\text { wiped }}$.

She wiped the table.

Other verbs that belong to this class are: laba (someone) washes (something), linis (someone) cleans (something), hilamus (someone) washes the face, sara (someone) closes (something), bukas (someone) opens (something), wisik (someone) sprinkles (something), tagpi (someone) patches (something), dilig (someone) waters (something), talup (someone) peels (something), tabas (someone) cuts (a dress material following a pattern), and tali (someone) ties (something).

3. The third type of verb has the following semant1c and contextual features.

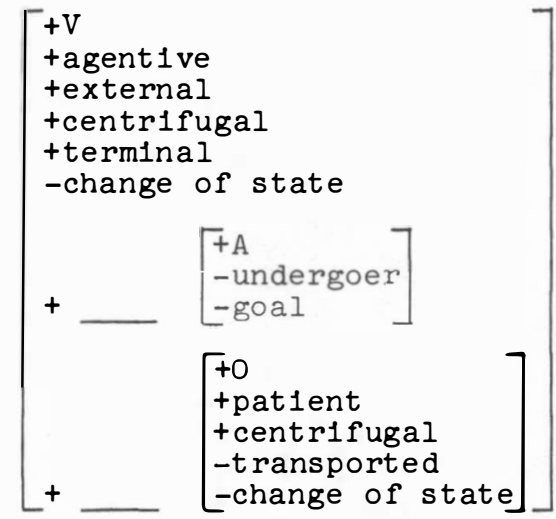

The only contrasting feature of this class of verb from the first and second types is the non-change-of-state effect of the verbal action upon the object. The rest of the features are the same as those characterlzing the first and second types of verbs.

Th1s type of verb requires two arguments too. One has the agent1ve case feature and the other, the objective case feature. However, the object does not undergo any change of state as the two earlier types do. Thus the verb ipon to gather, collect, has the complete meaning of (someone) gathers (something). 
Examples:

$\left[\begin{array}{l}+ \\ -c s\end{array}\right]\left[\begin{array}{l}+A \\ -g\end{array}\right]\left[\begin{array}{l}+0 \\ -c s\end{array}\right]$

Inipun niya ang basura.

gathered he garbage

He gathered (collected) the garbage.

(7) $\frac{\left[\begin{array}{l}+\mathrm{V} \\ -\mathrm{cs}\end{array}\right]}{\text { Inayos }} \frac{\left[\begin{array}{l}+\mathrm{A} \\ -\mathrm{B}\end{array}\right]}{\text { arranged }} \frac{\left[\begin{array}{l}+0 \\ -\mathrm{cs}\end{array}\right]}{\text { he }} \frac{\begin{array}{l}\text { ang mga silya. } \\ \text { chairs }\end{array}}{\text { He arranged the chairs. }}$

Verbs of this type are: halungkat (someone) ransacks (something), akay (someone) guides, leads (someone), alog (someone) jars (something), uga (someone) swings (someone), bitbit (someone) carries (something), buklat (someone) opens (something), hintay (someone) waits for (something), tipid (someone) economizes (something), tiklop (someone) folds (something) and aruga (someone) takes care of (someone).

4. The fourth type of verb has the following semant1c and contextual features.

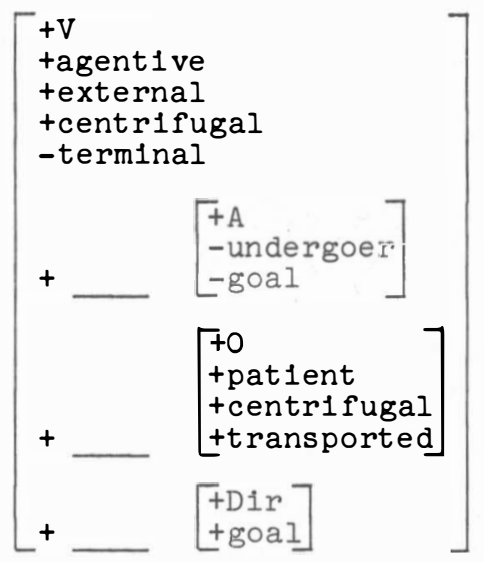

Unlike the flrst three types of verbs, this class is marked by the [-terminal] feature which indicates that a third argument, [+Direct1onal], is needed to complete the meaning of the verb. The [-terminal] feature also indicates that the object is transported or transferred to a third argument, the directional, where the centrifugal action terminates.

Th1s type of verb then requires three arguments, one having the agent1ve case feature further specifled as non-goal and source of the action, another having the objective case feature which is carried away from the agent toward a directional-goal, and lastly, an argument having 
the directional case feature further defined as [+goal] functioning as the recelver of the object. Thus the verb tapon to throw from this set has the meaning (someone) throws (something) (somewhere).

Examples:

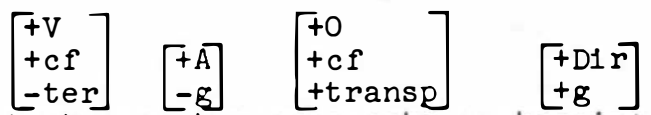

(8) laabot ng bata ang pako sa karpintero.

will hand-over child nail carpenter

The child will hand over some nails to the carpenter.

$$
[+\mathrm{V}] \quad[+\mathrm{A}] \quad[+\mathrm{O}] \quad[+\mathrm{D} 1 \mathrm{r}]
$$

(9) Ilalagay niya ang pera sa alkansiya.

will put he money piggy bank

He will put some money in the piggy bank.

\begin{tabular}{|c|c|c|c|}
\hline & {$[+\mathrm{V}]$} & {$[+0]$} & {$[+D 1 r]$} \\
\hline (10) & Itatapon ni Pedro & ang basura & sa labas. \\
\hline & will throw Pedro & garbage & outside \\
\hline
\end{tabular}

Other verbs that belong to this class are: abuloy (someone) contributes (something) (somewhere), bagsak (someone) drops (something) (somewhere), bigay (someone) gives (something) (to someone), bayad (someone) pays (someone) (something), lakip (someone) encloses (something) (somewhere), salansan (someone) files (something) (somewhere), sampay (someone) hangs (clothes) (somewhere), sabit (someone) hangs (something) (somewhere), sanla (someone) pawns (something) (somewhere), hulog (someone) drops (something) (somewhere), sabog (someone) scatters (something) (somewhere), kabit (someone) connects (something) (somewhere), lipat (someone) transfers (something) (somewhere), akyat (someone) carries up (something) (somewhere), lako (someone) peddles (something) (somewhere), budbud (someone) distributes (some particle-like matter) (somewhere), halang (someone) blocks (something) (somewhere), tali (someone) ties (something) (somewhere), taya (someone) bets (something) (somewhere), tago (someone) hides (something) (somewhere), sandig (someone) leans (something) (somewhere), libing (someone) buries (someone) (somewhere) and babad (someone) soaks (something) (somewhere).

5. The fifth type has the following semant1c and contextual features. 


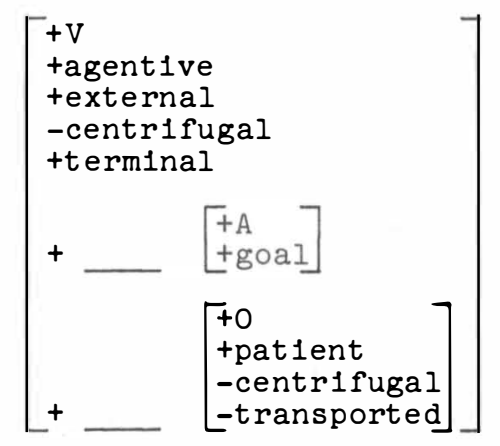

Th1s type of verb differs from the previous classes of verbs in that 1 t has a [-centrifugal] feature which indicates that the verbal action 1 s toward the agent where 1 t terminates. As in the first three types of verbs, the [+terminal] feature indicates that the action is not carried beyond the object.

Verbs of this type require two arguments, one having the agent1ve case feature which 1s both the source and goal of the action and another having the objective case feature. The object is further marked [-centrifugal] because the object is brought toward the agent, and marked [-transported] because the action terminates at the object. The verb kain to eat from this class has the complete meaning of (someone) eats (something).

Examples:

(11) Humuli ang mama ngmanok.

$$
\begin{aligned}
& {\left[\begin{array}{l}
+\mathrm{V} \\
-\mathrm{cf} \\
+\mathrm{ter}
\end{array}\right]} \\
& \left.\frac{\text { Humuli }}{\text { caught the man chicken }} \begin{array}{l}
+\mathrm{A} \\
+\mathrm{B}
\end{array}\right] \\
& \text { The man caught a chicken. }
\end{aligned}
$$

$[+\mathrm{V}] \quad[+\mathrm{A}] \quad[+\mathrm{O}]$

(12) Umamoy siya ng bulaklak.

smelled she flower

she smelled the flower.

[+V] [+A] [+O]

(13) Uminom siya ng alak.

drank he wine

He drank some wine.

Other verbs that belong to this class are: kain (someone) eats (something), lulon (someone) swallows (something), ampon (someone) adopts (someone), subo (someone) takes in (food), sipsip (someone) sips (something), sunggab (someone) grabs (something), tikim (someone) tastes 
(something), tawag (someone) calls (someone), lagok (someone) gulps down (something), igip (someone) fetches (water), kabig (someone) draws (something) towards self, hithit (someone) smokes (something), langhap (someone) inhales (something) and higop (someone) sucks in, sips (something).

6. The slxth type of verb has the following semant1c and contextual features.

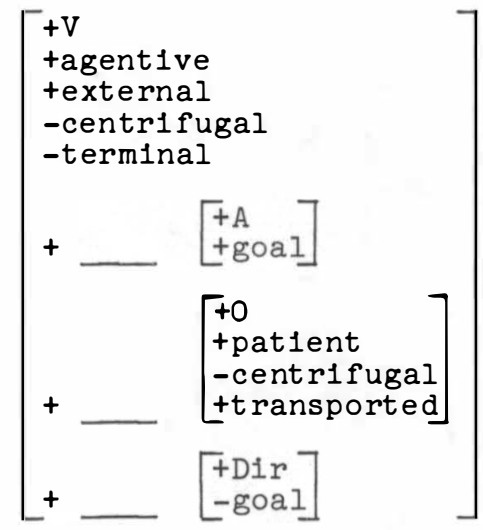

In contrast to the fifth type of verb, the [-terminal] feature indicates the requirement of a directional argument to complete 1 ts meaning. The verbal action transports the object from a directional argument to the agent.

Th1s type of verb then, requires three arguments. One has the agentive case feature, but in this instance 1t is further defined as the goal of the action. The second is marked by the object1ve case feature further specifled as [-centrifugal], because the action transports or carrles the object towards the agent from a directional case feature further specifled as [-goal]. The verb kuha to get that belongs to this class of verb has the meaning (someone) gets (something) (from somewhere).

Examples:

(14) Humiram ang tatay $\left[\begin{array}{l}\text { ng pera sa bangko. } \\ +B \\ \text { ttransp }\end{array}\right.$

borrowed the father money bank

The father borrowed some money from the bank.

(15) Humiling ang bata $\frac{\text { ng manika sa nanay niya. }}{[+\mathrm{O}]}$.
asked for the child doll mother her
The child asked for a doll from her mother. 


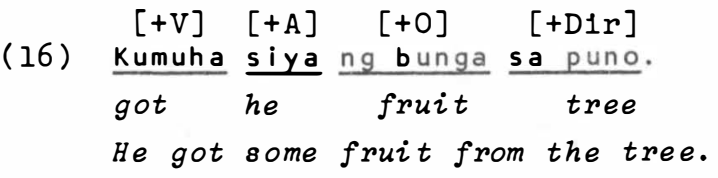

Other verbs that belong to this class are: hingi (someone) asks (from someone) (for something), dukot (someone) draws out (something) (from somewhere), tanggap (someone) receives (something) (from somewhere), abot (someone) reaches (for something) (from somewhere), agaw (someone) snatches (something) (from somewhere), hila, haltak (someone) pulls horizontally (something) (from somewhere), bunot (someone) pulls vertically (something) (from somewhere), hanap (someone) searches (something) (from somewhere), buhat (someone) lifts (something) (from somewhere), sungkit (someone) picks fruits by a pole (from somewhere) and kalawit (someone) hooks (something) (from somewhere).

7. The seventh type of verb has the following semant1c and contextual features.

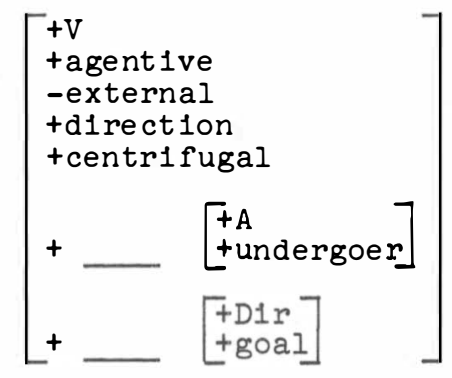

The presence of the [-external] feature in this type of verb different1ates 1t from the previous classes of verbs, because this indicates an Internally 1nduced action rather than action performed externally. The [+direction] feature indicates that the action shows movement toward or from a directional argument. In this particular class of verb, the movement is toward the directional argument [+centrifugal].

The verbs that belong to this class require two arguments. One argument has the agent1ve case feature and is the initiator or source as well as the undergoer of the action. The other has the directional case feature which completes the central meaning of the verb as the goal of the action. Punta to go from this class has the meaning (someone) goes (somewhere).

Examples:

(17) $[+\mathrm{V}] \quad[+\mathrm{A}] \quad[+\mathrm{D} 1 \mathrm{r}]$

(17) $\frac{\text { Pumunta }}{\text { went }} \frac{\text { siya sa Honolulu. }}{\text { he }} \frac{\text { Honolulu }}{\text { Hentula }}$

He went to Honolulu. 
(18) umakbay ang lola sa akin.

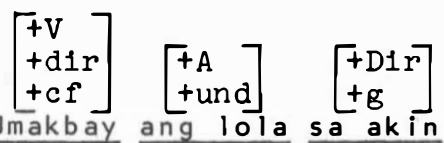

Zeaned-on-arm the grandmother on me

Grandmother put her arm on me (my shoulder).

Other verbs that belong to this class are: dapo (someone) alights (somewhere), kapit (someone) holds (somewhere), pasok (someone) enters (somewhere), tingin (someone) looks (somewhere), luhod (someone) kneels (somewhere), upo (someone) sits down (somewhere), damay (someone) helps or aids (somewhere), higa (someone lies down somewhere), tayo (someone) stands up, lakad (someone) walks (somewhere), takbo (someone) runs (somewhere), gapang (someone) crawls (somewhere), dapa (someone) lies on his stomach (somewhere) and thaya (someone) lies on his back (somewhere).

8. The elght type of verb has the following semant1c and contextual features.

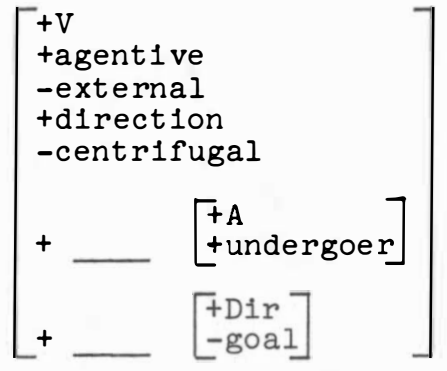

Th1s class of verb contrasts with the seventh type in that instead of being marked positively for the feature centrifugal, it is marked negatively, [-centrifugal]. Th1s means that the action moves away from the directional argument.

The verbs that belong to this class require two arguments. One has the agent1ve case feature wh1ch is undergoer of the action 1t 1n1t1ates. The other has the directional case feature which completes the central meaning of the verb by belng the source of the action. Bitiw to let go, from this class has the meaning (someone) lets go (from somewhere).

Examples:

$$
\left[\begin{array}{l}
+\mathrm{V} \\
+\mathrm{dir} \\
-\mathrm{cf}
\end{array}\right]\left[\begin{array}{l}
+\mathrm{A} \\
\text { tund }
\end{array}\right] \quad\left[\begin{array}{l}
+\mathrm{D} 1 \mathrm{r} \\
-\mathrm{goal}
\end{array}\right]
$$

(19) Bumitiw siya sa sanga ng puno.

Let go he frombranch tree

He let go of the branch of the tree. 
$[+\mathrm{V}] \quad[+\mathrm{A}] \quad[+\mathrm{D} 1 \mathrm{r}]$

(20) Humiwalay siya sa akin.

separated she from me

She separated from me.

Other verbs that belong to this class are: kalag (someone) releases (himself) (from somewhere), takas (someone) escapes (from somewhere), alis (someone) leaves (from somewhere), layas (someone) runs away (from somewhere) and balik (someone) comes back (from somewhere).

9. The ninth type of verb has the following semantic and contextual features.

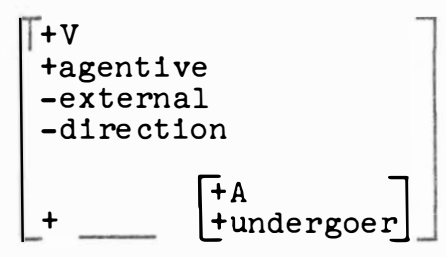

Th1s class of verb has the feature [-direction] wh1ch indicates that the action does not involve any movement.

A verb of this type requires only one type of argument, one having the agent1ve case feature further specifled as [+undergoer]. This signifles that the agent is both inftiator and undergoer of the action. The verb iyak to cry belongs to this class of verbs with the full meaning of (someone) cries.

Examples:

(21) Bumahin ang tao.

sneezed the man

The man sneezed.

(22) $\frac{\text { Gumising si Pedro }}{\text { woke up }} \frac{[+\mathrm{A}]}{\text { Pedro }}$

Pedro woke up.

(23) $[+\mathrm{V}] \quad[+\mathrm{A}]$

(23) Ngumiti siya.

smiled she

She smiled.

Other verbs that belong to this class are: galaw (someone) moves, handa (someone) gets ready, hilik (someone) snores, iglip (someone) takes a nap, hiyaw (someone) shouts, simangot (someone) frowns, pila 
(someone) falls in line, tahan (someone) stops crying, tigil (someone) stops, ubo (someone) coughs, hinga (someone) breathes and tahol (someone) barks.

10. The tenth type of verb has the following semant1c and contextual features.

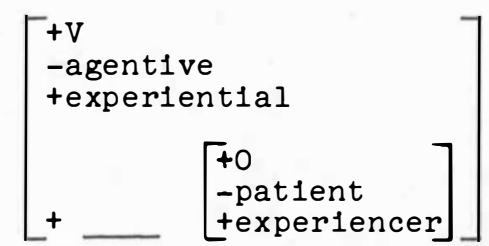

In contrast to the previous classes, these verbshave a [-agent1ve] feature, which means that the verbs do not co-occur with arguments having the agent1ve case. The [+experient1al] feature indicates that these verbs exh1b1t psychological events.

The verbs that belong to this class require an argument having the objective case which 'experiences or feels' the action stated by the verb. The verb galit to become/feel/get angry belongs to this class of verbs.

Examples:

(24) $\begin{aligned} & \left.\begin{array}{l}+\mathrm{V} \\ +\mathrm{exp}\end{array}\right] \\ & \left.\begin{array}{l}+0 \\ +\exp \end{array}\right]\end{aligned}$

got angry the man

The man got angry.

(25) $[+\mathrm{V}] \quad[+\mathrm{O}]$

(25) Nalungkot ang babae.

became sad the woman

The woman became sad.

$$
[+\mathrm{V}] \quad[+0]
$$

(26) Naloko ang estudyante.

got crazy the student

The student got crazy.

Other verbs that belong to this class are: tuwa (someone) feels happy, glad, inis (someone) feels bored, buwisit (someone) feels exasperated, lito (someone) feels confused, hilo (someone) feels dizay, gutom (someone) feels hungry, whaw (someone) feels thirsty, inip (someone) feels impatient, takot (someone) feels frightened and gulat (someone) feels surprised. 
11. The eleventh type of verb has the following semant1c and contextual features.

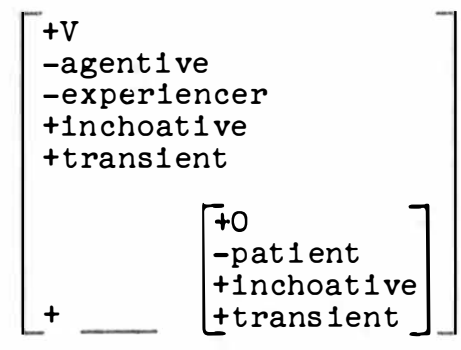

The verbs belonging to this class have the [+1nchoat1ve] feature which causes a nominal to undergo a change of state, specifically a process of becoming. They also contain the [+transient] feature which means that the referent of a nominal undergoes momentary change.

Th1s class requires only one type of argument, one that has the object1ve case feature further subcategorized as [-patient] dictated by the [-agent1ve] feature of the verb. The argument is also marked $[+1 \mathrm{n}-$ choat1ve] to Indicate that 1 t may undergo the process of becoming. The [+transient] subfeature of the objective case indicates that the nominal undergoes temporary change.

Pula to blush is an example. It means to go through a momentary process of becoming red.

Examples :

$\left[\begin{array}{l}+\mathrm{V} \\ + \text { trans }\end{array}\right]\left[\begin{array}{l}\text { O } \\ + \text { trans }\end{array}\right]$

(27) Nangitim siya.

became tanned he

He was tanned.

[+V] [+o]

(28) Namutla siya.

became pale she

She became pale.

Other verbs that belong to this class are: puti to become temporarily fair in cmmplexion, payat to become momentarily thin, ngalumata to look like one has lost much sleep, katl to itch momentarily, maga to become swollen, sakit to feel pain and ngawit to feel tired.

12. The twelfth type of verb has the following semantic and contextual features. 


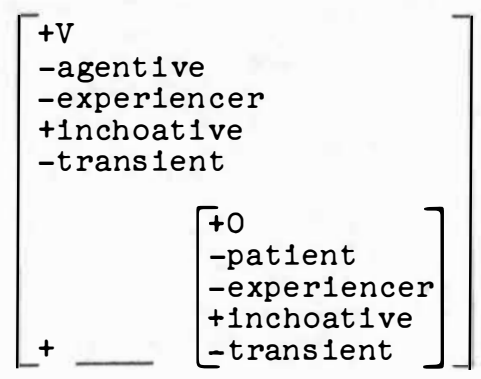

The verbs belonging to this class contrast from the eleventh class by belng marked [-transient]. Th1s feature indicates that the process of becoming, [+1nchoative], is of a non-temporary nature.

Like the previous class, this verb requires one type of argument, one that has the objective case feature with the subfeature [-transient]. Th1s feature indicates that the process which the object undergoes is of a more permanent nature. Ganda is an example of th1s type of verb. It means to go through a process of becoming beautiful.

Examples:

(29) Lumaki ang halaman.

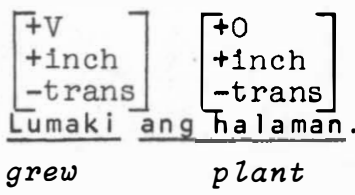

The plant grew.

$$
[+\mathrm{V}] \quad[+\mathrm{O}]
$$

(30) Gumanda si Maria.

became beautiful Maria

Maria became beautifur.

$[+\mathrm{V}] \quad[+0]$

(31) Dumilim ang langit.

The sky became dark.

Other verbs that belong to this class are: pula to become red, puti to become white, payat to become thin, itim to become dark, lago to become luxuriant, tamis to become sweet, alat to become salty, dumi to become dirty, lala to become worse, liit to become small, lamig to become cold, liwanag to become bright, clear, labo to become blurred, taas to become tall, init to become warm, dilim to become dark, sikip to become tight and luwag to become Zoose.

13. The thirteenth type of verb has the following semantic and contextual features. 


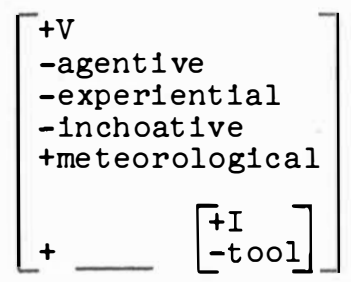

These verbs have a [+meteorologlcal] feature which is restricted to events of natural phenomena.

Th1s class of verb occurs with an argument marked [+1nstrumental] wh1ch also has the subfeature [-tool]. However, this type of argument never surfaces. An example is ulan to rain.

Examples:

(32)

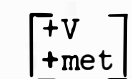

Lumindol.

quaked

It quaked.

$$
[+\mathrm{V}]
$$

(33) Humangin.

blew (wind)

The wind blew.

(34) Umaraw.

shone (sun)

The sun shone.

Other verbs that belong to this class are: kulog to thunder, bagyo to storm, kidlat to lightning, baha to flood and ambon to drizzle.

14. The fourteenth type of verb has the following semantic and contextual features.

$$
\left.\begin{array}{l}
+\mathrm{V} \\
\text {-agent1ve } \\
\text {-experient1al } \\
\text { - Inchoat1ve } \\
\text {-meteorological } \\
\text { +terminal } \\
{\left[\begin{array}{l}
\text { +o } \\
\text {-patient } \\
\text {-experiencer } \\
\text {-1nchoat1ve } \\
\text {-transported }
\end{array}\right]}
\end{array}\right]
$$

These verbs have a [-meteorological] feature 1ndicating all types of action not depicting acts of nature. The [+terminal] feature of the verb slgnifles the absence of movement or direction. 
Verbs of this class require a type of argument having the object1ve case feature wh1ch undergoes the process stated by the verb and such action ending w1th 1t [-transported]. The verb kulo that belongs to this set of verbs has the meaning undergo a process of boiling.

Examples:

35) tter -transported

$$
\left[\begin{array}{l}
+\mathrm{V} \\
- \text { met } \\
+ \text { ter }
\end{array}\right] \quad\left[\begin{array}{l}
+0 \\
-1 \text { nchoat1 ve } \\
- \text { transported }
\end{array}\right]
$$

(35) Kumukulo ang tubig.

boiling the water

The water is boiling.

Other verbs that belong to this class are: hinto to stop, putok to explode, kaluskos to make a rustling sound, bula to bubble, andar to start (motor), uga to shake, bukas to open, sara to close and buka to bloom.

15. The fifteenth type of verb has the following semantic and contextual features.

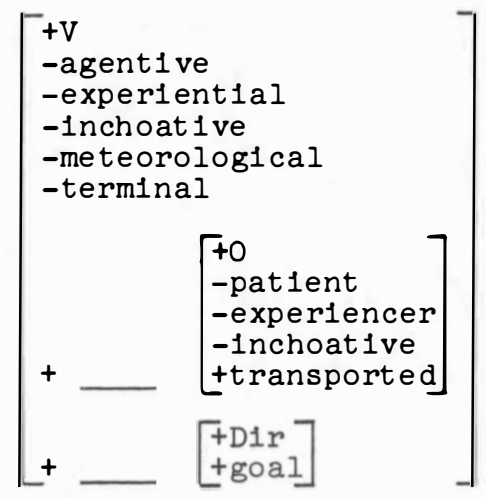

These verbs have a [-meteorological] feature and a [-terminal] feature, the latter indicating a directional non-act-of-nature type of action. They require two kinds of arguments. One has the objective feature, which undergoes the process stated by the verb. Th1s object is directed toward the second argument which has a directional case feature where the action terminates or ends. Bagsak to fall whlch belongs to this class of verbs means to fall (somewhere).

Examples:

(36) [-ter] [transp [tgoal]

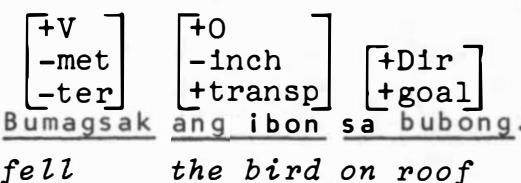

The bird fell on the roof. 
(37) $\frac{\begin{array}{c}{[+\mathrm{V}]} \\ \text { Bumaon }\end{array}}{\text { sank }} \frac{\text { ang gulong }}{\text { wheel }} \frac{\begin{array}{c}{[+\mathrm{D} 1 \mathrm{r}]} \\ \text { sutik }\end{array}}{\text { mud }}$

The wheel sank in the mud.

Other verbs from this class are: bangga to crash (somewhere), dikit to stick (somewhere), angat to raise (somewhere), bakas to leave a trace (somewhere), tagos to penetrate (somewhere), halang to block the way or opening (somewhere), tusok to pierce (somewhere), lubog to sink (somewhere), apaw to overflow (somewhere), tapon to be thrown (somewhere), tulo to drip (somewhere), litaw to appear (from somewhere), ikot to go around, dausdos to slide (somewhere), lutang to float (somewhere), agos to flow (somewhere), ligwak to spizl (somewhere), luwa to protrude, bulge and gulong to roll (somewhere).

\section{Summary}

In this chapter, the major subcategorization of the Tagalog verbs have been discussed. Only the inherent types of cases such as the agent1ve, the object1ve, the directional and the instrument are treated In th1s chapter because these are the non-predictable and nuclear cases that make up the verbal structure as understood by the native speaker. The non-1nherent cases like the benefactive and the affected cases are not included in the case frame of the verb because these are predictable from the inherent cases present in the proposition.

Locat1ves wh1ch can be attached to any type of sentence are also not discussed in this chapter because these are not relevant to the subcategorization of the verbs. Time has not been discussed as one of the cases in this study. Other studies (Taylor 1971) use T1me in the subcategorization of the verbs. In this study, 1t is treated as being outs1de the nominal phrases used to subcategorize the verbs. As such, T1me falls under the category of modal1ty. 'Model cases' (Cook 1972: 45), or adverbial phrases of time, place, and clrcumstance are generally optional to the sentence structure because the1r wide range of use makes them of little help in defining the characterlstics of any particular verb.

The underlying structure of the verb and 1ts arguments have been discussed in Chapters II to V. The next chapters will discuss the surface case forms. A superficial examination will show that there is a many-to-one correspondence between case and case forms. Wh1le there is no apparent one-to-one correspondence between the two, the next chapters w1ll 1llustrate that surface forms are not as haphazard as they appear to be. The postulation of verbal semant1c features along with the syntact1c case frames makes 1t possible to expla1n most of the surface 
forms. However, as will be seen, exceptions remaln. The point of this study is that the semantic features must be considered for the explanation of surface forms and at least those postulated are necessary. 



\title{
CHAPTER VI \\ SURFACE CASE FORMS IN THE NOUN PHRASES
}

\begin{abstract}
Non-subject noun phrases following the verbs in Tagalog are partially marked for case by formal surface distinctions. The case relationships are marked by case forms: the case marking particles and verbal affixes. The case marking particles are $n g$ or sa before common nouns, $n i$ or kay, before proper nouns, $n g$-pronouns and demonstrat1ves and sa-pronouns and demonstratives. ${ }^{1}$ In addition to these NP case markers, there are also compound forms incorporating them: e.g., para sa / para kay for, dahil sa / dahil kay because of and sa pamamaitan ng by means of.
\end{abstract}

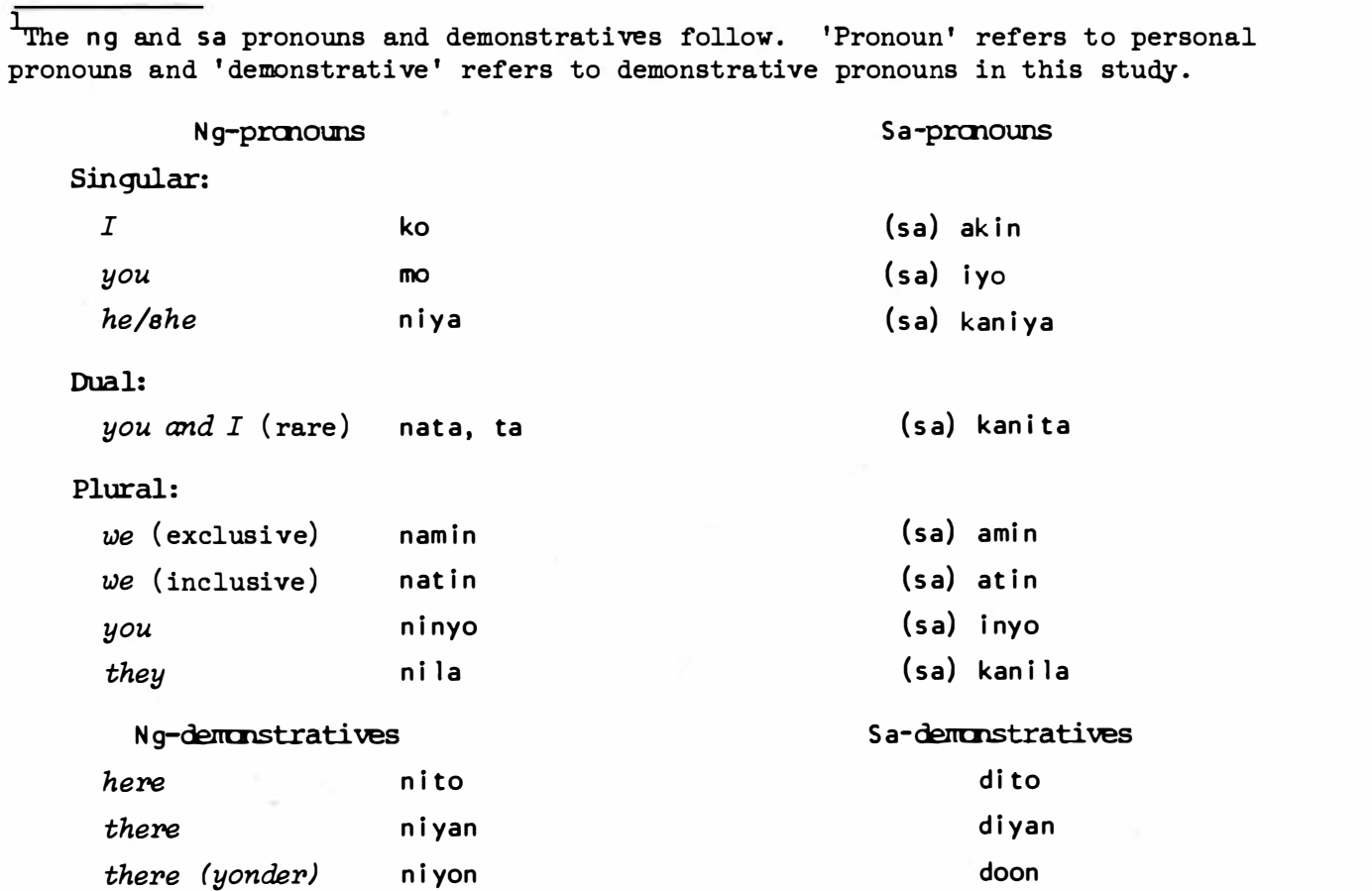


The number of surface case forms introduclng noun phrases creates a problem. The case marking particles are not in one-to-one correspondence w1th the number of Tagalog cases; there are more cases than forms. Th1s necessitates a discussion of how the underlying cases are marked in the surface structure. Non-subject markers w1ll be 1llustrated first.

\subsection{THE INHERENT NOUN PHRASES}

\subsubsection{The Agentive Noun Phrase}

The non-subject agent1ve (A) noun phrase is marked in the surface structure by the particle $n g$ before common nouns and $n i$ before proper nouns. Ng-pronouns or demonstrat1ves can replace the $\mathrm{ng} / \mathrm{ni}$-marked phrases. No surface distinctions are avallable in the case form to show the subfeatures of this case.

Examples:

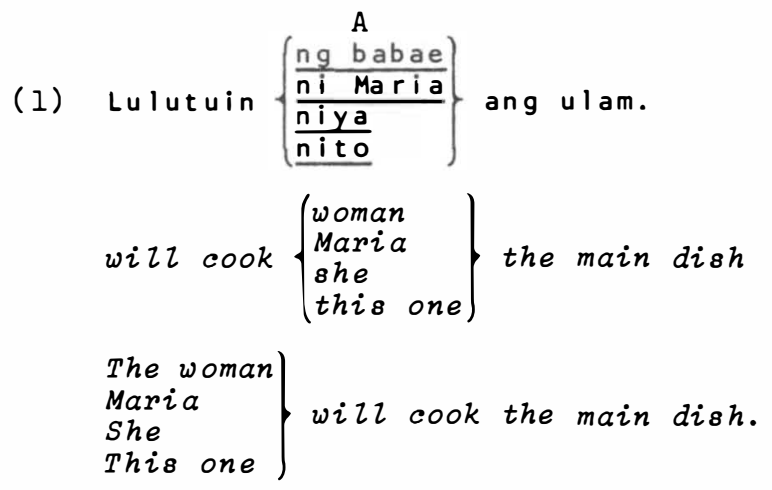

(2) Kinuha $\left\{\begin{array}{l}\text { A } \\ \frac{\frac{n g \text { tao }}{n i \text { Pedro }}}{\frac{n i y a}{n i t o}}\end{array}\right\}$ ang pera got $\left\{\begin{array}{l}\operatorname{man} \\ \text { Pedro } \\ \text { he } \\ \text { this }\end{array}\right\}$ the money

$\left.\begin{array}{l}\text { The man } \\ \text { Pedro } \\ \text { He } \\ \text { This one }\end{array}\right\}$ took the money.

\subsubsection{THE OBJECTIVE NOUN PHRASE}

L1ke the agent1ve noun phrase, the object1ve (0) nominal expression 1s marked by $\mathrm{ng}$ before common nouns. But unlike the A phrase, the 0 phrase 1 s not marked by $n i$ nor $n g$ pronouns. Instead of $n i$-marked 
phrases and ng-pronouns, kay-marked phrases and sa-pronouns are used. The 0 phrase can st1ll be replaced by ng-demonstratives. Agaln, the many subfeatures of this case are unmarked by case forms.

Example:

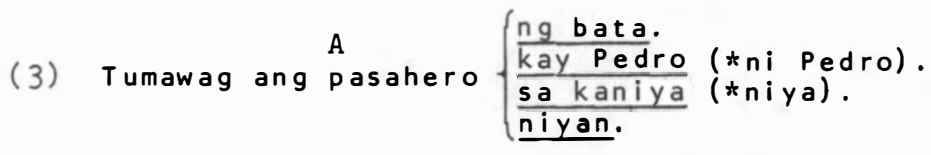

$$
\begin{aligned}
& \text { called the passenger }\left\{\begin{array}{l}
\text { child } \\
\text { Pedro } \\
\text { him } \\
\text { that one }
\end{array}\right. \\
& \text { The passenger called }\left\{\begin{array}{l}
\text { the child. } \\
\text { Pedro. } \\
\text { him. } \\
\text { that one. }
\end{array}\right.
\end{aligned}
$$

\subsubsection{The Directional Noun Phrase}

The directional ( $D 1 r$ ) NP's are marked by sa before common nouns and kay before proper nouns. Sa-pronouns or demonstratives can replace D1r NP's marked by sa/kay.

Example:

$$
\begin{aligned}
& \text { (4) Pumunta si Maria }\left\{\begin{array}{l}
\text { D1r } \\
\frac{\text { sa kanila. }}{\text { sabukid }} . \\
\frac{\text { doon. }}{\text { kayena }} \text {. }
\end{array}\right. \\
& \text { went Maria }\left\{\begin{array}{l}
\text { their place } \\
\text { the field } \\
\text { there } \\
\text { Nena }
\end{array}\right. \\
& \text { Maria went }\left\{\begin{array}{l}
\text { to their place. } \\
\text { to the field. } \\
\text { there. } \\
\text { to Nena. }
\end{array}\right.
\end{aligned}
$$

\subsubsection{The Locative Noun Phrase}

The locative (L) NP's are marked by sa. Unllke the directional NP's, the locative noun phrases are limlted to place nouns so the case markers are limited to $s a$ and sa-demonstratives.

Examples :

(5) Nagluto siya $\frac{\text { L }}{\text { A } \frac{\text { dito }}{\text { dito }} \text {. }}$

cooked she lin a saucepan

She cooked in $\begin{aligned} & \text { a saucepan. } \\ & \text { here. }\end{aligned}$ 
(6) Lumilipad ang ibon $\left\{\frac{\text { sa langit. }}{\text { doon. }}\right.$.

$$
\begin{aligned}
& \text { flying bird }\left\{\begin{array}{l}
\text { sky } \\
\text { there }
\end{array}\right. \\
& \text { The bird is flying }\left\{\begin{array}{l}
\text { in the sky. } \\
\text { there. }
\end{array}\right.
\end{aligned}
$$

Though necessary to the full meaning of the verb, most of the inherent locatives are not expressed in the surface structure because they are already 1mplied or closely assoclated with the verb. For example, the verb to cook 1mplies utensils; and to fly, the sky as a medium.

There are locative phrases that function like adverblal expressions of place. These, though marked the same way as the inherent locative phrases, can occur with all verb types. The following sentences 1llustrate:

(7) Kumain siya ng mais sa ilalim ng puno.

$$
\text { ate he corn under a tree }
$$

He ate corn under a tree.

(8) Nagaral siya sa kuwarto.
studied she room
She studied in the room.

In other words, locat1ves can occur with all verbs, and particular locatives, the 'Inherent' locatives, are 1mplied for certain verbs. Both therefore may occur in a sentence.

Example:

$\mathrm{L}_{1}$ (adv.place) $\quad \mathrm{L}_{2}$ (1nherent)

(9) Sa kusina siya nagluto ng adobo sa kasirola.

in the kitchen she cooked adobo saucepan

She cooked 'adobo' in a saucepan in the kitchen.

Chomsky makes the same distinction in Aspects (1965). He classifies $\mathrm{L}_{1}$ above as a Verb Phrase Complement and $\mathrm{L}_{2}$ as a Verbal Complement. 'Verbs', he states, 'w1ll be subcategorized with respect to Verbal Complements but not w1th respect to Verb Phrase Complements' (1965:102).

\subsubsection{The Instrumental Noun Phrase (Force)}

As discussed in Section 2.3.1.5, a very small set of natural phenomena nouns belongs to the inherent instrumental-force case category. Since these nouns are suppressed before they reach the surface, there 1s no way of determining what their case forms look like. Th1s type 
of case 1s only marked overtly in the verb (see Section 7.4.1.5).

\subsection{THE NON-INHERENT NOUN PHRASES}

\subsubsection{The Instrumental Noun Phrase}

The instrumental (I) NP's are marked by ng or sa pamamagitan ng by means of. Both ng's have forms 1dent1cal to the agent1ve markers. Without an agent1ve NP present, the I phrase 1s always marked by $n g$, otherw1se, it can be marked by $n g$ or sa pamamagitan $n g$, generally w1th sa pamamagitan $n g$, to differentlate 1 f from the ng-agent1ve phrase.

Examples :

W1th Agents:

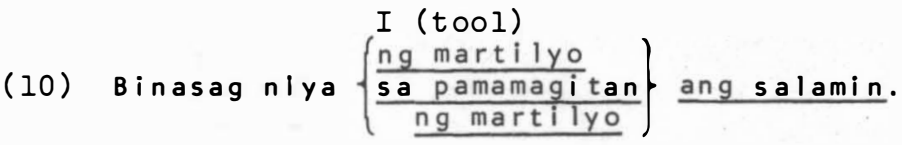

broke he $\left\{\begin{array}{c}\text { with hammer } \\ b y \text { means of } \\ a \text { hammer }\end{array}\right\}$ the mirror

He broke the mirror with a hammer.

W1th Implied Agents:

(11) Binanga $\frac{\mathrm{ng} \text { (trak }}{\text { hit ang poste. }}$
hit the truck the post

The truck hit the post.

W1thout the agent expressed (that 1s, the driver of the truck), the instrumental NP's are always marked by $\mathrm{ng}$ and the sentence 1mplies the presence of an agent. As mentioned in Chapter II, the instrumental force is often the role of noun phrases in sentences having impersonal ent1ties such as forces of nature (1.e., raln, flood, wind, wave, etc.). These noun phrases are marked by $\mathbf{n g}$ and may be replaced by $n g-d e m o n-$ strat1ves.

Examples :

$$
\begin{aligned}
& \text { I (force) } \\
& \text { (12) Nalunod siya } \frac{\text { ng malaking alon. }}{\text { nito. }} \\
& \text { drowned he }\left\{\begin{array}{l}
\text { big wave } \\
\text { this one }
\end{array}\right. \\
& \text { He was drowned by }\left\{\begin{array}{l}
a \text { big wave. } \\
\text { this one. }
\end{array}\right.
\end{aligned}
$$


(13) Nabuwal ing (force)
fezl wind the tree
The wind blew down the tree.

When both the agent and the instrument are present in the deep structure, the instrument is often omitted in the surface structure.

Example:

(14) Nasagasaan ang bata A

ng tsuper.

ran over the child driver

The child was run over by the driver.

Th1s is also true when the instrument is closely assoclated w1th the verb. Run over is a verb assoclated with some kind of vehicle so 1 t is unnecessary in the surface structure. However, 1t may appear in the surface structure unlike th next example.

Many concrete nouns which are instrumental in concept can be used as verb bases. These verbs carry an instrumental meaning and the 1dentical instrumental NP's that co-occur with them are automatically deleted.

Th1s 1s simliar to Fillmore's 'cognate-object' constructions (1968a:85). In the absence of an instrumental NP, the agent1ve NP 1s often present in the surface structure.

Example:

$$
\begin{aligned}
& \text { (15) Isususi ng tatay ang pinto (ng susi). } \\
& \text { lock-with-key father the door (key) } \\
& \text { The father will lock the door. }
\end{aligned}
$$

\subsubsection{The Benefactive Noun Phrase}

The benefact1ve (B) phrase is marked by para sa before common nouns and para kay before proper nouns. These NP's may be replaced by para plus sa-pronouns or sa-demonstratives.

Examples :

(16) Humiram siyang libro para kay Ben sa aklatan.
borrowed he book for Ben library
He borrowed a book for Ben in the library.




$$
\begin{aligned}
& \text { (17) Bumili ka ng pagkain }\left\{\begin{array}{l}
\frac{\text { Bara sa anak mo. }}{\text { parasa kaniya. }} \\
\frac{\text { parakay Mila. }}{\text { parasabahay. }} \\
\frac{\text { paradito. }}{\text { para }}
\end{array}\right. \\
& \text { buy you food for }\left\{\begin{array}{l}
\text { your child } \\
\text { him } \\
\text { Mila } \\
\text { the house } \\
\text { this }
\end{array}\right. \\
& \text { Buy some food for }\left\{\begin{array}{l}
\text { your chizd. } \\
\text { him. } \\
\text { Mila. } \\
\text { the house. } \\
\text { this. }
\end{array}\right.
\end{aligned}
$$

\subsubsection{The Affected Noun Phrase}

The case-marking particle of the affected (Af) case cannot be determined because it is always in subject form. Th1s case is only marked overtly in the verb by a verbal affix.

Example:

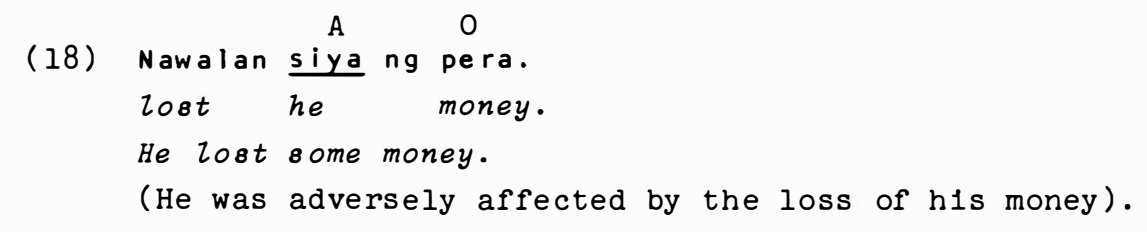

\subsection{SUPPRESSED NOUN PHRASES IN THE SURFACE STRUCTURE}

In Chapter $\mathrm{V}$, the verbs were subcategorlzed according to cases and subcases that they require to complete their central meaning. However, there is no exact correspondence between these and the number of obligatorlly present syntact1c constituents in expressions containing these verbs. Syntactically, certain conceptually understood arguments or roles may be 'suppressed' in the surface structure under certain conditions.

Fillmore explains the suppression of some cases in the surface structure by the introduction of the case notion of (1) built-in roles, (2) coreferent1al roles and (3) vacant roles (see Cook 1971:14).

\subsubsection{Built-In Roles}

There are two types of bullt-in roles. One has a very high select1vity between a specific verb and a noun expression. The object, directional or instrument complement, is incorporated into the verb 
1tself. Fillmore used the verb 'to dream (a dream)' to discuss 'cognate-object' constructions in his 'Case for Case' article (1968a:85). The term 'incorporated roles' is used here to refer to similar constructions (see Fillmore 1969:82). The other type is the llexicalized roles', whlch are 'bullt-1n roles....1mplled by the lexical content of the verb 1tself' (see Cook 1971:14).

\subsubsection{Incorporated Roles}

The following sentences are 1llustrations of case incorporation in Tagalog not only affecting objects but also instruments, locations and directionals. The 1dentical nominal expression is often not given any linguist1c expression because 1t is redundant. But it is not grammat1cally forbldden.

\subsection{Incorporated objects}

In the following sentences, the verb bases, which are usually inherently nouns, have 1dentical objects which are not ordinarily expressed in the surface structure.

Examples:

Nangitlog ang manok $\frac{\text { Suppressed } 0}{\text { itlog) }}$.
laid-egg the hen
The hen laid an egg.

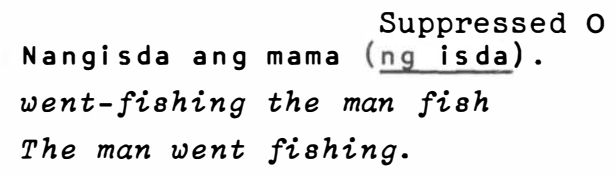

Other surface verb forms that take Incorporated objects are magbahay to build a house, magtsinelas to wear slippers, mamunga to bear fruit, manganak to give birth, manainip to dream, etc.

\subsection{Incorporated Instruments}

Many concrete nouns which can be used in instrumental NP's in Tagalog may also be used as verb bases. These Tagalog verbs which carry an instrumental meaning usually suppress an 1dent1cal I case in the surface structure.

Examples:

$$
\begin{aligned}
& \text { (21) Binato niya ang mga tao (ng bato). } \\
& \text { stoned he the people (with stone) } \\
& \text { He threw stones at the people. }
\end{aligned}
$$


(22) Isususi ng lalaki ang bahay (ng susi). will-Zock-with-key man the house (with key)

The man will lock the house.

(23) Babarilin ng sundalo ang kalaban (ngbaril). will-shoot-with gun soldier the enemy (with gun)

The soldier will shoot the enemy.

Other surface verb froms that take incorporated instruments are mamayong to use an umbre zla, mamana to shoot with an arrow, mambomba to bomb (to drop or leave a bomb), magasarol to use a hoe, magbunot to use a coconut husk and magkamay to use the hands.

Certain verbs that belong to the natural phenomena set take obligtorlly suppressed instrumental force.

Example :

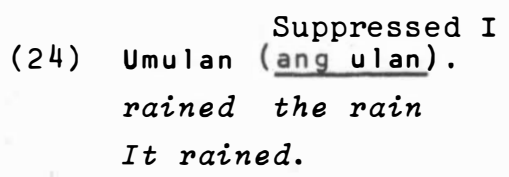

Other surface verb forms that incorporate instrumental force are umaraw the sun shone, umambon it drizzled and kumldlat the lightning struck.

\subsection{Incorporated Directionals}

A few verbs may take incorporated directionals; usually noun phrases again 1mplied by the lexical content of the verb.

Example:

(25) Kandungin mo ang bata ( $\left.\begin{array}{l}\text { Suppressed } D \\ \text { a kandungan mo }\end{array}\right)$. hold-on-lap you the child (on your lap)

Hold the ohild on your lap.

Other verbs that take Incorporated directionals are $1 \mathrm{tabi}$ to put beside and batukan to slap at nape of neok.

\subsubsection{Lexicalized Roles}

Unlike sentences with incorporated roles where the verbs are derived from nouns, sentences with lexicalized (Lex) roles have action verbs. For certain verbs, the nature of the understanding of one of the roles or cases is so clear that 1 t need not be expressed linguistically at 
all unless quite specific additional information is to be communicated. The missing expression in the surface structure is clearly apparent even if not lingulstically expressed. Such an expression may be linguistically manifested only if there is a need to qualify or quantify 1t in some way. In Tagalog, there are examples of lexicalized objects, instruments and directionals.

\subsection{Lexicalized Objects}

In the examples below, where the specific object is predictable or conceptually understood by the listener, it is dropped from the surface. The objective NP's of this type are often not expressed because they are closely assoclated with the central meaning or lexical content of the verb.

Example :

(26) Maglalaba ang babae (ng damit). wash-clothes the woman (clothes)

The woman will wash clothes.

The 0 case may surface if qualified or delimited as in the following example.

(27) Maglalaba ang babae ng medyas niya.

wash woman nylons

The woman will wash her nylons.

Some verbs are so closely assoclated with a speciflc object that the 0 case 1 s often deleted.

Example :

$$
\begin{aligned}
& \text { (28) Dumilat ka ( } \begin{array}{c}
\text { deleted o } \\
\text { ng mata mo) }
\end{array} \\
& \text { open-eyes you eye you } \\
& \text { Open your eyes. }
\end{aligned}
$$

The 0 case may surface again if quallfled or modifled in a speclal way .

Example:
(29) Idilat mo ang magaganda mong mata. open-eyes you the beautiful (pl.) your eyes Open your beautiful eyes.

The $O$ case 1 s left out of the surface structure in the first example because mata eye is subsumed as part of the meaning of the verb dilat open-the eyes. 
Other surface verb forms that take bullt-1n objects are maghilamos to wash (face), maghinaw to wash (hands), and magkula to bleach (clothes).

\subsection{Lexicalized Instruments}

Examples of this case notion among instruments are more evident. Agaln, the missing case is 1mplied by the lexical content of the verb. The typlcal instrument assoclated with sampal slap is a hand, and sipa kick is a foot and halik kiss is the lips. These bullt-1n instruments which are so closely assoclated with the meaning of the verb are not expressed at all in the surface structure unless qualifled in some way. Examples :

Suppressed I

(30) Tinaga niya ang sundalo. (assoclated I of taga is itak bolo) hacked he the soldier He hacked the soldier.

Expressed I

(31) Tinaga niya ang sundalo ng matalim na itak. hacked he soldier sharp bolo He hacked the soldier with a sharp bolo.

Suppressed I

(32) Nanaksak siya ng tao. stabbed he man He stabbed a man.

\author{
(assoclated I of saksak to stab \\ is a pointed tool or instrument \\ usually a knife)
}

Expressed I

(33) Sinaksak niya ang tao ng balisong.

stabbed he person jack-knife

He stabbed the man with a jack-knife.

Other surface verb forms that take bullt-1n instruments are suntukin to box (with fists), kagatin to bite (with teeth) and kurutin to pinch (with fingers).

\subsection{Lexicalized Directionals}

A directional-goal case may be present in the deep structure tut may not always surface because 1 ts presence 1 s lmplied in the lexical content of the verb. 
Examples:

Dumungaw si Maria (sa bintana).

Zooked-out-from-window Maria (from window)

Maria looked out of the window.

(35) Umahon ka na (

get-out-of-water you (from water)

Get out of the water.

Other surface verb forms that take bullt-in directionals are:

sumungaw to look out (of a portal), lumuwas to go (to the city from the country), bumangon to get up (from a place where one reclined), magpasan to carry (on shoulders), magkipkip to carry (under arm) and magsunong to carry (on head).

\subsubsection{Coreferential Roles}

Coreferential roles may occur with a single referent when two distinct notions are apparent. Tagalog reflexive sentences have the same referent for the $A$ and the $O$ roles or cases. The $O$ case may surface as ng sarili one's self but it is most often suppressed in the surface structure.

Examples :

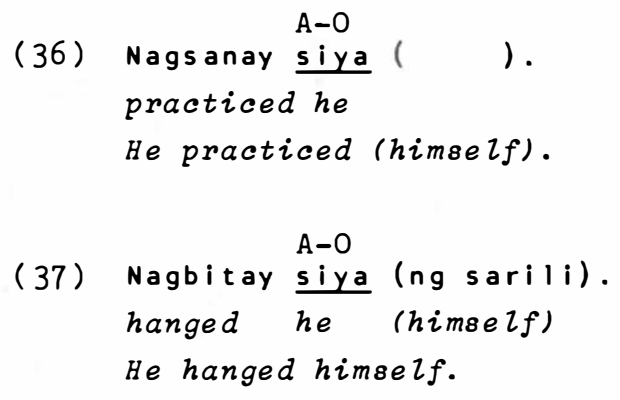

There is a reflexive meaning of the verb when 1t occurs with the A-0 coreferential case.

(38) Nagbaril $\begin{aligned} & \text { A-O } \\ & \text { siya }\end{aligned}$

shot (self) he

He shot himself.

Siya he/him in the sentence above has two distinct case notions: one, the agent1ve instigator of the action and the other, the undergoer object of the action. Both case notions have only one semantic referent. 
In the underlying structure though, there are two arguments that the verb takes: one the agent and the other the object. The 1dentical 01 s, however, deleted before it reaches the surface. In some instances, 1t does surface, especially when subjectivalized.

Example:

(39) Binaril niya ang sarili niya.

shot he himself

He shot himself.

Other surface verb forms that require an A-O case are magamot to treat one's self for an illness, magaliw to enjoy one's self, maghit to shave one's self, magkamot to scratch one's self and magbigti to hang one's self.

\subsubsection{Vacant Roles}

'Vacant roles' are case notions wh1ch are not necessarlly manifested In the surface structure, but must be present in the deep structure (see Cook 1971:14).

\subsubsection{Vacant Objective Role}

Example:

Nagnakaw siya sa bangko (ng pera).
robbed he from bank money
He robbed the bank.

\subsubsection{Vacant Instrumental Role}

Example :

(41) Bumili siya ng pagkain sa palengke (sa pamamagitan ng pera) .

bought he food from market (by means of money)

He bought food in the market.

Verbs can have two or more types of roles or noun phrases suppressed. Examples:

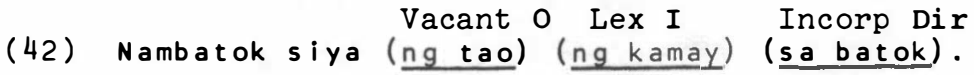
hit-at-nape-of-neck he (somebody) (with hands) (at nape of neck) He hit (someone, with flat of hand, at the nape of the neck). 


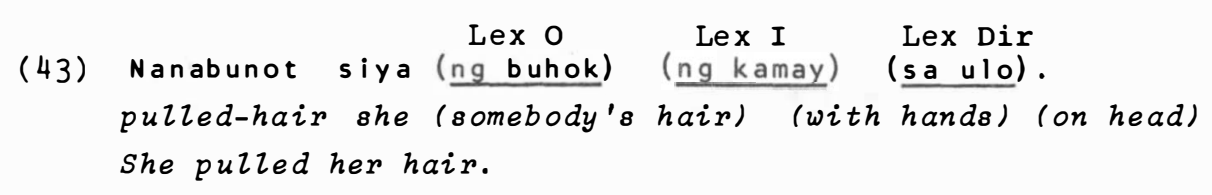

\subsection{SURFACE REALIZATION OF ARGUMENTS}

From the examples glven above, it is apparent that the noun phrases that can occur in the surface structure do not match on a one-to-one basis the case roles conceptually required by the verb. For example, the verb maglaba to Zaunder has an obl1gatory semant1c case frame of [_. $\mathrm{AO}]$ to Zaunder clothes but a syntact1c surface case frame of $[\ldots(0)]$ where the object may or may not occur w1th the verb. Syntact1cally, the [ $A(0)]$ case frame can be 11 lustrated as follows.

Examples :

[
(44) Naglaba siya.
Zaundered she
She Zaundered.
$[\mathrm{AO}]$
(45) Naglaba siya ng maruming damit.
Zaundered she dirty clothes
She laundered some dirty clothes.

In the deep structure all the suppressed expressions mentioned in this chapter are obligatorily present. Th1s study has not attempted to show how the suppressed cases are treated in the surface structure. Fillmore proposes a 'coreference deletion' rule which provides for the deletion of the second of two coreferent1al cases (see Cook 1971:15). A further study of Tagalog verbs is needed to mark each one for the obligatory or optional occurrence of each accompanying deep structure case in the surface structure.

6.4.1. The next chapter w1ll discuss the other case form that marks case relationships in the surface structure - the verbal affix.

The following is a summary of the case markers in the noun phrase. 
CASE

CASE FORMS

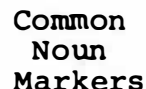
Proper Noun Markers sg/pl

Pronouns $\begin{array}{r}\text { Demon- } \\ \text { stratives }\end{array}$

Markers

A. Inherent Cases
1. Agent1ve
ng
2. Object1ve
ng
3. Directional
s a
4. Locat1ve
s a
5. Instrumental (force)
n 9

ni/nina

ng-pro

ng-dem

kay/kina

s a-pro

ng-dem

kay/kina

s a-pro

s a-dem

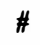

$\#$

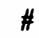

\#

s a-dem

\#

B. Non-inherent Cases

1a. Instrumental (w1thout agents)

b. Instrumental (w1th agents )

(s a pamamagitan) ng

2. Benefact1ve

parasa

parakay/

kina

para

s a-pro

3. Affected

$$
\#
$$

$\#$ para + s a-dem

ng-dem

ng-pro ng-dem

\#

\# means no case form 



\section{CHAPTER VII}

SURFACE MANIFESTATIONS OF TAGALOG CASES IN THE VERBS

\subsection{INTRODUCTION}

In a Tagalog sentence, there exists a pecullar relationsh1p between the verb and one nominal expression. Th1s relationship is similar to the Predicate/Subject relationship in English. However, in English generally only two to four nominal expressions can be made the subject, the agent and the object (sometimes the dat1ve or instrument). Tagalog, on the other hand, can subjectivalize one of as many as five to six nominal expressions. These include the agent, object, directional, instrument, locat1ve and benefactive nominal expressions.

Early Ph1lippine lingulsts referred to this relationship between the verb and one particular nominal expression as 'volce'. Later the relationship was called 'focus'. The subject, the phrase in focus in Tagalog, 1s marked by the particle ang instead of the case-marking particles ng and sa. When marked ang, the focused phrase loses 1ts original case marker and most investigators of Phllippine languages state that the case relationship of the neutralized phrase to the verb 1s indicated by the verbal affix. Later lingulsts (e.g., Kess, Schachter, Constantino) however, observed that there is a many-to-one correspondence between the verbal afflx and the focused phrase - that verbal affixes are not sure indicators of the case or volce relationship of the verb to 1 ts favored nominal expression. It seems imperative therefore, that case relationships 1nstead of being based on surface forms, be determined in the deep structure as advocated by Fillmore.

\subsection{SUBJECT AS A SURFACE PHENOMENON}

Subject is treated in this study as a surface phenomenon and the feature [+subject] 1s added to the surface structure. It means definiteness. The question then arises as to the role of surface structure in 
semant1c interpretation because this is counter to the theory wh1ch stipulates that semant1c interpretation must be entirely determined by the deep structure (Chomsky 1971:209).

In support of the position taken here, it may be observed that many aspects of surface structure appear to have a role in determining semant1c interpretation. Jackendoff shows by means of strong evidence that this is so. For example, he proposes that negation and quantifier are assoclated with the phrases of the surface structure, and their interpretation 1 s determined by the phrases in which they appear and their relat1ve order (see Chomsky 1971:209). Chomsky seems convinced by Jackendoff's evidence and states that 'there is no reason at all why properties of surface structure should not play a role in determining semantic interpretation, and the considerations brought forward earlier suggest that in fact they do play such a role' (Chomsky 1971:214).

The model used in this study is an extension of Chomsky's standard transformational theory 1ncluding a possible semant1c interpretative role by the surface structure. The following diagram dep1cts the relat1onships held in this study. The surface structure as w1ll as the deep structure have a relationship to the semantics of the language.

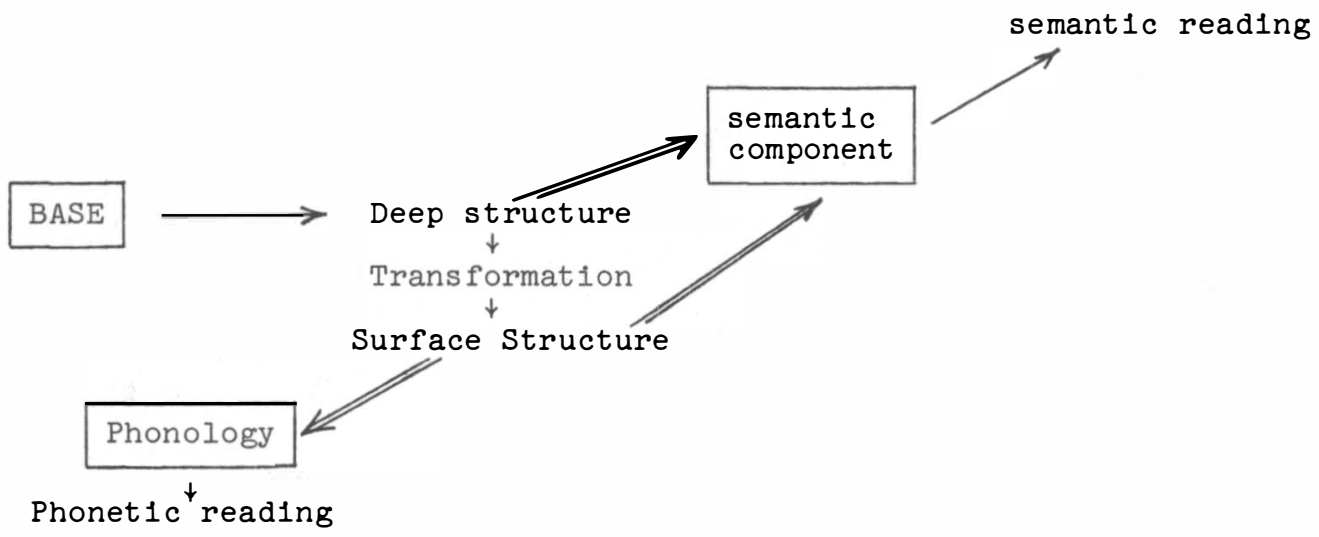

The introduction of 'subject' by a transformational rule is only possible if we assume that surface structure can play a role in semant1c interpretation. The use of ang to mark the subject in Tagalog in the surface structure carried with it the meaning of definiteness. The semant1c component must have access to the surface structure in order to assign the correct semantic interpretation (definiteness).

\subsection{PROCESS OF SUBJECTIUALIZATION}

In Fillmore's analysis, there is no subject in the deep structure. H1s base rule consists of a verb followed by case terms later rewritten 
as categorles. One of these verbal complements is chosen as subject by a transformational rule. Fillmore views the relation 'subject' as a 'surface-structure phenomenon' (1968a:17). In other words, nouns that start out as complements as described by Fillmore, in summarizing McKaughan's work on Maranao, become subjects in the surface structure. The process of subjectivalization or primary toplcalization is stated as follows by Fillmore for Maranao:

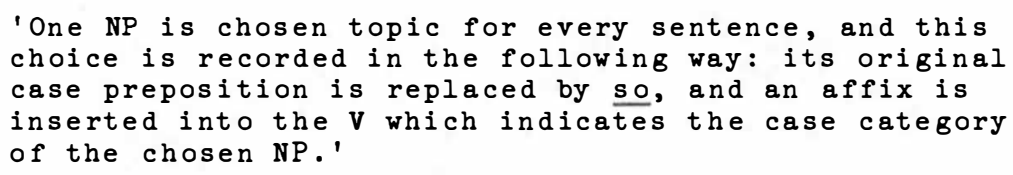

The same process occurs in Tagalog. When a complement is chosen as subject, ang (or si if what follows is a proper noun) replaces the casemarking particle. Subjectivalization then is a process which results in a 'neutralization of underlying case distinctions to a single form, usually called the "nominat1ve"' (F1llmore 1968a:49).

Following Fillmore, this study treats the subject as an aspect of the surface structure. The author agrees w1th McKaughan that 'top1callzation (or subjectivalization) of one of the NP complements would best be described in the grammar as a late transformation.' Southard (1971) gives the opposite view (1.e., subjects exist in the deep structure).

The writer was influenced in making this decision early in the analysis of the data. When golng through a list of verbs to get the case environment of each one from 1ts total meaning, the concept of subject never entered into the analysis as a factor in the subclassification of the verbs. As Mirlkitan1 (1972:113) says, 'subject in 1tself is not a case relation,' rather '....1t is the nomination of a particular phrase or entity as beling the favored case in a given sentence.' In describing th1s, Mirlkitanl worked out a detalled transformational process called 'subject formation' for Kapampangan, a major Ph1l1ppine language. Brlefly, her subject formation process consists of four subprocesses: subject marking, subject determiner incorporation, node changing and case incorporation. However, she introduces the feature [+su] on the PP (prepositional phrase) level whereas the subject feature is introduced here at the terminal level (the $\mathrm{N}$ level). Except for node changing, the same steps used by Mirlkitanl are used here for the process of subjectivalization.

Transformational rules given below show how the following processes occur: subject marking and copy1ng, $K$ case feature transfer, and 1ncorporation in the verb. These rules also handle simultaneously the lexical spelling of the de-case-featurized $K$ as well as the changes in 1ts feature specifications. 
7.3.1. Subject Marking (Obligatory), TR\#1

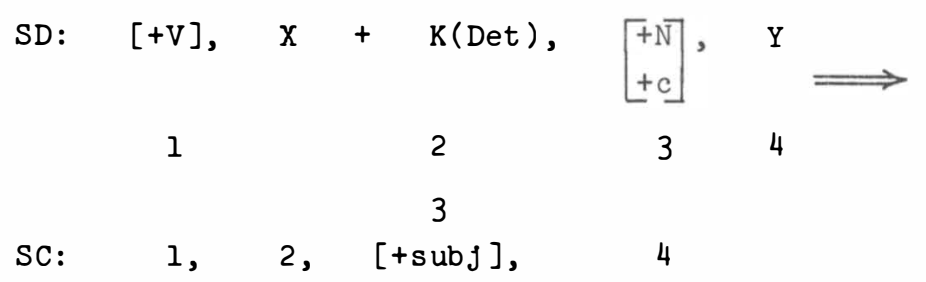

The structural description (SD) refers to any underlying sentence with a verb [+V] which is followed by a noun which is case marked [+c]. Th1s [+c] may be agent, object, instrument, benefactive, directional or locative. The particular case-marked noun may be preceded by a casemarking particle (K), which may be followed by a determiner (det) and also by any element symbollzed by $x$. It may be followed by any other element symbolized by $Y$. The constituents of the sentence are numbered $1-4$.

The structural change (SC) reads that the particular case-marked noun referred to in the SD which undergoes Transformational Rule \#l is marked [+subject]. The choice of a particular noun as subject is restricted to the inherent cases that occur obligatorlly with the verb. Generally, all the types of cases discussed in Chapter II can be subjectivalized. But as discussed in Chapter VI certain cases present in the deep structure do not surface. These suppressed cases are predicted by the semant1c properties of the verb. So only those cases that can be realized in the surface structure can be subjectivalized. If there is only one actant in the deep structure of the sentence, then 1t automatically becomes subject of the sentence. ${ }^{l}$ Any of the five KP's that may occur In a sentence (see BR\#I) may be marked subject, though only one may be marked subject in a given sentence.

\subsubsection{K Case Feature Incorporation, TR\#2}

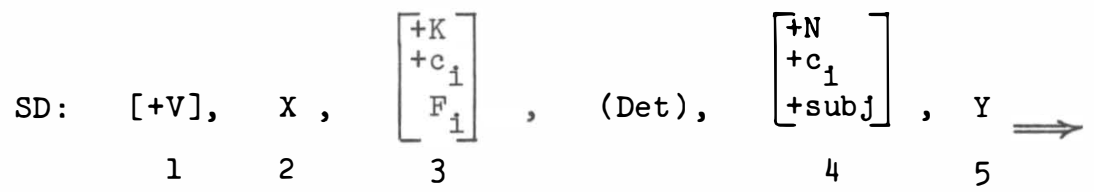

$$
\begin{aligned}
& \text { SC: }\left[\begin{array}{l}
1 \\
+c_{i}
\end{array}\right], 2,\left[\begin{array}{c}
+K \\
+ \text { subj } \\
F_{i}
\end{array}\right],, 4,5
\end{aligned}
$$

Cond1tion: TR\#2 obligatorily applies after TR\#l.

$\mathrm{SD}$ reads that the noun marked [+subject] has a certain case [ $\left.+\mathrm{c}_{1}\right]$ which is shared by a particle [+K] whlch precedes it (see BR\#7.1). The constituents of the sentence are numbered 1-5. 
$S C$ reads that the case feature $\left[+c_{1}\right]$ of the particle $(K)$ is transferred to and incorporated in the verb. The feature [+subject] of the $\mathrm{N}$ 1s copled into the feature matrix of the $K$.

The $K$ that loses 1 ts case feature $\left[+c_{1}\right]$ retalns the rest of 1 ts original features $\left(F_{1}\right)$ plus the feature [+subject]. The $K$ is not speclfled with the following features: [+K, +subject, tsingular, \pm common, tanimate].

The subject-marked $K$ which has the feature [+common] 1s transformationally replaced by ang before common nouns and that which has the feature [-common] is replaced by si or sina in the surface structure.

The subject marker K's with thelr features follow.

$\begin{array}{ll}\text { ang } & {[+K,+ \text { sub } j,+ \text { com }]} \\ \text { si } & {[+K,+ \text { sub } j,+s g,- \text { com }]} \\ \text { sina } & {[+K,+ \text { subj, }- \text { sg, }- \text { com }]}\end{array}$

The incorporated $K$ case feature comes to the surface in combination with aspect and other features of the verb as a verbal affix. Th1s verbal affix is thus the surface marking of the underlying case relationship that holds between the subject of the sentence and the verb, and 1 s therefore the case form (though 1 also often carrles other values). There is however no one-to-one correspondence between the verbal affix and the case relationsh1p 1t happens to mark. For example $a$ verb marked by the incorporated $K$ case feature [+0] can be marked by the verbal affix $i-,-i n,-a n, m a-,-u m-$ or mang- depending upon the semant1c and syntactic characteristics of the verb, something that will be discussed in later paragraphs.

Morphophonem1c rules not given here are needed to show the result of the varlous comblnations of case, aspect and other features of the verb.

A sentence demonstrating flve NP expansions of the verb hiram to borrow with 1ts different subjectivalization possiblilties is given be low.

1. Agent as Subject:

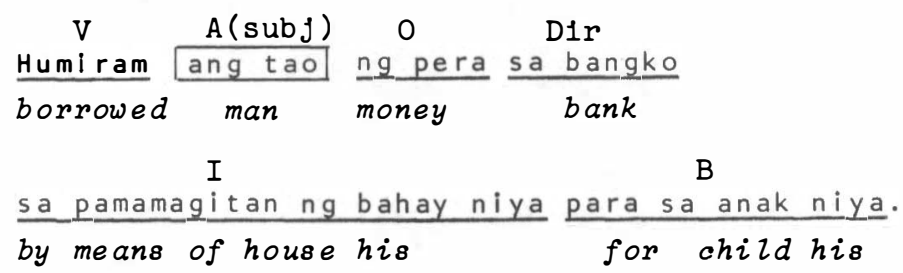

\footnotetext{
Subjects never occur in special types of sentences. An example of a subjectless type of sentence has the verb marked with the feature [-recent] which means recently completed action.
} 
2. Object as Subject:

$$
\begin{aligned}
& \text { Hiniram ng tao ang pera sa bangko sa pamamagitan } \\
& \text { ng bahay niya para sa anak niya. }
\end{aligned}
$$

3. Directional as Subject:

$$
\begin{gathered}
\text { Hiniraman ng tao ng pera } \frac{\operatorname{Dir}(\mathrm{subj})}{\mathrm{ang} \text { bangko }} \text { sa pamamagitan } \\
\text { ng bahay niya para sa anak niya. }
\end{gathered}
$$

4. Instrument as Subject:

$$
\begin{aligned}
& \text { Ipinanghiram ng tao ng pera sa bangko } \\
& \text { I (subj) } \\
& \text { ang bahay niya para sa anak niya. }
\end{aligned}
$$

5. Benefactive as Subject:

$$
\begin{aligned}
& \text { Inihiram ng tao ng pera sa bangko sa pamamagitan ng } \\
& \text { bahay niya anganak niya. } \\
& \text { The man borrowed some money from the bank for his } \\
& \text { son through a mortgage (by mortgaging his house). }
\end{aligned}
$$

The following example 1llustrates the locative as subject.

$$
\begin{aligned}
& \text { 6. Tinirhan niya ang bahay namin } \\
& \text { lived he house our } \\
& \text { He lived in our house. }
\end{aligned}
$$

\subsection{VERBAL AFFIXES AS CASE INDICATORS}

Having discussed the case marking particle in the previous chapter as one of the surface varlables in case 1dentification, this section w1ll focus on how the underlying cases are marked in the verb when chosen as subject.

\subsubsection{Inherent Cases as Marked in the Verb}

\subsubsection{The Agentive Noun Phrase as Subject}

When the agent1ve phrase is subject1valized, it is generally marked by the prefix mag- in the verb. 
Example :

$$
\begin{aligned}
& \text { (1) Magluluto }\left[\begin{array}{l}
\text { +A } \\
- \text { undergoer } \\
\text { gi Maria } \\
\text { siya } \\
\text { ito }
\end{array}\right] \text { ng ulam. } \\
& \text { wizl cook the woman main dish } \\
& \text { The woman } \\
& \left.\begin{array}{l}
\text { Maria } \\
\text { The one }
\end{array}\right\} \text { wizl cook the main dish. }
\end{aligned}
$$

However, -um- also marks the agent1ve phrase as subject in some verbs.

Example:

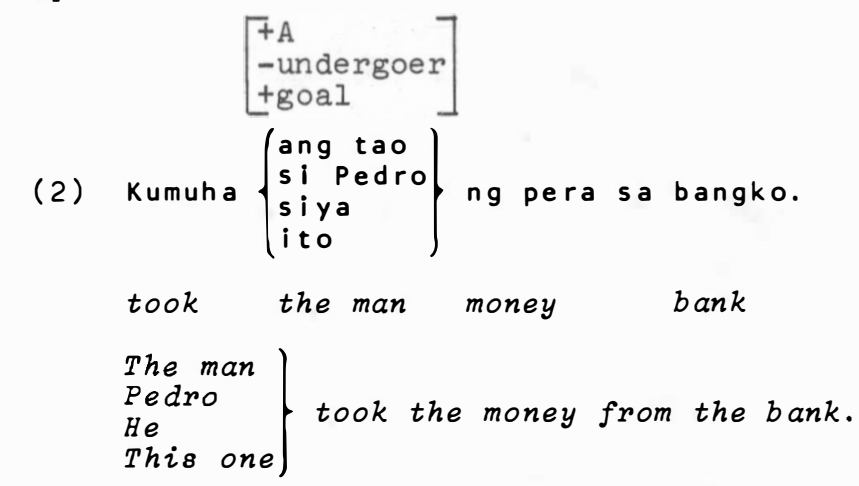

Lopez (1941:94), when confronted w1th sentences having both the magand -um- marking the agent1ve phrase as subject, confesses that 'such constructions give occasion to the almost unexplainable difficulty of distinguishing when to use -um- and when mag- which results,' he says, In 'the safest way....being an appeal to the Sprachgefühl, the speechfeeling, a fact which is true also with other languages.' P1ttman (1966) was confronted w1th the same problem and made an exhaustive list on the use of mag- and -um-. Th1s study profits from these discussions, and by the use of subcases or semant1c features, explains formally large numbers of verbs using mag- and -um-.

Lopez' Sprachgefühl led h1m to call the -um-verbs agent or actor (1nternal) (1941:94) and the mag- verbs as agent or actor (external) (1941:99). But the [texternal] feature 1s not enough to handle the distinction between the two markers. Semantically, -um- marks the subjectivalization of two types of agents and three types of objects.

The following examples will lllustrate the different types of subjectivalized nominals marked by -um-. 
(3) Umiinom ako ng gatas.

drinking $I \quad$ milk

I'm drinking milk.

(4) Pumasok sa bahay si Bino.

entered house Bino

Bino entered the house.

$$
\left[\begin{array}{l}
+0 \\
\text { +inchoative } \\
\text {-transient }
\end{array}\right]
$$

(5) Pumuti ang buhok niya.

became-white his hair

His hair turned grey.

(6) Bumagsak siya sa putik.

fell he mud puddle

He fell in the mud puddle.

(7) Kumulo ang tubig.

$$
\left[\begin{array}{l}
+0 \\
\text {-inchoative } \\
\text {-transported }
\end{array}\right]
$$

boiled water

The water boiled.

In examples \#3 and \#4, the verbs with - um- refer to agents as subjects wh1ch undergo the action they inftiate or agents that act as the goal toward which the action 1s directed. Verbs with mag- on the other hand refer to agents as subjects that perform actions away from or external to them.

Between the two agent subject markers in the verb, mag- forms however, are more predictable than -um- forms. Lopez' definition of the type of agent they mark as subject is falrly accurate. There are a few examples that do not Indicate 'external' action but these are special uses. 
Examples:

(8) Nagtiis siya.

$$
\left[\begin{array}{l}
+0 \\
\text { texperiencer }
\end{array}\right]
$$

suffered (with fortitude) she

she suffered.

(9) Nagantok siya.

$$
\left[\begin{array}{l}
+0 \\
\text { texperiencer }
\end{array}\right]
$$

became-sleepy she

She became sleepy.

In many sentences where there 1s only one noun phrase, the -um-affix appears as the case marker.

Examples:

(10)

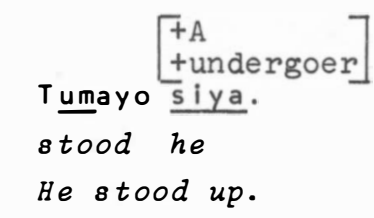

(11.)

$$
\left[\begin{array}{l}
\text { to } \\
\text { +inchoat1 ve } \\
\text {-translent }
\end{array}\right]
$$

Gumanda ang $\mathfrak{b}$ ahay.

became beautiful house

The house became beautiful.

(12) Lumitaw ang aswang.

$$
\left[\begin{array}{l}
+0 \\
\text { - Inchoat1ve } \\
\text { transported }
\end{array}\right]
$$

The ghost appeared.

Very few verbs take the ma- afflx to mark the agent1ve nominal phrase as subject. Th1s phrase is the only obligatory nominal phrase in such sentences.

Example:

(13) Naligo ang bata.

took-a-bath child

The child took a bath. 


\subsubsection{The objective Noun Phrase as Subject}

When the objective phrase is subjectlvalized, it can be marked in the verb by one of three affixes: $i-$, $-i n$ or - an if the agentive noun phrase is also present. If the objective phrase is the only actant in the sentence, -um-, mang- or ma- in the verb marks the objective phrase as subjectivalized. Again there is no one-to-one correspondence between a subject1vallzed object1ve phrase and the verbal affix that indicates 1ts case relationship to the verb.

The problem of affix overlap, that 1s, the same case marked by several affixes, may be in great measure resolved by looking into the cooccurrence of the cases, the1r subcases and the semant1c characteristics of the verbs.

Semantically, with agents present in the sentence, there are four types of subject1valized objects marked by -in in the verb, one marked by $i$ - and another one by -an. Without agents, one type of object is marked by mang- In the verb, one type is marked by ma-, two types marked by -um- and a last type marked by -um- or ma-. Differences of case forms in the verb in combination with the verb features (classes) mark some subcase differences, at least more so than do the particle case forms introducing noun phrases.

\subsection{With Agentive Noun Phrases}

Examples: (Observations based on the examples follow them.)

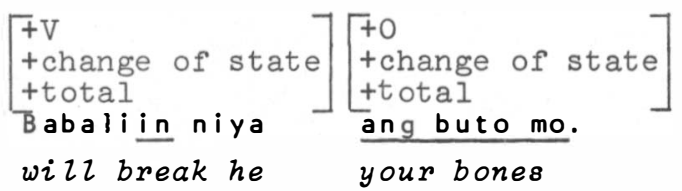

He will break your bones.

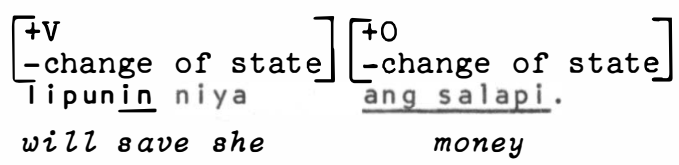

She will save some money.

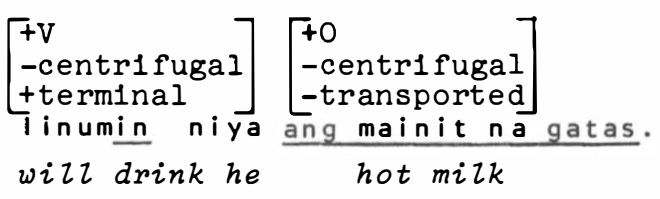

He will drink hot milk. 


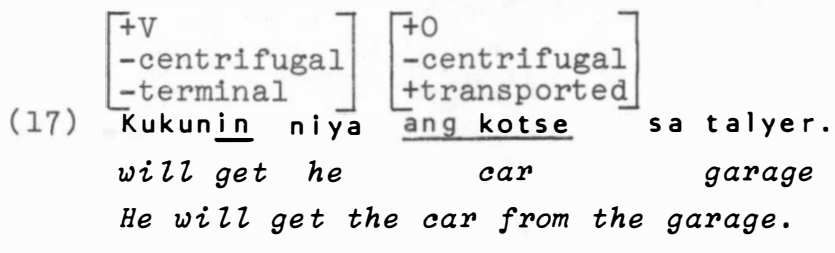

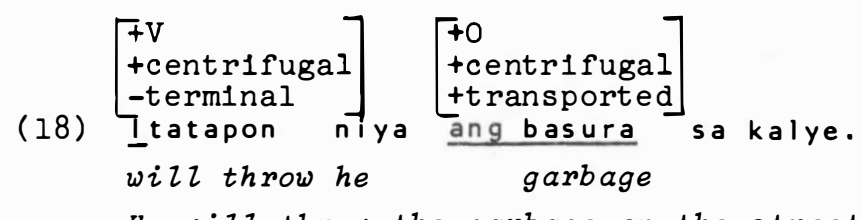

He will throw the garbage on the street.

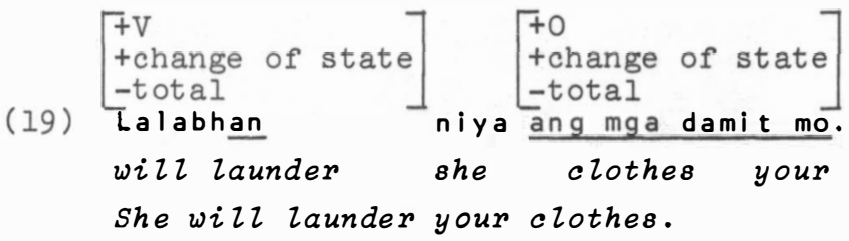

The -in affix marks the object1ve phrase as subject in examples \#1417. However with the use of features, each of these objects is distinguished from the others, though all are marked 1dentically in the surface structure.

The -in verbal affix indicates four types of objects as subjects. One undergoes total change (\#14), another no change at all (\#15), the third 1s moved toward the agent (\#16) while the fourth one is moved toward the agent from a directional source (\#17).

Examples \#18 and \#19 also 1ndicate by verbal affixes that the objective phrase is subject. However, unlike the first four examples, different afflxes mark different types of objects.

1 - marks a type of object as subject wh1ch 1s transported away from an agent to a directional goal (\#18). -An marks a type of object which undergoes partial change (\#19).

\subsection{Without Agentive Noun Phrases}

Examples:

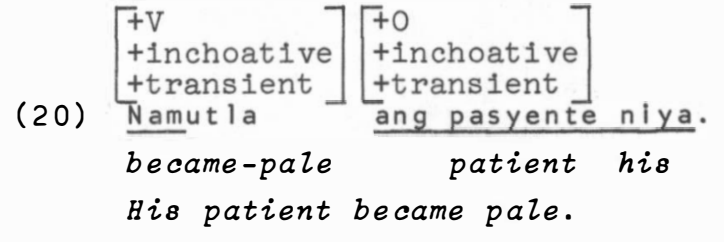


(21)

$\left[\begin{array}{l}+\mathrm{V} \\ \text { texperient1al }\end{array}\right]\left[\begin{array}{l}+\mathrm{O} \\ \text { texperiencer }\end{array}\right]$

Nalungkot siya.

sad

She was saddened.

(22)

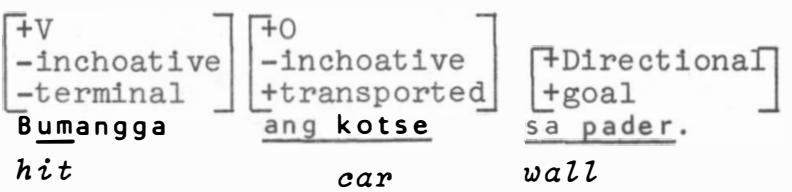

The car hit the wall.

(23)

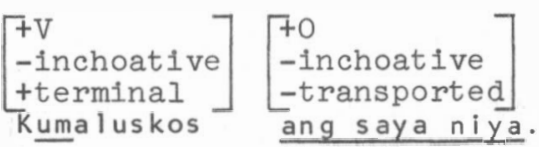

made a rustling sound skirt her

Her skirt made a rustling sound.

(24)

\section{$\left[\begin{array}{l}+\mathrm{V} \\ + \text { inchoative } \\ \text {-transient }\end{array}\right]$}

Lumago

became-more

Mang- marks a type of object that undergoes temporal change (\#20). Ma- marks a type of object that undergoes some kind of psychological experlence (\#21). Um- marks three types of objects, one wh1ch undergoes a process of becoming (\#24), another which causes some kind of movement (\#23), and another wh1ch is transported to a directional goal (\#22).

There is no way of finding out from the sentences above what the nonsubjectivalized form of the $O$ phrase that occurs alone in a sentence looks like. However, with the use of an agent in a causative sense, the non-subject form of the 0 phrase can be brought out.

Example:

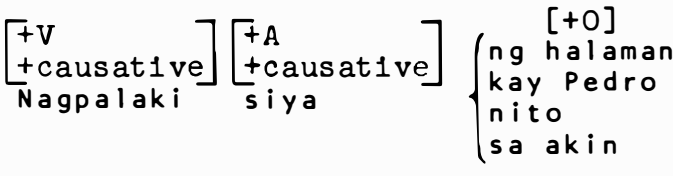

$$
\begin{aligned}
& \text { caused-to-grow he }\left\{\begin{array}{l}
\text { plant } \\
\text { Pedro } \\
\text { this one } \\
\text { me }
\end{array}\right.
\end{aligned}
$$




$$
\text { He caused }\left\{\begin{array}{l}
\text { the plant } \\
\text { Pedro } \\
\text { this one } \\
\text { me }
\end{array}\right\} \text { to grow. }
$$

7.4.1.3. The Directional Noun Phrase as Subject

When the directional (D1r) phrase is subjectivalized, the verb takes the -an affix. Semantically, two types of directional phrases are marked by -an in the verb when subjectivalized.

Examples:

$$
\begin{aligned}
& \text { (26) Pupuntahan nlya }\left[\begin{array}{l}
+D 1 r \\
+ \text { goal }
\end{array}\right] \\
& \text { (26) Pupuntahan nlya ang palengke. } \\
& \text { wizl go she market } \\
& \text { She will go to market. } \\
& \begin{array}{l}
\text { (27) HIhiraman niya ng pera } \frac{\left[\begin{array}{l}
+D 1 r \\
- \text { ang }
\end{array}\right]}{\text { nanay }} \text {. } \\
\text { will borrow he money mother } \\
\text { He will borrow some money from mother. }
\end{array}
\end{aligned}
$$

7.4.1.4. The Locative Noun Phrase as Subject

The locative noun phrase is rarely subjectlvalized. When 1 it 1 , the verb takes the pag- -an compound affix or -an to indicate 1ts underlying locative case function in the sentence.

Example:

$$
\begin{aligned}
& \text { (28) Pinaglutuan nlya ang kaldero. } \\
& \text { cooked she the kettle }
\end{aligned}
$$

Because the directional phrase and the locative phrase are marked simllarly by $s a$, the difference is sometimes made clear by contrasting sentences like the following.

$$
\begin{aligned}
& \text { (29) Sinulatan niya ang mesa. } \\
& \text { wrote he the table } \\
& \text { He wrote (directly) on the table. }
\end{aligned}
$$

(30) Pinagsulatan nlya ang mesa.

$$
\begin{aligned}
& \text { wrote he the table } \\
& \text { He wrote on the table. / He used the table to write on. }
\end{aligned}
$$


7.4.1.5. The Instrumental Noun Phrase (Force) as Subject

As discussed previously, the instrumental force belonging to the inherent case category never surfaces. Instead 1 ts presence is 1nd1cated by the affix-um- in the verb.

Examples:

(31)

$$
\begin{aligned}
& \text { Umuulan. } \\
& \text { raining } \\
& \text { It's raining. }
\end{aligned}
$$

(32) Umaambon.

drizaling

It's drizaling.

\subsubsection{Non-inherent Cases as Marked in the Verb}

\subsubsection{The Instrumental Noun Phrase as Subject}

When the instrumental noun phrase is subjectivalized, it is marked In the verb by prefixes ipang- or $i-1 f$ it functions as a tool and maka- if 1 acts as an instrumental force [-tool]. When the instrumental tool phrase is subjectivalized, the objective case marking part1cle $n g$ is often changed to sa.

Examples:

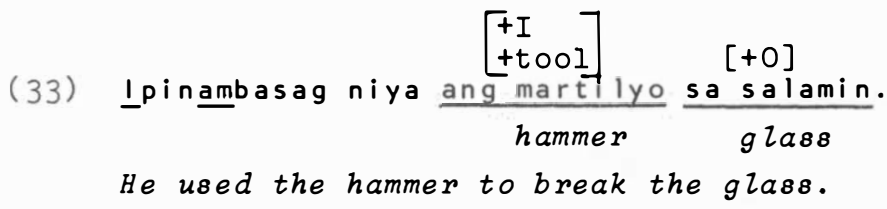

(34) Lpinunas niya ang trapo samesa. used-to-wipe she rag table She used the rag to wipe off the table.

(35) Nakabasa ng tao ang ulan. was drenched person rain The person was drenched by the rain. 
(36) Nakamatay ng pasyente ang TB.

$$
\left.\underset{[+0]}{\text { g pasyente }} \begin{array}{l}
+I \\
- \text { ang } T B
\end{array}\right] .
$$

(37) Nakasagasa ng mama ang trak.

ran over man truck

The truck ran over the man.

(38) Nakasira [+o] $\left[\begin{array}{l}+I \\ -t \circ 01\end{array}\right]$
ruined
life his gambling
Gambling ruined his life.

\subsubsection{The Benefactive Noun Phrase as Subject}

When subject1val1zed, the benefact1ve noun phrase is marked in the verb by the preflx $i$ - (when the corresponding sentence having the agent1ve noun phrase as subject is marked by the affix -um- in the verb) or ipag- (when the corresponding agent1ve noun phrase as subject is marked by the affix mag- in the verb).

Examples:

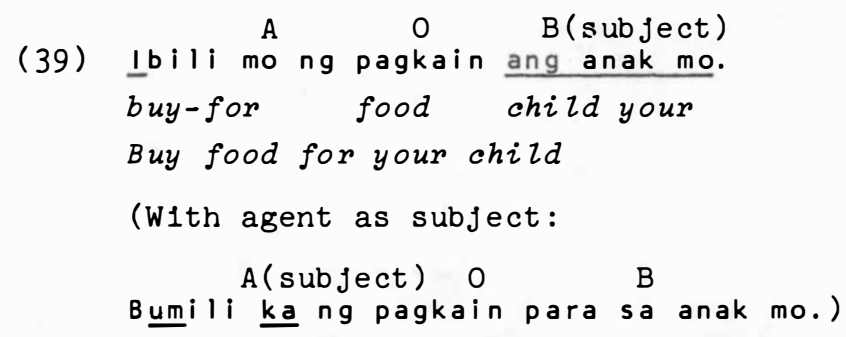

A B (subject) 0
(40) Ipaglaba mo siyang damit.

wash (clothes)-for you him clothes

Wash clothes for him.

(W1th agent as subject:

$$
A \text { (sutject) } O \quad B
$$

Maglaba ka ng damit para sa kaniya.) 


\subsubsection{The Affected Noun Phrase as Subject}

The affected noun phrase is always subject1valized. It is marked in the verb by the ma- -an compound affix.

Example:

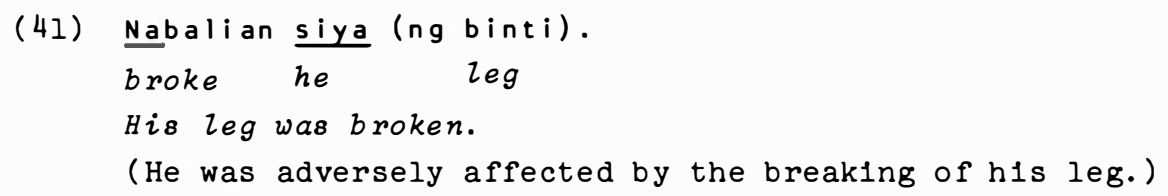

\subsubsection{Surface Realization of Tagalog Cases}

The following is a summary of the surface realization of Tagalog cases.

Nominal Phrases

Sub ject1valized

A. Inherent

1. Agent1ve

2. Object1ve

(w1thout agents)

3. Directional

4. Locatives

5. Instrumental (force)

$$
\text { Non-subject }
$$

Case Marking Particles Case Marking

\section{Verbal Affixes}

B. Non-inherent 1. Instrumental
(w1th agents)

(w1thout agents)

2. Benefactive

3. Affected

$$
\begin{gathered}
n g / n i / n g f_{- \text {-demonst }}^{\text {-denoun }} \\
\text { ng/kay/sa -pro } \\
n g \text {-dem } \\
\# \\
\text { sa/kay/sal-pro } \\
\text { sa/ \#/sa -dem }
\end{gathered}
$$$$
\text { \# }
$$

i-, ipang-

sa pamamagitan $n g /$

sa pamamagitan ( $n i$ ),

sa pamamagitan $n g_{\{}^{- \text {prom }}$

ng

$$
\begin{aligned}
& \text { para sa / para kay / } \\
& \text { para }+\mathbf{s a}_{\left\{\begin{array}{l}
\text {-prom } \\
\text {-dem }
\end{array}\right.}
\end{aligned}
$$

$$
\begin{aligned}
& \text { mag-, -um-, ma- } \\
& i-,-i n--a n \\
& \text {-um-, mang-, ma- } \\
& \text {-an, -in } \\
& \text { pag- -an, -an } \\
& \text {-um- }
\end{aligned}
$$

Attention 1 s directed to the kinds of verbal affixes that surface when the different cases are subjectlvalized. The agent1ve, for example, may have mag-, -um-, or ma- to indicate the case. The usual way to handle the fact that different forms mark the same case has been by

\# no case marking indicator. 
classifying verbs according to the afflx, thereby making the affixes allomorphs. All three verbs in this instance are called actor-focus in earlier works, having three subclassiflcations. Accordingly, the verb bases are classified as mag-verbs, -um- verbs or ma- verbs. However, as indicated elsewhere in this study, this type of classification is not sat1sfactory.

In order to reach an explanation for the differences in affixes the central meaning of the verbs has been analyzed and the semantic information formalized by means of features. These features are also used to explain what varled roles are marked by the same affix where a single aff1x may mark more than one case role.

The next chart (w1th problems to be polnted out shortly) shows there is a close correspondence between the case function and the case form (verbal affix). The case form is given in the first column and the case function in the form of features in the second. The third column gives the slgniflcant verbal semant1c features.

\section{Surface Realization (Verbal Affixes)}

\section{Subjectivalized Cases with Their Features}

Agentive Case

$$
\left[\begin{array}{l}
\text {-und } \\
\text {-goal }
\end{array}\right]
$$

Semantic Features (Verbal)

$$
\left[\begin{array}{l}
\operatorname{text} \\
+\operatorname{cf}
\end{array}\right]
$$

2. $-U M-$

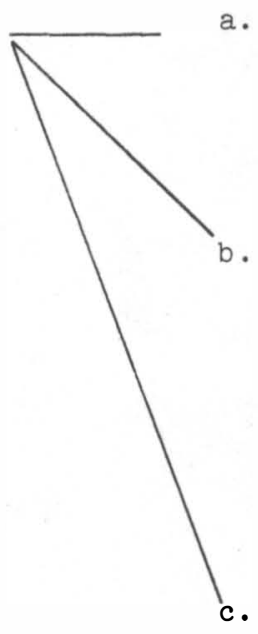

a. Agentive Case
(1) $\left[\begin{array}{l}\text {-und } \\ \text { tgoal }\end{array}\right]$
(2) [tund]
$\left[\begin{array}{l}\text { text } \\ -c f\end{array}\right]$
$[$-ext]

Objective Case

(1) $\left[\begin{array}{l}\text { tinch } \\ \text {-trans }\end{array}\right]$

$$
\begin{aligned}
& {\left[\begin{array}{l}
\text { tinch } \\
\text {-trans }
\end{array}\right]} \\
& {\left[\begin{array}{l}
\text {-inch } \\
\text { ter }
\end{array}\right]} \\
& {\left[\begin{array}{l}
\text {-inch } \\
\text {-ter }
\end{array}\right]}
\end{aligned}
$$

(2) $\left[\begin{array}{l}\text {-1nch } \\ \text {-transp }\end{array}\right]$

(3) $\left[\begin{array}{l}\text {-1nch } \\ \text { transp }\end{array}\right]$

Instrumental Case(Force)

$$
\text { [-tool] }
$$$$
\left[\begin{array}{l}
\text {-inch } \\
\text { tmet }
\end{array}\right]
$$

3. MA-

Objective Case

$$
\text { [+exp] }
$$

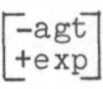


Surface Realization
(Verbal Affixes)

4. - IN

5. 1-

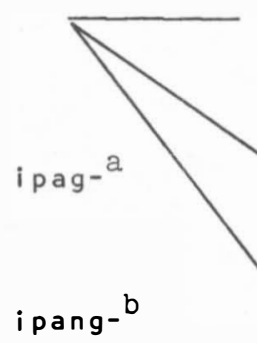

a. Objective Case

$$
\left[\begin{array}{l}
\text { tcf } \\
\text { ttransp }
\end{array}\right]
$$

Benefactive Case

[tben]

[+agt ]

[ +agt ]
$\left[\begin{array}{l}+t e r \\ +c s \\ +t\end{array}\right]$
$\left[\begin{array}{l}\text { tter } \\ +\operatorname{cf} \\ -\operatorname{cs}\end{array}\right]$
$\left[\begin{array}{l}-\operatorname{cf} \\ \operatorname{tter}\end{array}\right]$
$\left[\begin{array}{l}-c f \\ -t e r\end{array}\right]$
( I) $\left[\begin{array}{l}+c s \\ +t\end{array}\right]$

$\left[\begin{array}{l}\text { tof } \\ \text { ter }\end{array}\right]$

ipang-

c. Instrumental Case

[t tool]
Semantic Features

(Verbal)

a. Directional Case
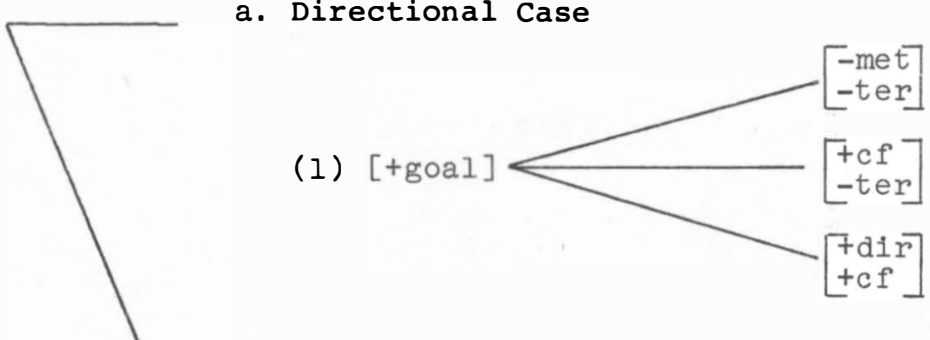

6. $-A N$

$\gamma$

(2)

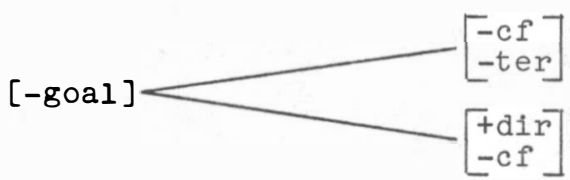

b. Objective Case

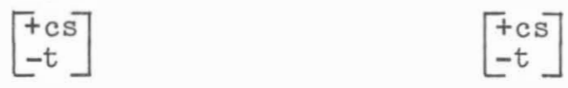

\footnotetext{
alpag- is derived from mag- verbs and $i$ - from -um- verbs.

${ }^{b}$ With some verb bases ipang- is in free variation with $i-$, with others only ipangis allowed.
} 

Surface Realization
(Verbal Affixes)

7. $P A G--A N$

8. MAN G-

9. $M A--A N$
Subjectivalized Cases with Their Features

Locative Case

$[+\mathrm{L}]$

Objective Case

$$
\left[\begin{array}{l}
\text { tinch } \\
\text { trans }
\end{array}\right]
$$

Affected Case

[+af]
Semantic Features

(Verba 1)

[+local]

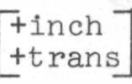

10. MAKA-

Instrumental Case(Force)

$$
\left[\begin{array}{ll}
+I & \\
-t \circ o l
\end{array}\right]
$$

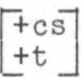

The following comments highlight the facts displayed in the chart.

1. The mag- affix marks the agent1ve case for a subjectivallzed noun phrase assigned the nominal subcase features [-undergoer], [-goal] by the semant1c features [+external], [+centrifugal] of the verb. In other words, mag- indicates that the agent is nelther the undergoer of the action nor the goal of the action. Examples of these verbs are in Classes 1, 2, 3 and 4 of Chapter V. There are some overlaps especially in Class 1 whlch w1ll be discussed later in this chapter.

2. The affix-um- marks the agent1ve case of a subjectivalized noun phrase assigned the nominal subcase features [-undergoer], [+goal] by the [+external], [-centrifugal] features of the verb. The difference in the agents for those that take mag-and those that take -um- is obvious; nelther are undergoers of the action of the verb, but the second is the goal of the action, where the first is not. Examples of these 1.e., -um- verbs are In Classes 5 and 6 of Chapter V.

The -um-affix also marks another type of subject1valized agent1ve phrase which does undergo the action of the verb assigned by the feature [-external]. Classes 7,8 and 9 of the verb in Chapter V give 1llustrations of this type of correspondence.

Bes1des marking the agent1ve as subject, the affix-um- also signals the object as subject. There are three types of objects characterized by the features that the afflx -um-corresponds to. See Classes 12, 14 and 15 respectively for examples. Note that -um- also marks the instrumental case when the feature [-tool] is involved as assigned by the semant1c features of the verbs indicated in the chart. 
3. The ma- affix signals the object as subject. Th1s type of object 1s assigned the feature [+experiencer] by the [+experiential] feature of the verb. Class 10 1llustrates this type of object.

4. The affix -in also slgnals the object as subject. Four types of objects are marked by the same afflx. The chart above gives the distinctions among these objects.

5. The affix $i$ - marks three types of case roles as subject: the object1ve, the benefact1ve and the instrumental cases. Again, each case role is made distinct from each of the others by means of 1 ts respective features. 1-marks a transported type of object as subject. 1 - or ipag- verbs mark the beneflclary as subject if the verbal feature [+agent1ve] 1s present. I- or ipang-verbs mark the instrument as subject if the same feature is present.

6. The affix -an marks the directional and objective cases as subject.

7-9. The affixes pag- -an, mang- and ma- -an have a one-to-one correspondence with case function.

10. Maka- marks the instrumental force or cause as subject.

It $1 \mathrm{~s}$ clear from this information that a single surface form marks various roles. The differences become apparent through the use of semant1c features.

The next chart is rearranged, though it gives the same information as the one just discussed. The arrangement shows that the same case role may be marked by different verbal afflxes. Where many forms correspond to a single case function, the features again may be used to predict when to use each affix. Sentence examples from the earlier parts of this chapter are c1ted for each affix. 
SUBJECTIVALIZED CASE

1. Inherent Cases

a. Agentive Case
SEMANTIC FEATURES

SURFACE REALIZATION

EXAMPLES

Verbal Nominal

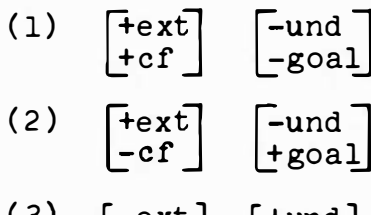

(3) [-ext] [tund]

b. Objective Case

(w1th agent1ve involvement)
(1) $\left[\begin{array}{l}+c s \\ +t\end{array}\right]\left[\begin{array}{l}t c s \\ +t\end{array}\right]$
(2) $\left[\begin{array}{l}+\mathrm{cf} \\ -\mathrm{cs}\end{array}\right]\left[\begin{array}{l}+\mathrm{cf} \\ -\mathrm{cs}\end{array}\right]$
(3) $\left[\begin{array}{l}\text {-cr } \\ \text { ter }\end{array}\right]\left[\begin{array}{l}\text {-cr } \\ \text { transp }\end{array}\right]$
(4) $\left[\begin{array}{l}\text {-cr } \\ \text {-ter }\end{array}\right]\left[\begin{array}{l}\text {-cr } \\ \text { transp }\end{array}\right]$
(5) $\left[\begin{array}{l}\text { tcr } \\ \text { ter }\end{array}\right]\left[\begin{array}{l}+c f \\ +t r a n s p\end{array}\right]$
(6) $\left[\begin{array}{l}+c s \\ -t\end{array}\right] \quad\left[\begin{array}{l}t c s \\ -t\end{array}\right]$

MAG-

$-U M-$

$-U M-$

- IN $[M A G-] \sim[-U M-]^{a}$

- IN [MAG-]

- IN $[-U M-]$

-IN [-UM- ]

1- [MAG-]

$-A N \quad[M A G-]$
$\# 1$

$\# 2,3$

\#4, 10

\#1 4

\#16

\#17

\#18

\#19

\footnotetext{
Q Bases that occur with affixes in brackets also occur with the affixes being cited.
} 
SUBJECTIVALIZED CASE

SEMANTIC FEATURES

$$
\text { Verbal Nominal }
$$

(without agentive involvement)

\begin{tabular}{|c|c|c|c|}
\hline (1) & {$\left[\begin{array}{l}\text { tinch } \\
\text {-trans }\end{array}\right]$} & {$\left[\begin{array}{l}\text { tinch } \\
\text {-trans }\end{array}\right]$} & $-U M-$ \\
\hline (2) & {$\left[\begin{array}{l}+1 \text { nch } \\
+ \text { trans }\end{array}\right]$} & {$\left[\begin{array}{l}\text { tinch } \\
\text { ttrans }\end{array}\right]$} & MANG \\
\hline (3) & {$[+\exp ]$} & {$[+\exp ]$} & $M A-$ \\
\hline (4) & {$\left[\begin{array}{l}\text {-1nch } \\
\text { tter }\end{array}\right]$} & {$\left[\begin{array}{l}\text {-1nch } \\
- \text { transp }\end{array}\right.$} & -UM- \\
\hline (5) & {$\left[\begin{array}{l}\text {-1nch } \\
\text {-ter }\end{array}\right]$} & {$\left[\begin{array}{l}\text {-1nch } \\
+ \text { transp }\end{array}\right.$} & -UM- \\
\hline
\end{tabular}

c. Directional Case

$\begin{array}{lllll}\text { (1) } & {\left[\begin{array}{l}\text { tcf } \\ \text {-ter }\end{array}\right]} & {[\text { goal }]} & \text {-AN } & \text { \#26 } \\ \text { (2) } & {[\text { tolr }]} & {[\text { tgoal }]} & -A N & \text { \#29 } \\ \text { (3) } & {\left[\begin{array}{l}\text {-cf } \\ \text {-ter }\end{array}\right]} & {[- \text { goal }]} & -A N & \text { \#27 }\end{array}$

d. Locative Case

$[+$ local $][+\mathrm{L}]$

$(P A G-)-A N$

e. Instrumental Case(Force)
$\# 28,30$

$\# 5,11,24$

\#20

\#21

$\# 7,23$

\# 6,12

\#31,32 
SUBJECTIVALIZED CASE

2. Non-1nherent Case

a. Instrumental Case

(with agent1ve involvement)

$\begin{array}{ll}{[+ \text { agt }] \quad[+t o 0 l]} & \text { IPANG- } \\ & \text { I (PANG)- }\end{array}$

$\# 33$
$\# 34$

(w1thout agent1ve 1nvolvement (1nstrumental-force))

[-agt $]$ [-tool] MAKA-

$1-[-U M-]$

$[$ tagt $] \quad[$ tben $]$

IPAG- [MAG-]

\#39

\#40

c. Affected Case
$M A--A N$

$\# 41,42$ 
Note that the agentive case as subject 1s marked by mag- or - um- in the surface structure. Mag-1s differentlated from the f1rst -um-by the distinctive feature [+centrifugal] and from the second -um- by the feature [+external].

The object1ve case wh1ch co-occurs with agents is marked by -in, ior -an in the surface structure. The feature [-total] distinguishes the an- verb from the in-verb, and the features [+centrifugal], [-terminal] separate the $i$ - verbs from the other two.

On the other hand, where the object1ve case 1s the only argument in the sentence, 1t is marked as subject by the -um-, ma- or mang-affixes In the surface structure. Ma- verbs are differentlated from the -umand mang-verbs by the feature [texperient1al]. Mang- verbs are differentlated from -um- verbs by the feature [+transient].

In predicting the use of -um- or mag- marking the agent as subject, the verbal features [texternal] and [tcentrifugal] are 1mportant.

To predict -an marking the directional goal or the directional source as subject, the feature [tcentrifugal] does not seem necessary. The two functions are not marked distinctly in the surface structure. Only the features [-ter], [tdir] are relevant.

The slgniflcant features that may predict -in (marking the object as subject) are [+change of state] with [+total], [-change of state] and [-centrifugal].

To predict ma-, marking the object as subject, the [+experiential] feature is 1mportant. To differentlate mang- from the rest, the [+translent] feature is relevant. The feature non-experiential with the exception of the [+transient] feature can predict the occurrence of - um- verbs (wh1ch mark the object as subject). The rest of the features, [ \pm inchoative], [ \pm met], do not seem relevant in predicting the -um- affix.

\subsubsection{Problems and Exceptions}

Basically the features [texternal] and [tcentrifugal] predict in general the appearance of a mag- verb or an -um-verb in the surface structure. Where marked [+external] and [+centrifugal] a mag- verb appears and where marked [+external], [-centrifugal], the -um- verb appears. However there is one major exception in the set of verbs marked [+centrifugal]. These verbs behave like class 1 verbs. Where one expects a mag- verb to appear from the display of features, -um- verbs also occur with the same base. If not for this exception, there would be a neat division between mag- verbs marked by the [+centrifugal] 
feature and the -um- verbs marked by the [-centrifugal] feature. ${ }^{1}$

Some verbs are clearly mag- verbs. (See Class 1 verbs in Chapter V.) There is an overlap when the same base may occur w1th both - um- and magaffixes. There are two kinds of explanations that may account for the overlap. One is semantic and the other syntact1c.

For certain bases like putol to cut, ${ }^{2}$ the -um- verb denotes obtaining part of the object and the mag- verb denotes general action. For example, pumutol means to cut off (a part, a piece, a branch) from the whole and magputol means to cut. Thus the verbs differ semantically and because of thelr speclalized meaning, the -um- verbs may be classified separately from the1r mag- counterparts.

Another type of mag- and -um- alternation occurs w1th 'destruct1ve' verbs. ${ }^{3}$ In this alternation each affix seems to favor a different type of construction. The -um- verbs occur in what Constantino terms a 'definite' type of sentence (1965:77). The verb follows the subject and 1s preceded by the subject marker ang. Th1s verb functions as a nominalized form. The mag- verb on the other hand occurs in the regular narrat1ve or 's1tuational' type sentence (1965:96).

Examples :

$$
\begin{aligned}
& \frac{\text { Siya }}{\text { he }} \frac{\text { ang bumasag }}{\text { broke it log. }} \\
& \text { He was the one who broke the egg. }
\end{aligned}
$$

$\frac{\text { Nagbasag }}{\text { broke }} \frac{\text { iya }}{\text { he }} \frac{\text { ng it log. }}{\text { egg }}$

\footnotetext{
The writer went over this list of exceptions with two other native speakers of Tagalog and there was no agreement on which base was only a mag- verb or an -um- verb. One tended toward the use of -um- over mag- while the other preferred it the other way. Both agreed though that they would prefer to use -in for these verbs. A study of Tagalog dialects may help in explaining the alternation in the use of mag- and -umaffixes.

${ }^{2}$ other examples are hiwa to slice (off), punit to tear (off), bali to break (off), taga to hack (off) and gupit to cut (off) with scissors.

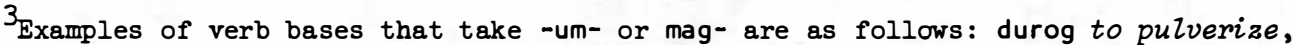
tunaw to me $\mathrm{lt}$, tabas to cut (following a pattern), bayo to poind, sibak to split (with an axe), tadtad to chop into small pieces, kudkud to grate, tilad to chop (wood), lusaw to liquify, katay to slaughter, dikdik to pound, gayat to shred, giba to demol$i s h$, tas tas to rip, biyak to cleave, basag to break, lukot to crumple, wrinkle, gusot to discrray, tibag to cut down (Zzomber), pis a to crush, pindot to squeese, pinch, tist is to operate, giling to grind, pukpok to pound, likha to cause to bring about, bigkas to recite, gawa to make, katha to create, yari to bring into being, buo to construct, hubog to form and sunog to burm.
} 
If the writer were to restrict the considerations here to the situational type sentence, the -um- verbs occurring in definite sentences would be ellminated (though the problem is not solved).

The mag- forms also seem most naturally used in 1mperative sentences. Example:

$\frac{\text { Magbasag }}{\text { break }} \frac{\text { a }}{\text { you tatlong itlog. }}$ three eggs

(You) break three eggs.

Another difference between -um- and mag- forms results from the restrictions in the type of subject each affix occurs with. Certaln-umforms of the verbs from Class 1 co-occur w1th human subjects whereas the mag- forms co-occur w1th nonhuman but anlmate objects. Examples: pumatay to kill (human beings), magpatay to slaughter or kill (nonhuman beings); and bumuhay to support or keep alive (human beings), magbuhay to keep alive (plants or nonhuman beings).

In a few Instances only the -um- form of the verb occurs because the mag- form carrles a reflexive meaning. Examples: gumamot to cure someone, maggamot to cure oneself; bumaril to shoot someone, magbaril to shoot oneself.

Very few examples like basa to read, sulat to write and gawa to make appear only as -um- verbs belonging to Class 1. These are mostly 'creat1ve' verbs.

The verbs in question w1th -um- that behave like Class 1 verbs most frequently appear in the surface structure as in-verbs with the object subjectivalized. The problem is thus usually avolded by speakers.

There are some other exceptions w1th verbs in other classes to the case function and form correlations given in the summary charts. One is the use of mag- verbs wh1ch are characterlzed as having the features [+external], [-centrifugal], generally attributed to-um-verbs. There are however very few of these exceptions. Qu1te a number are reflexive verbs. Examples are magnakaw to steal and magbaril to shoot oneself. (The rest of the reflexive examples known to the writer are given above).

A few ma- verbs too can be characterlzed by the same features as the -um- verbs, having [+external] and [-centrifugal] features. Examples are matuto to Zearn and manood to watch. ${ }^{1}$ Other case grammarlans have analysed these as requiring datives or experiencers.

The verbs characterized as [-external] have very few ma- examples: matulog to sleep and maligo to take a bath. A very rare example of the

\footnotetext{
${ }$ Other examples of this type of ma- verbs are makinig to Zisten and maalaala to remember.
} 
[-external], [-centrifugal] features of the verb is mangaling to come from which is marked by the affix mang-. A few mag- ${ }^{1}$ forms also occur.

There are very few examples of verbs marked [+1nchoat1ve], [-translent] that take ma-. The writer knows of only one exception. The verb 1s mamatay to die.

of the verbs marked [texperiential], there are a few exceptions. One rare example is magantok to feel sleepy. There is also an in-form of this verb (1.e., antukin to feel sleepy). Other exceptions marked [+experlent1al] are a few mag- verbs, mostly psychologlcal, which seem to 1mply a dellberateness of action usually assoclated with agentundergoers of the activity. An example is magdamdam to feel slighted. ${ }^{2}$

The verbs marked [-external], [+direction] and [+centrifugal] that appear with -an to mark the directional phrase as subject in the surface structure have a few verbs with the $-i n$ afflx as exceptions. Examples are lakarin to walk to, takbuhin to run to, langoyin to swim, dalawin to visit, pasukin to enter and akyatin to climb. The writer is not sure how to classify these verbs. They suggest movement, but the last three examples co-occur with phrases marked by elther sa (directional phrase marker) or ng (object1ve phrase marker) when not subject1valized.

One possible reason for this overlap may be the syntactic difference between directional phrases marked by $-i n$ and those marked by -an. Most of the verb bases that occur with the -in affix in transitive sentences also occur with the -an affix in intransitive sentences. Examples are takbuhin to run to, takbuhan to take something by running to someone; pasukin to enter, pasukan to bring in something to someone; labasin to go out to, labasan to bring out something to someone; akyatin to climb, akyatan to bring up something to someone.

The [+external], [+centrifugal] and [-change of state] features wh1ch predict a mag- form of the verb sometimes surface as an -um-verb. The only exceptions known to the writer are bumilang to count and gumamit to $u s e$.

All of these exceptions underline the perversity of language. The system described here glves many more answers than hitherto clted, but exceptions must still be listed to cover all the data. It may be that w1th more semant1c features the problems c1ted here can be solved. At any rate exceptions are manageable within the system.

The examples are magbuhat to come from and magsimula to begin from.

${ }^{2}$ Other examples of this type of mag- verbs are magtampo to sulk and maghinanakit to feel hurt. 



\title{
CHAPTER VIII
}

\author{
CONCLUSION
}

According to Re1d (1965:11), traditional works on the classiflcation of verbs in Philipplne languages focus on the1r 'potential occurrence w1th volce (and somet1mes aspect) affixes'. Kess, after concentrating on the study of 'focus construction types' of Tagalog verbs, concludes that 'while the verb-topic relationship appears to be a satisfactory point of departure for such an examination, a more extensive study should include relationships beyond that of the verb and topic' (1967: 102). He realizes that a surface consideration of focus is not sufflclent for a complete analysis of Tagalog verbal constructions. As a matter of fact, in retrospect, he polnts out 'that if description of verbal types in Tagalog is to proceed much beyond the stage of discussion that has been reached, we will have to drop the notion of focus as such and merely consider the voice-marking affixes of verbs as surface properties which may or may not correspond to anything meaningful' (1971:8).

Unlike the previous studies on Phllipplne verbal classifications, this study focuses on the complex symbol of the verb. Semantic verbal features are posited glving a better system of classification. 'Focus' or the overt manifestation of case in the verb is discussed only after verbs have been subcategorlzed according to the different types of complements or noun phrases they require.

This study is also an attempt to uncover the underlying case relationships in the Tagalog sentence and the dominant role the verb plays in dictating the types of cases 1t allows to co-occur with 1t. It makes no attempt to match these case relationships with the1r means of expression in any one-to-one correlation (1.e., verbal affixes or part1cles that may happen to mark the varlous cases in the surface structure). As emphasized a number of times in this study, there is no perfect correspondence between the deep cases and overt surface manifestations 
of these deep cases. However, it is possible to explain a large number of surface structure facts by an understanding of the deep structure case relationships, and by then matching the features of the verbs and the nouns by selectional rules, resulting in the realization that semantics plays an 1mportant part in the analysis of the Tagalog case system.

The maln purpose of this study has been to explain the case system of Tagalog by classifying verbs in a manner that would be sensitive both to the syntact1c and semantic relationships existing between the verb and the cases that occur with 1t. Each case under discussion has 1ts own subset of cases for a more precise characterization of the relationship between the verb and the noun phrases that occur with 1 t.

To formalize these syntact1c-semant1c relationships in the sentence, semant1c features for the verbs have been made prominent here, perhaps a step in a continuing effort to explain and understand Ph1lippine languages. Kess suggests the feature approach in his dissertation when he says 'future research might well attempt to determine how many additional features may be relevant in describing collocational restrictions which govern syntact1c relationships' and again when he adds, 'minute subcategorlzation....w1ll lead to ever more precise characterizations of collocational restrictions' (1967:103).

Although as stated before, this study is experimental and needs empirical validation, it is hoped to have accomplished the following: (1) presented a more adequate and precise subcategorization of Tagalog verbs by the use of features; and (2) made an attempt to formalize the introspective judgements of this native speaker about the case system of Tagalog verbs, thus getting closer to semant1c adequacy, and at the same time avolding the notational problems particularly of Fillmore's case grammar.

The flfteen classes of verbs discussed in Chapter $V$ may not be all Inclusive of Tagalog verb types, but the great majority of Tagalog verbs fall into these classes. Th1s classification has been made using eleven verbal semant1c features, and flve cases with thirteen subcases. Though these features may not all be relevant in the definition of the underlying case relationships in Tagalog sentences, some of them surely are signiflcant in formalizing what has been termed the native speaker's intultion about his language, his understanding of the full semantic and syntactic meaning of a verb even when 1 t 1 s out of context.

However, this study has not been developed far enough to be able to predict the surface realizations of all of these cases. As Chapter VI and VII lllustrate, the underlying case function and the surface case forms do not match. More rules are needed to correlate surface forms 
with deep structure cases. In other words, how can the underlying case features match the observable case manifestations in a sentence?

What this study hopes to have proven is that the exclusive use of surface information is not sufficlent to 1dentify true case relationships in a sentence. It also indicates that the final criterion in deep case 1dent1fication or the only means of 1dentifylng cases lies w1th the semant1c information from the deep structure.

The semant1c information presented in this study may serve as a basis for further research in the causative and equational sentences of Tagalog. These toplcs have been barely touched in the analysis of the Tagalog language. A comprehens1ve study of the causatives and equationals added to what has been done in this study will contribute toward an ultimate explanation of the underlying case system of Tagalog. 


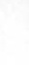


APPENDIX A

SEMANTIC FEATURE DISPLAYS OF THE VERB AND THE CASES 
[+V]

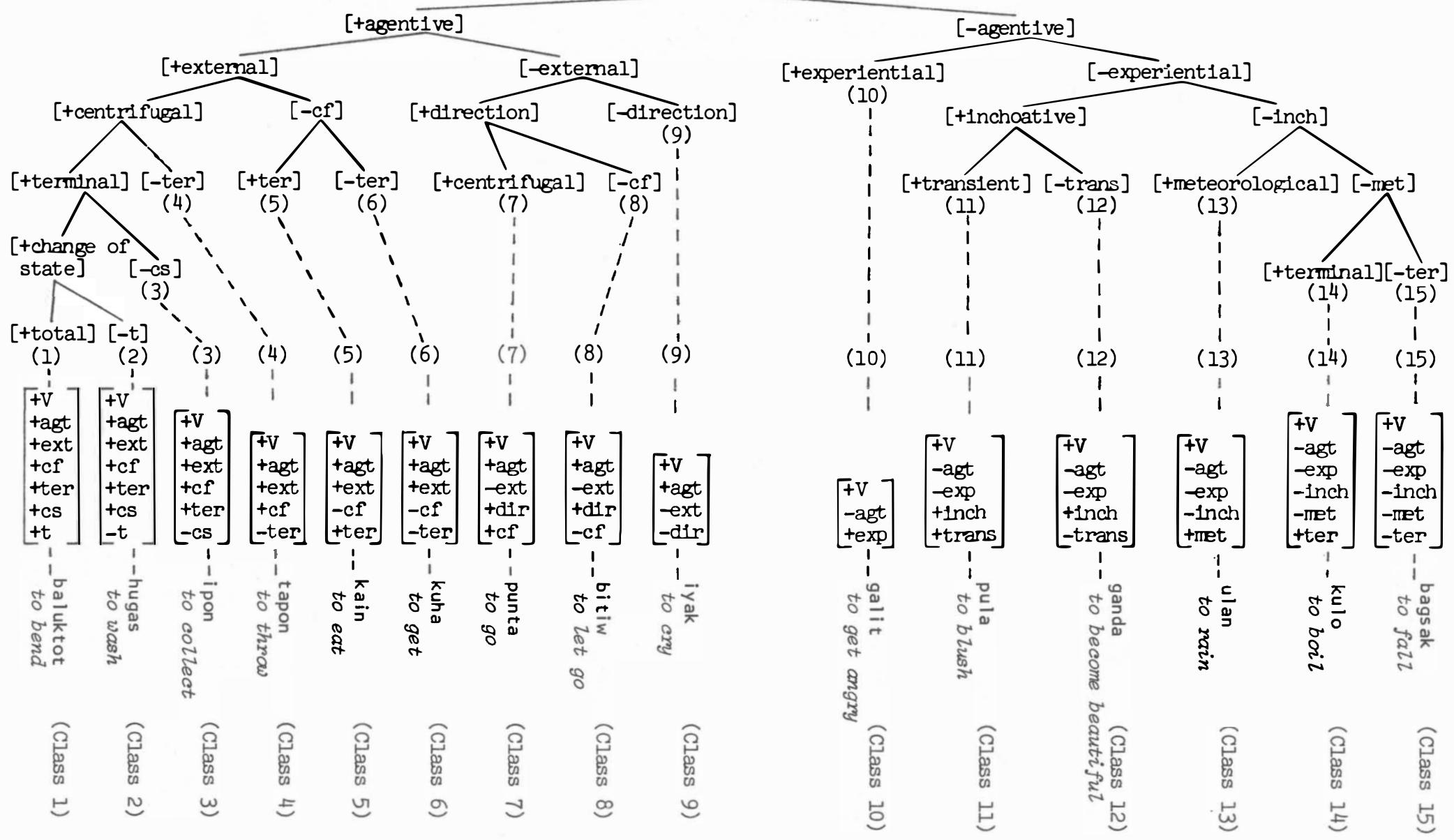


2. Semantic Feature Tree of the object

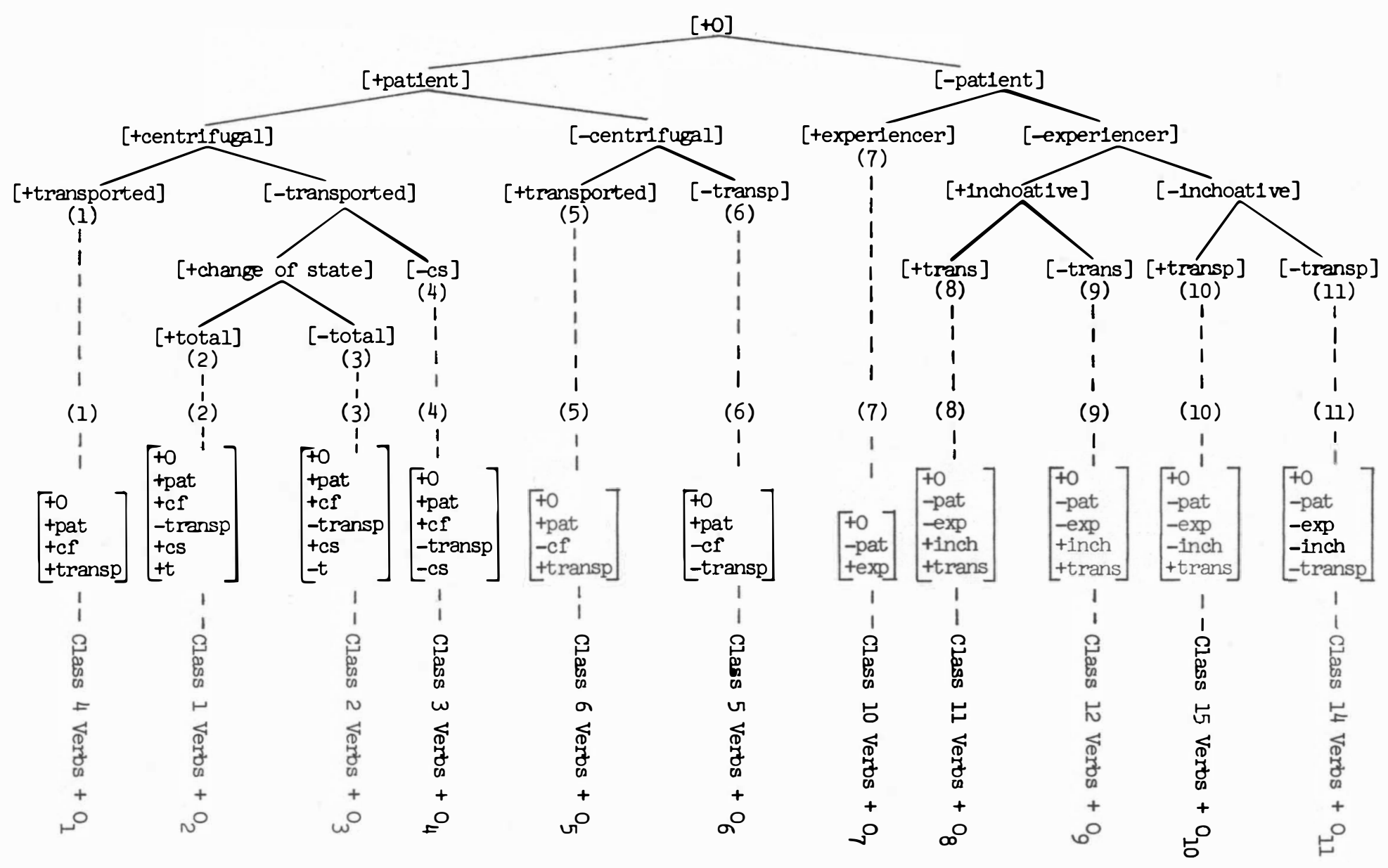


3. Semantic Feature Tree of the Agent

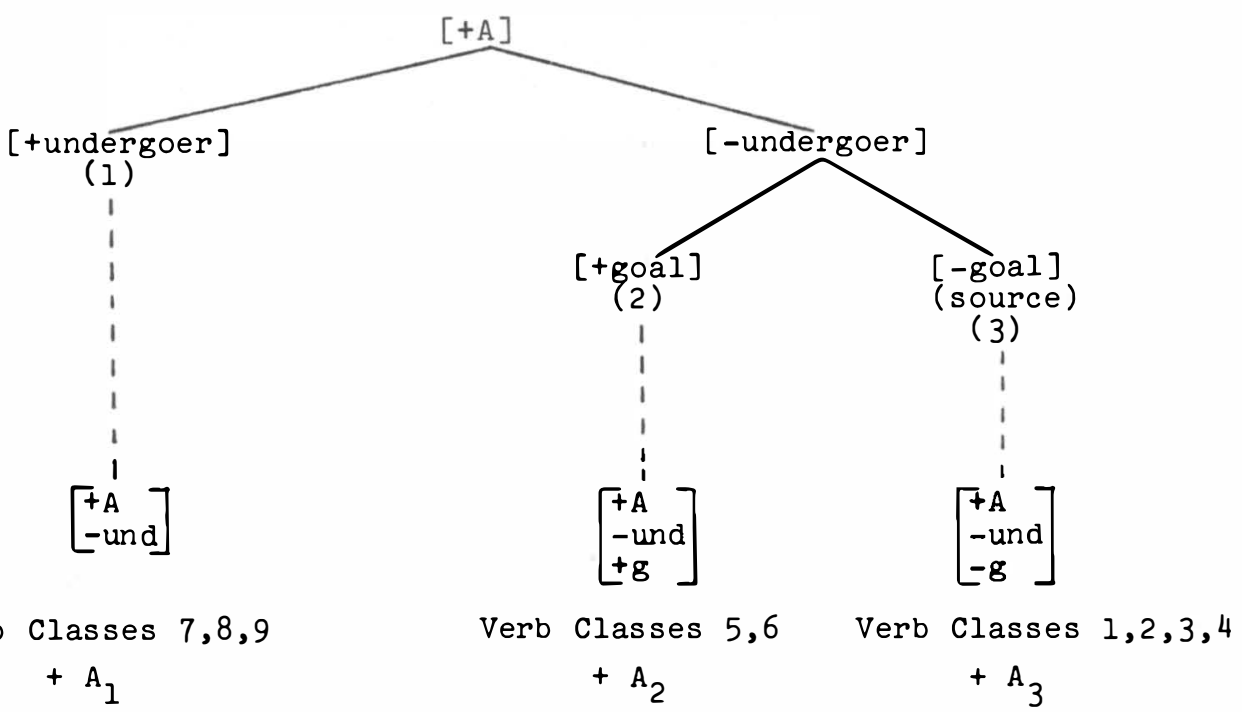

4. Semantic Feature Tree of the Directional

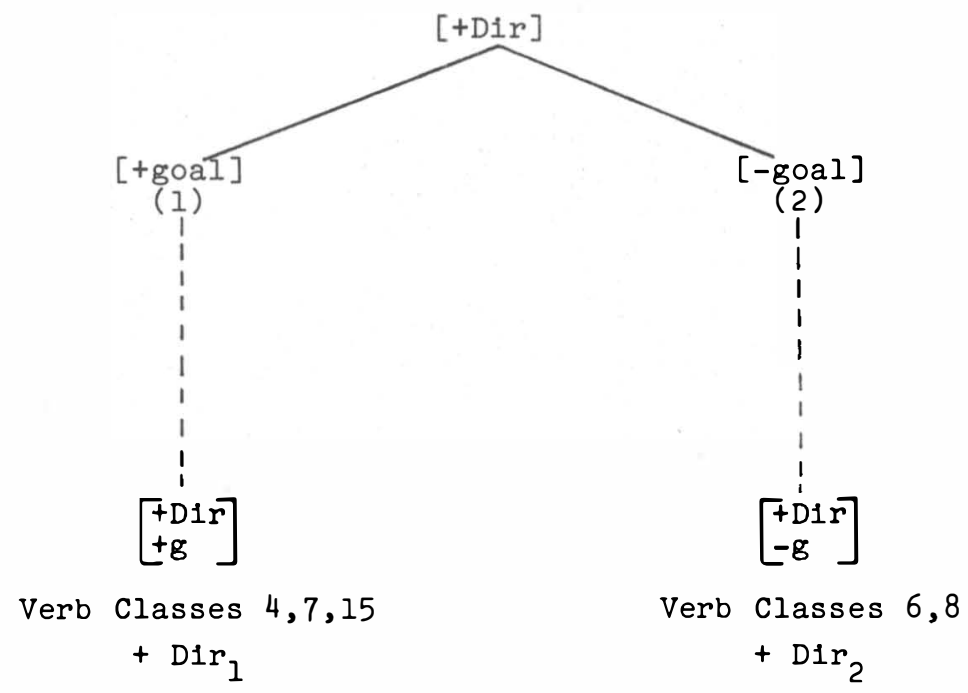


5. Semantic Feature Tree of the Instrument

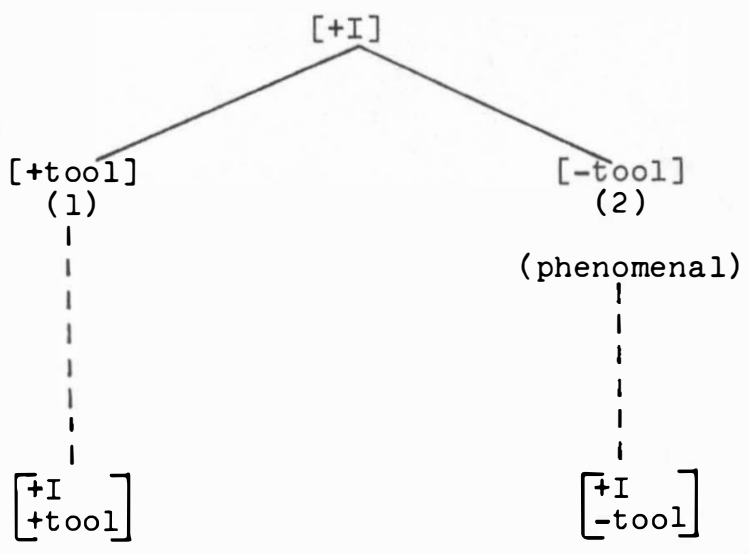




\section{APPENDIX B}

BASE RULES

The following restates the base rules discussed in detall in Chapter III. Deta1ls are found in the pages enclosed in parentheses after each rule.

$$
\begin{aligned}
& \text { BR\# 1. } \quad \mathrm{S} \longrightarrow \mathrm{V}+(\mathrm{KP})^{5} \\
& \text { BR\#2. } V \longrightarrow c . s \text {. } \\
& 2.1[+\mathrm{V}] \longrightarrow\left[\begin{array}{l}
\text { tagt } \\
\text { tneut. asp. }
\end{array}\right] \\
& 2.11[\text { tagt }] \longrightarrow[\text { text }] \\
& 2.111[+ \text { ext }] \longrightarrow\left[\begin{array}{l} 
\pm c f \\
\pm t e r
\end{array}\right] \\
& 2.1 \mathrm{v}[\text { tter }] \longrightarrow[ \pm \mathrm{cs}] \\
& \text { 2.v }[+\mathrm{cs}] \longrightarrow[ \pm \mathrm{t}] \\
& \text { 2. v1 [-ext] } \rightarrow[ \pm d 1 r] \\
& \text { 2.v11 }[+\mathrm{d} 1 \mathrm{r}] \longrightarrow[ \pm \mathrm{cf}] \\
& \text { 2.v111 [-agt] } \longrightarrow[ \pm \exp ] \\
& 2.1 x \quad[-\exp ] \longrightarrow[ \pm 1 n c h] \\
& \text { 2.x [tinch] } \longrightarrow \text { [ttrans] } \\
& \text { 2. } x 1 \quad[-1 \text { nch }] \longrightarrow[ \pm \text { met }] \\
& \text { 2. } x 11 \quad[\text {-met }] \longrightarrow[\text { tter] } \\
& \text { 2.x111 [-neut. asp.] } \rightarrow \text { [tbegun] } \\
& \text { 2. } x 1 \mathrm{v}[\text { +begun] } \longrightarrow[ \pm \mathrm{comp}] \\
& \text { 2. xv [tcomp] } \rightarrow[ \pm \text { recent }]
\end{aligned}
$$




$$
\begin{aligned}
& \text { BR\#3. } \quad \mathrm{KP} \longrightarrow \mathrm{K}+\mathrm{NP} \\
& \text { BR\# 4. } \quad \mathrm{NP} \longrightarrow(\text { Det })+\mathrm{N} \\
& \text { BR\#5. } \mathrm{N} \longrightarrow \text { c.s. } \\
& 5.1[+\mathrm{N}] \longrightarrow[ \pm \mathrm{com}] \\
& 5.11[+\mathrm{com}] \longrightarrow[ \pm \mathrm{con} c] \\
& 5.111[+ \text { conc }] \longrightarrow[ \pm \text { count }] \\
& 5.1 \mathrm{v}[\text { tcount }] \longrightarrow\left[\begin{array}{l}
\text { tan } \\
\pm s
\end{array}\right] \\
& \text { 5.v }[-\mathrm{com}] \longrightarrow\left[\begin{array}{l} 
\pm \mathrm{an} \\
\pm \mathrm{sg}
\end{array}\right] \\
& \text { 5.v1 }[+\mathrm{N}] \longrightarrow[ \pm \mathrm{O}] \\
& \text { 5.v11 }[+0] \longrightarrow[-A,-I,-D 1 r,-L] \\
& \text { 5. v111 [-O ] } \rightarrow[+\mathrm{A}] \\
& 5.1 \mathrm{x}[+\mathrm{A}] \longrightarrow[-\mathrm{I},-\mathrm{D} 1 \mathrm{r},-\mathrm{L}] \\
& \text { 5.x }[-\mathrm{A}] \longrightarrow[ \pm \mathrm{Dir}] \\
& \text { 5.x1 [+D1r] } \rightarrow[-I,-L] \\
& 5 . x 11 \quad[-\mathrm{D} 1 \mathrm{r}] \longrightarrow[ \pm \mathrm{I}] \\
& \text { 5. } \times 111[+I] \longrightarrow[-\mathrm{L}] \\
& \text { 5.xiv }[-I] \longrightarrow[ \pm L] \\
& \text { 5.xv }[+0] \longrightarrow[\text { pat }] \\
& 5 . x v 1 \quad[\text { pat }] \longrightarrow\left[\begin{array}{l} 
\pm c f \\
\pm t \text { ransp }
\end{array}\right] \\
& \text { 5.xv11 [-transp] } \longrightarrow[ \pm c s] \\
& 5 . x v 111[+c s] \longrightarrow[ \pm t] \\
& 5 . x 1 x \quad\left[\begin{array}{c}
\text { tan } \\
\text {-pat }
\end{array}\right] \longrightarrow[ \pm \text { exp }] \\
& \text { 5. } x x \quad\left[\begin{array}{l}
\text {-an } \\
\text {-pat }
\end{array}\right] \longrightarrow[\text {-exp] } \\
& \text { 5. } x \times 1 \quad[-\exp ] \longrightarrow[ \pm 1 \text { nch }] \\
& 5 . x \times 11[+1 \mathrm{nch}] \longrightarrow \text { [ttrans] } \\
& 5 . x \times 111 \quad[-1 n c h] \longrightarrow[ \pm t r a n s p]
\end{aligned}
$$




$$
\begin{aligned}
& 5 . x \times 1 v \quad\left[\begin{array}{l}
+N \\
\tan
\end{array}\right] \longrightarrow[ \pm A] \\
& 5 . x \times v \quad\left[\begin{array}{c}
+N \\
-a n
\end{array}\right] \longrightarrow[-A] \\
& 5 . x x v 1[+\mathrm{A}] \longrightarrow[\text { [und }] \\
& \text { 5. } x x v 11 \quad[\text {-und }] \longrightarrow[ \pm \mathrm{g}] \\
& 5 . x \times v 111 \quad[+\mathrm{D} 1 \mathrm{r}] \longrightarrow[ \pm \mathrm{g}] \\
& 5 . x \times 1 x \quad[+I] \longrightarrow[ \pm t 001] \\
& 7.1[+K] \longrightarrow\left[\begin{array}{l}
\alpha c o m \\
\beta C
\end{array}\right] /\left[\begin{array}{l}
+N \\
\alpha c \text { om } \\
\beta C
\end{array}\right] \\
& 7.11\left[\begin{array}{l}
+K \\
-c o m
\end{array}\right] \longrightarrow\left[\begin{array}{l}
+a n \\
\alpha s g
\end{array}\right] / \cdot\left[\begin{array}{l}
+N \\
+a n \\
\alpha s g
\end{array}\right]
\end{aligned}
$$




\section{APPENDIX C}

\section{SELECTIONAL REDUNDANCY RULES}

The following restates the selectional redundancy rules discussed in

detall in Chapter IV. Detalls are found in the pages enclosed in parentheses after each rule.

SRR\# I.

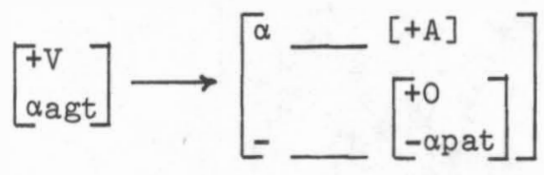

SRR\#2.

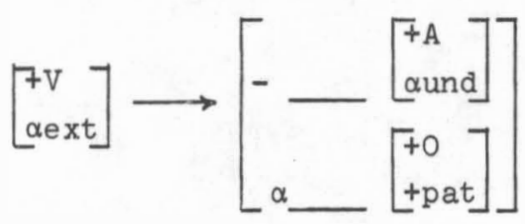

SRR\# 3 .

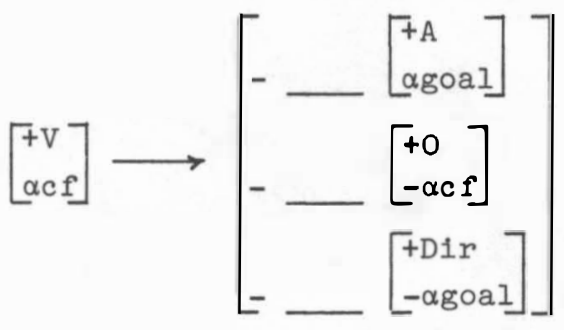

SRR\#4 .

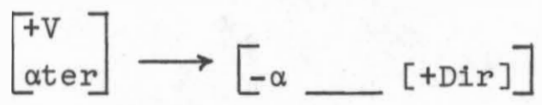

SRR\#5.

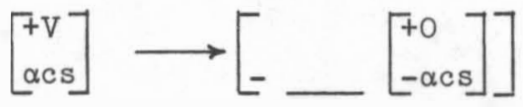


$\mathrm{SRR}$ 6. $\left[\begin{array}{l}+\mathrm{V} \\ \alpha \mathrm{t}\end{array}\right] \longrightarrow\left[-\left[\begin{array}{l}+0 \\ -\alpha t\end{array}\right]\right]$

SRR\#7. $\left[\begin{array}{l}+\mathrm{V} \\ \alpha t e r\end{array}\right] \longrightarrow\left[-\left[\begin{array}{l}+0 \\ -\alpha \text { trans }\end{array}\right]\right]$

SRR\#8. $\left[\begin{array}{l}+\mathrm{v} \\ -\mathrm{d} 1 \mathrm{r}\end{array}\right] \longrightarrow\left[-\left[\begin{array}{l}-\mathrm{D} 1 \mathrm{r}] \\ -\end{array}\right.\right.$

SRR\#9. $\left[\begin{array}{l}+\mathrm{v} \\ \alpha \exp \end{array}\right] \rightarrow\left[-\left[\begin{array}{l}+0 \\ -\alpha e x p\end{array}\right]\right.$

SRR\#10. $\left[\begin{array}{l}+\mathrm{V} \\ \alpha \text { inch }\end{array}\right] \longrightarrow\left[-\left[\begin{array}{l}+0 \\ -\alpha 1 \mathrm{nch}\end{array}\right]\right]$

SRR\# 11. $\left[\begin{array}{l}+\mathrm{V} \\ \alpha \text { trans }\end{array}\right] \rightarrow\left[-\left[\begin{array}{l}+0 \\ -\alpha \text { trans }\end{array}\right]\right]$

SRR\#12. $\left[\begin{array}{l}+\mathrm{V} \\ \text { aagt }\end{array}\right] \rightarrow\left[-\left[\begin{array}{l}+\mathrm{I} \\ -\alpha \text { tool }\end{array}\right]\right]$ 


\section{APPENDIX D}

MAJOR CLASSES OF TAGALOG VERBS

The following restates the semant1c and contextual case features of fifteen classes of Tagalog verbs. These classes are discussed in detall in Chapter V.

Class 1.

$$
\left[\begin{array}{l}
+v \\
+a g t \\
+e x t \\
+c f \\
+t e r \\
+c s \\
+t
\end{array}\right]
$$
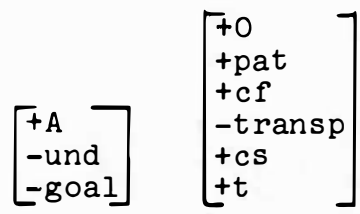

baluktot

to bend

Class 2.
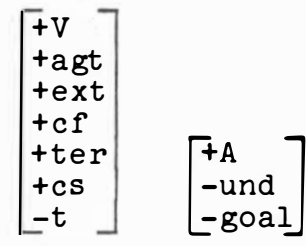

$\left[\begin{array}{l}+0 \\ + \text { pat } \\ +c f \\ - \text { transp } \\ +c s \\ -t\end{array}\right]$

hugas

to wash

Class 3 .

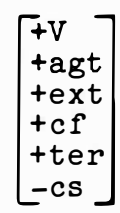

$\left[\begin{array}{l}+0 \\ + \text { pat } \\ +c f \\ - \text { transp } \\ \text {-cs }\end{array}\right]$

ipon

$\left[\begin{array}{l}\text { tA } \\ \text {-und } \\ \text {-goal }\end{array}\right]$

to save

Class 4.
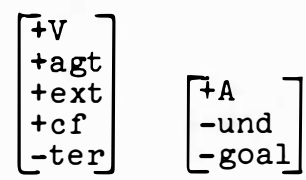
+0
+ pat
$+\mathrm{cf}$
transp

$\left[\begin{array}{l}+\mathrm{D} 1 \mathrm{r} \\ +\mathrm{goal}\end{array}\right]$

tapon

-goal

to throw

Class 5.

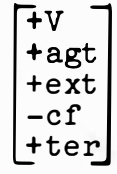

$\left[\begin{array}{l}+\mathrm{A} \\ + \text { goal }\end{array}\right]$

$\left[\begin{array}{l}\text { +o } \\ + \text { pat } \\ - \text { cf } \\ \text {-transp }\end{array}\right]$

huli

to catch 
Class 6.

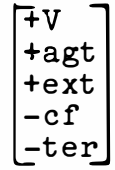

$\left[\begin{array}{l}+\mathrm{A} \\ \text { tgoal }\end{array}\right]\left[\begin{array}{l}+0 \\ + \text { pat } \\ -\mathrm{cf} \\ + \text { transp }\end{array}\right]$ $\left[\begin{array}{l}\text { D1r } \\ \text {-goal }\end{array}\right]$

hi ram -goal to borrow

Class 7 .

$\left[\begin{array}{l}+v \\ +a g t \\ -e x t \\ +d 1 r \\ +c f\end{array}\right]$

$\left[\begin{array}{l}+\mathrm{A} \\ \text { tund }\end{array}\right]\left[\begin{array}{l}+\mathrm{D} 1 \mathrm{r} \\ +\mathrm{g} O \mathrm{al}\end{array}\right]$

punta

to go

Class 8.

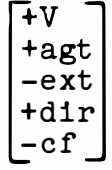

$\left[\begin{array}{l}\text { t A } \\ \text { tund }\end{array}\right]$

$\left[\begin{array}{l}\text { D1r } \\ \text {-goal }\end{array}\right]$

bitiw

to let go

Class 9.

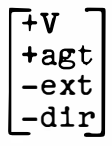

$\left[\begin{array}{l}\text { tA } \\ \text { tund }\end{array}\right] \begin{aligned} & \text { iyak } \\ & \text { to cry }\end{aligned}$

Class 10.

$$
\left[\begin{array}{l}
+v \\
- \text { agt } \\
+ \text { exp }
\end{array}\right]
$$$$
\left[\begin{array}{l}
+0 \\
\text {-pat } \\
\text { texp }
\end{array}\right]
$$

galit

to get angry

Class 11.

$$
\left[\begin{array}{l}
+\mathrm{V} \\
\text {-agt } \\
-\mathrm{exp} \\
+ \text { 1nch } \\
\text { trans }
\end{array}\right]
$$$$
\left[\begin{array}{l}
\text { +o } \\
\text {-pat } \\
+ \text { 1nch } \\
\text { +trans }
\end{array}\right]
$$

i t i m

to get tanned

Class 12.

$$
\left[\begin{array}{l}
\text { +v } \\
\text {-agt } \\
\text {-exp } \\
\text { +1nch } \\
\text {-trans }
\end{array}\right]
$$$$
\left[\begin{array}{l}
\text { +o } \\
\text {-pat } \\
\text {-exp } \\
\text { +1nch } \\
\text {-trans }
\end{array}\right]
$$

ganda

to become beautifuz

Class 13.

$$
\left[\begin{array}{l}
+\mathrm{V} \\
\text {-agt } \\
\text {-exp } \\
\text {-1nch } \\
\text { +met }
\end{array}\right]
$$$$
\left[\begin{array}{l}
7 I \\
-t \circ 0]
\end{array}\right]
$$

ulan to rain

Class 14.

$$
\left[\begin{array}{l}
+\mathrm{V} \\
\text {-agt } \\
\text {-exp } \\
\text {-1nch } \\
\text {-met } \\
+ \text { ter }
\end{array}\right]
$$$$
\left[\begin{array}{l}
+0 \\
\text {-pat } \\
\text {-exp } \\
\text { - Inch } \\
\text {-transp }
\end{array}\right]
$$$$
\text { kulo }
$$$$
\text { to boil }
$$ 
Class 15

$$
\left[\begin{array}{l}
\text { +v } \\
\text { - agt } \\
\text {-exp } \\
\text { - Inch } \\
\text { - met } \\
\text {-ter }
\end{array}\right]\left[\begin{array}{l}
+0 \\
- \text { pat } \\
- \text { exp } \\
-1 \text { ch } \\
\text { +transp }
\end{array}\right]
$$$$
\left[\begin{array}{l}
\text { tDir } \\
+ \text { goal }
\end{array}\right]
$$$$
\text { bags ak }
$$$$
\text { to fall }
$$ 


\section{BIBLIOGRAPHY}

ANDERSON, John

1971 The grammar of case: towards a localistic theory. (Cambridge studies in linguistics, 4.) Cambridge, Cambridge Un1versity Press.

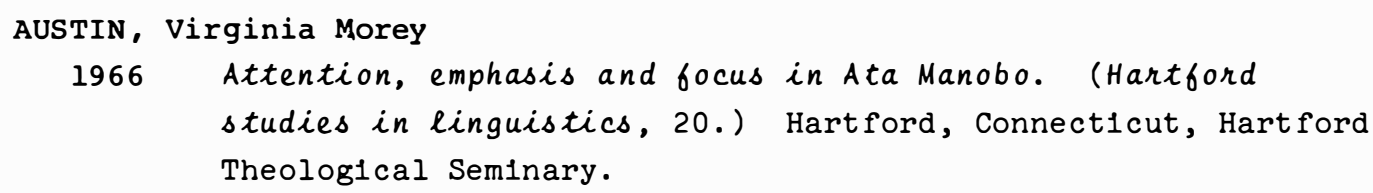

1906 'Expression of case by the verb in Tagalog.' Journal of the American oriental Society 27:183-9.

1916 'The Tagalog verb.' Journal of the American Oriental Society $36: 398-414$.

1925 A grammar of the Tagalog language. (American Oriental Series, I.) New Haven, Connecticut, American Orlental Soclety.

1930 'A semant1c analys1s of case.' Curme Volume of linguistic studies, ed. by James T. Hatfleld, et al., 34-49. Baltimore, Waverly Press.

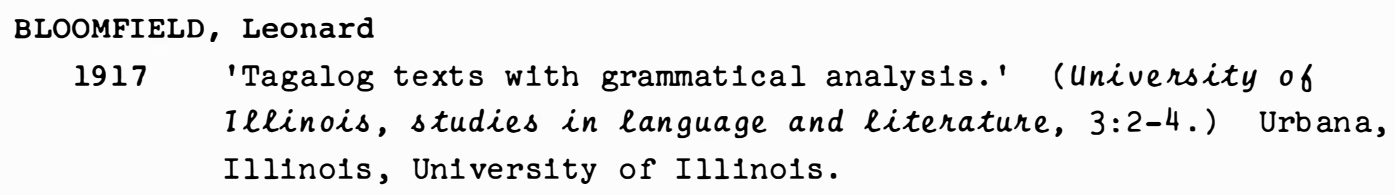


BOWEN, Donald J.

1965 Beginning Tagalog. Berkeley and Los Angeles, University of Callforn1a Press.

BUREAU OF PUBLIC SCHOOLS

1950 'Scope and uses of the verbal affixes -um- and mag-.' (Bulletin no. 2:1-13.) Department of Educat1on, Ph1l1ppines.

CAPELL, Arthur

1964 'Verbal system In Ph1l1ppine languages.' Philippine Journal of Science 93:231-49.

CENA, R.M.

1971 'Case opposition in Tagalog.' The Ohio State University working papers in linguistics, 133-148.

CENSUS OF THE PHILIPPINES

1960-63 Vols. I \& 2, Man1la, Bureau of Census and Stat1st1cs.

CHAFE, Wallace L.

1970 Meaning and the structure of language. Ch1cago, The Un1versity of Ch1cago Press.

1971 'D1rect1onal1ty and paraphrase.' Language 47:1-26.

CHOMSKY, Noam

1965 Aspects of the theory of syntax. Cambridge, M.I.T. Press.

1970 'Remarks on nominal1zat1on.' Readings in English transformational grammar, ed. by Roderlck A. Jacobs and Peter S. Rosenbaum, 184-221. Waltham, Mass., Ginn and Company.

1971 'Deep structure, surface structure and semant1c interpretat1on.' Semantics: An interdisciplinary reader in philosophy, linguistics and psychology, ed. by Danny D. Stelnberg and Leon A. Jakovob1ts, 183-216. Cambridge, Cambr1dge Un1vers1ty Press.

COOK, Walter A., S.J.

1971 'Improvements in case grammar 1970.' Languages and linguistics: working papers no. 2:10-22. Washington, D.C., Georgetown Univers1ty Press. 
$1972 \mathrm{a}$ 'A set of postulates for case grammar analys1s.' Languages and linguistics: working papers no. 4:35-49. Washington, D.C., Georgetown Un1vers1ty Press.

$1972 \mathrm{~b}$ 'A case grammar matr1x.' Languages and linguistics: working papers no. 6:15-47. Washington, D.C., Georgetown University Press.

CONSTANTINO, Ernesto

1965 'The sentence patterns of twenty-s1x Ph1llppine languages.' Lingua 15:71-124.

1970 'The deep structures of the Ph1lipplne languages.' The Archive 1.2:67-79. Quezon C1ty, University of the Philippines.

1971 'Tagalog and other major languages of the Philippines.' Current trends in linguistics, ed. by Thomas A. Sebeok, vol. VIII, Linguistics in Oceania. The Hague, Mouton.

DEAN, James

1958 'Some princ1pal grammat1cal relations of B1laan.' Oceania linguistics monograph no. 3, ed. by A. Capell and S. Wurm, 59-64. Austral1a, Univers1ty of Sydney.

FILLMORE, Charles J.

1966a 'A proposal concerning English prepositions.' Georgetown University monograph series on languages and linguistics, 19, ed. by Franc1s P. Dinneen, S.J., 19-33. Washington, D.C., Georgetown Un1vers1ty Press.

$1966 \mathrm{~b}$ 'Toward a modern theory of case.' The Ohio State University project on linguistic analysis report no. 13:1-24. (Reprinted in Modern studies in English, ed. by Dav1d A. Relbel and Sanford S. Schane. 1969.)

1968 a 'The case for case.' Universals in linguistic theory, ed. by Emmon Bach and Robert T. Harms, 1-88. New York, Holt, Rinehart and Winston, Inc.

$1968 \mathrm{~b}$ 'Lexical entries for verbs.' Foundations of Language 4:37393. 
1969 'Types of lexical information.' Working papers in linguistics no. 2:65-103. Columbus, Oh10, The Oh1o State Un1vers1ty. (Also in studies in syntax and semantics, ed. by F. Klefer (Foundations of Language Supplementary Series no. 10.) 1969.)

$1970 \mathrm{a}$ 'The grammar of hitting and break1ng.' Readings in English transformational grammar, ed. by Roderick A. Jacobs and Peter S. Rosenbaum, 120-33. Waltham, Mass., G1nn and Company.

$1970 \mathrm{~b}$ 'Subjects, speakers and roles.' Working papers in linguistics no. 4:31-63. Columbus, Oh10, The Oh10 State Un1vers1ty.

1970c Lecture notes from Linguist1c Soclety of America Summer Linguist1c Inst1tute at the Oh1o State Un1versity.

1971 'Some problems for case grammar.' Working papers in linguistics no. 10:245-65. Columbus, Oh10, The Oh10 State Un1 versity.

GOLDIN, Mark G.

1968 Spanish case and function. Washington, D.C., Georgetown Un1vers1ty Press.

GONZALES, Andrew, F.S.C.

1971 Outline of a generative semantic description of Pampangan. Unpublished Ph.D. dissertation. University of California at Berkeley.

GUZMAN, Videa de.

1968 Tagalog verbal co-occurrence with afbixes and complements. Term paper. Linguistics 650 .

HALLIDAY, M.A.K.

1968 'Notes on transitivity and theme in English.' Journal of Linguistics 4:179-215.

HARRISON, S.P.

1971 Neutralization, diffusion and the concept of case. Term paper. Linguistics 650 . 
HEALEY, Phyllis M.

1960 An Agta grammar. Man1la, The Inst1tute of National Language and the Summer Inst1tute of Lingulstics Ph1lippine Branch.

HUDDLESTON, Rodney

1970 'Some remarks on case grammar.' Linguistic Inquiry 1.4:50111 .

JACOBS, Roderick A. and Peter S. ROSENBAUM

1970 Studies in English transformational grammar. Waltham, Ginn and Company.

KERR, Harland B.

1965 The case-marking and classifying function of Cotabato and Manobo volce affixes.' Oceanic Linguistics 4:15-47.

KESS, Joseph Francis

1967 Syntactic Features of Tagalog verbs. Unpublished Ph.D. dissertation. University of Hawa11.

1971 The utility of focus. Unpublished manuscript.

LAKOFF, George

1968 'Instrumental adverbs and the concept of deep structure.' Foundations of Language 4.1:4-29.

1970 Irregularity in syntax. New York, Holt, Rinehart and Winston, Inc.

LANGACKER, Ronald

1970 'Review of Goldin, Spanish case and function.' Language $46.1: 167-85$.

LANDE, Nobleza Asuncion

1970 Theoretical and methodological trends in Philippine linguist1cs research:1560-1970.' Anthropological Linguistics $12.6: 208-25$.

LANGENDOEN, D. Terence

1970 Essentials of English grammar. New York, Holt, Rinehart and Winston, Inc. 


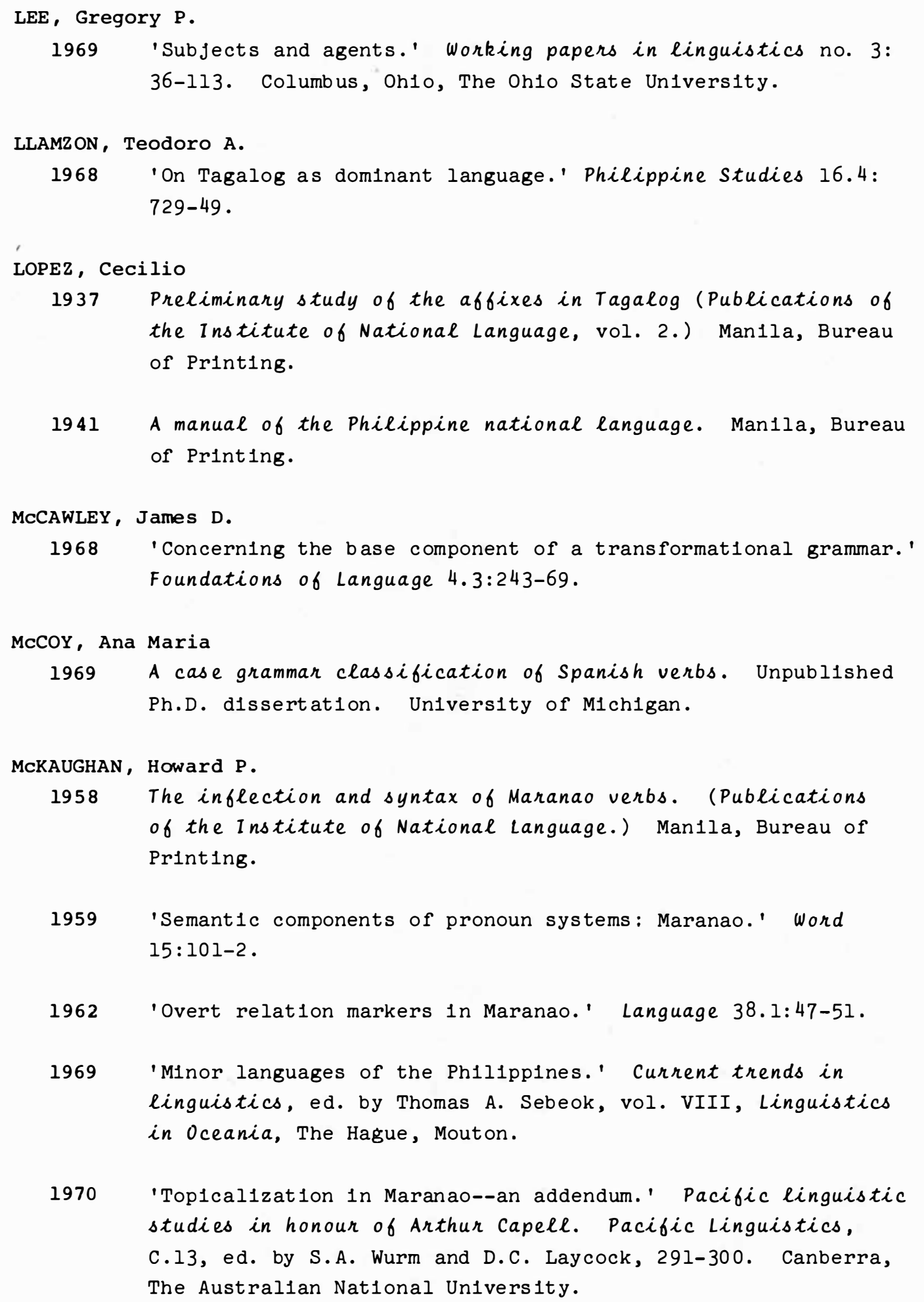

1941 A manual of the Philippine national language. Man1la, Bureau of Printing.

1969 A case grammar classification of Spanish verbs. Unpublished Ph.D. dissertation. University of Michigan.

MCKAUGHAN, Howard P.

1958 The inflection and syntax of Maranao verbs. (Publications of the Institute of National Language.) Man1la, Bureau of Printing.

1959 'Semant1c components of pronoun systems: Maranao.' Word $15: 101-2$.

1962 'Overt relation markers in Maranao.' Language 38.1:47-51.

1969 'Minor languages of the Ph1l1ppines.' Current trends in linguistics, ed. by Thomas A. Sebeok, vol. VIII, Linguistics in Oceania, The Hague, Mouton.

1970 'Top1cal1zation In Maranao--an addendum.' Pacific linguistic studies in honour of Arthur capell. Pacific Linguistics, C.13, ed. by S.A. Wurm and D.C. Laycock, 291-300. Canberra, The Australian National University. 
1972 Subject versus topic. Unpublished manuscript. To appear in a Festschrift in honor of Dr Cec1l1o Lopez, Ph1lippines.

MEMBERS OF S.I.L.

1964 Papers on Philippine linguistics. Oceanic Linguistics 3:1.

MILLER, J.E.

1970 'Stat1ve verbs in Russ1an.' Foundations of Language 6:489504.

MIRIKITANI, Leatrice T.

1972 Kapampangan syntax. (Oceanic Linguistics special publication no. 10.) Honolulu, University of Hawa11 Press.

NILSEN, Don Lee Fred

1971 Towards a semantic specification of deep case. Unpublished Ph.D. dissertation. Un1versity of Michigan.

OTANES, Fe T.

1970 'Some transformational rules on noun derivation in Tagalog.' Philippine Journal of Linguistics 1.1:33-73.

PEI, Mario and Frank GAYNOR

1969 A dictionary of linguistics. Totowa, New Jersey, L1ttlefield, Adams and Company.

PIKE, Kenneth L.

1963 'A syntact1c paradigm.' Language 39:216-30.

PITTMAN, Richard

1966 'Tagalog -um- and mag-.' (Pacific Linguistics, A.8, 9-20.)

Canberra, The Australian National University.

RAMOS, Teresita V.

1971 Tagalog structures. (PALI language texts: Philippines, ed. by Howard P. McKaughan.) Honolulu, Univers1ty of Hawa11 Press.

REIBEL, David A. and Sanford A. SCHANE

1969 Modern studies in English, readings in transformational grammar. Englewood Cliffs, N.J., Prentice-Hall, Inc. 
REID, Lawrence A.

1966 An Ivatan syntax. Oceanic Linguistics special publication no. 2.) University of Hawa11 Press.

ROBINSON, Jane J.

1970 'Case, category and conf1guration.' Journal of Linguistics $6.1: 57-80$.

SASAKI, TSuYoshi

1971 'Case grammar for Japanese.' Languages and linguistics: working papers no. 2:61-76. Washington, D.C., Georgetown Un1vers1ty Press.

SCHACHTER, Paul

1961 'Structural amb1gu1ty in Tagalog.' Language Learning 11: $135-45$.

SCHACHTER, Paul and Fe T. OTANES

1972 Tagalog reference grammar. Berkeley, Los Angeles, London, University of Callfornia Press.

SOUTHARD, O. Bruce

1971 'Tagalog, English and toplcallzat1on.' working papers in linguistics no. 10:212-220. Columbus, Oh10, Oh1o State Un1vers1ty.

\section{STAROSTA, Stanley}

1970 'Some lexical redundancy rules for English nouns.' Working papers in linguistics no. 2:1-38. Honolulu, Un1vers1ty of Hawa11. To appear in Glossa.

1971 a Derivation and case in Sora verbs. Paper given at the 20th Internat1onal Congress of Orlentalists, Canberra. To appear In Indian Linguistics.

1971b 'Review of Lyons, "Introduction to theoretical linguistics."' Language $47: 2$.

$1971 \mathrm{c}$ 'Lexical derivation in a case grammar.' Working papers in Linguistics no. 3,8:83-102. 
1972 Case in the lexicon. Paper read at the llth International Congress of Linguists, Bologna.

STEINBERG, Danny and Leon A. JAKOBOVITS

1971 Semantics: An interdisciplinary reader in philosophy, linguistics and psychology. Cambridge, Cambridge Un1versity Press.

STEVENS, Alan M.

1969 Case grammar in Philippine languages. Paper read at Linguistic Soclety of America meeting.

STOCKWELL, Robert P.

1957 A contrastive analysis of English and Tagalog. Duplicated. Los Angeles, Callfornia, University of Cal1fornia.

TAYLOR, Harvey $M$.

1971 Case in Japanese. Seton Hall Unlvers1ty Press.

WARD, Jack

1970 'Philipplne linguistics studies: A blbllographic survey of the coverage in the l1terature.' Philippine Journal of Linguistics 2.1:92-115.

WOLFENDEN, Elmer

1961 A restatement of Tagalog grammar. Man1la, Summer Inst1tute of Linguistics and Institute of National Language. 